NIST

PUBLICATIONS

\title{
ELECTRODEPOSITION OF WEAR RESISTANT COATINGS
}

\author{
C. E. Johnson \\ D. S. Lashmore \\ D. R. Kelley \\ J. L. Mullen
}
U.S. DEPARTMENT OF COMMERCE Natlonal Instltute of Standards and Technology Materlals Sclence and EngIneerIng Laboratory
ElectrodepositIon Group
Metallurgy Division
Galthersburg, MD 20899

\section{Prepared for}
Office of Research and Technical Services Bureau of Engraving and Printing 14th and $C$ streets, $S W$ Washlngton, DC 20234

U.S. DEPARTMENT OF COMMERCE Robert A. Mosbacher, Secretary NATIONAL INSTITUTE OF STANDARDS AND TECHNOLOGY

John W. Lyons, Director
QC

100

.456

\#4301.

1990

C. 2 


\section{NATONAL WISTTUTE OR STANDARDS \& \\ TECHNOLOGY \\ Research Information Center \\ Geltiensurno, MD 20899}

\section{DATE DUE}

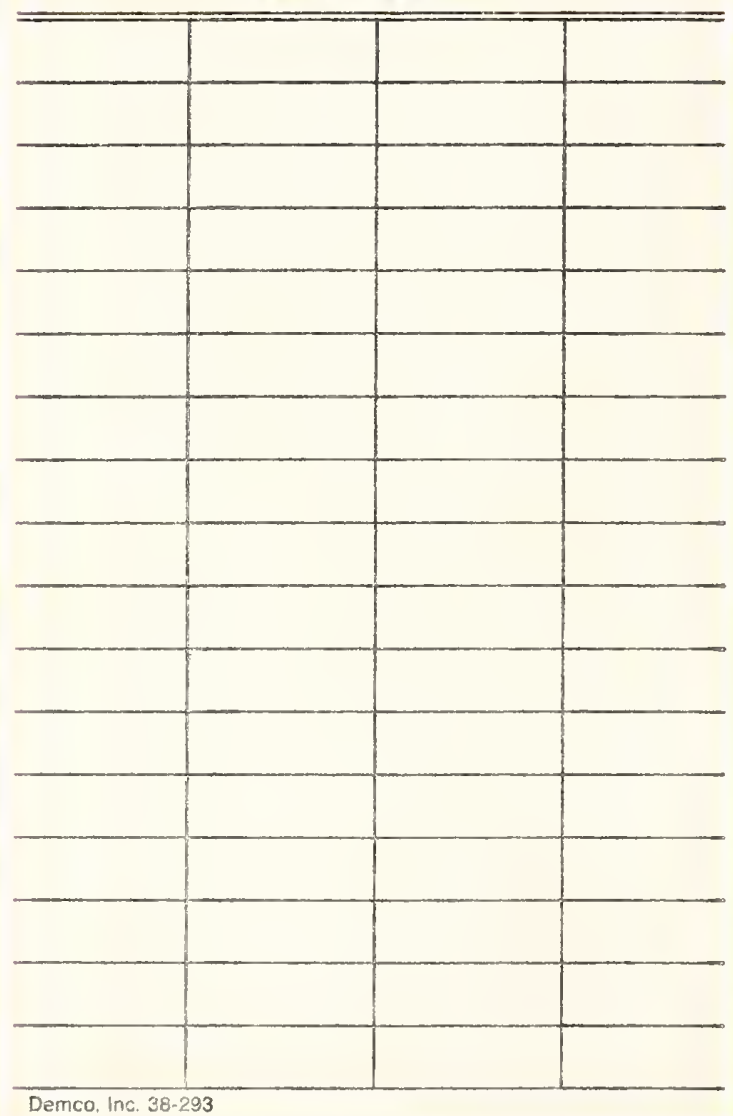




\section{ELECTRODEPOSITION OF}

WEAR RESISTANT

COATINGS

\author{
C. E. Johnson \\ D. S. Lashmore \\ D. R. Kelley \\ J. L. Mullen
}

U.S. DEPARTMENT OF COMMERCE Natlonal Institute of standards and Technology

Materlals Sclence and Englneoring Laboratory

Electrodeposition Group

Metallurgy Division

Galthersburg, MD 20899

Prepared for

Offlce of Research and Technlcal Servlces Bureau of Engraving and Printing 14th and $C$ streets, $5 W$ Washington, DC 20234

Aprll 1990

Final Report

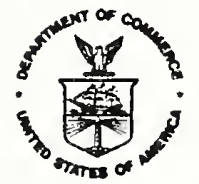

U.S. DEPARTMENT OF COMMERCE Robert A. Mosbacher, Secretary NATIONAL INSTITUTE OF STANDARDS AND TECHNOLOGY

John W. Lyons, Director 
TABLE OF CONTENTS

1. EXECUTIVE SUMMARY

2. INTRODUCTION

2.1 Objective

3. ANALYSIS OF PREMATURE PLATE FAILURE

3.1 Thickness Measurements

3.2 Hardness Measurements

3.3 Wear Evaluation

3.4 Electrolyte Analysis

3.5 Conclusions from Analysis of Worn Plates

3.6 Recommendations

3.6.1 Chromium Process

3.6.2 Nickel Process

3.6.3 Safety

3.6.4 Other

4. WEAR TEST DEVELOPMENT FOR COATING EVALUATION

5. MEASUREMENT OF CHROMIUM STRUCTURE AND PROPERTIES

5.1 Chromium Deposition by Direct Current (DC)

5.1.1 Electrolytes

5.1.2 Sample Preparation

5.1.3 Wear and Hardness

5.2 Chromium Deposition by Pulse Plating (PP)

5.2.1 Sample Preparation

5.2.2 Wear and Hardness

5.3 Chromium Alloys and Composites

5.4 Other Metals, Alloys, and Composites

6. PRIMARY WIPER BLADE COATINGS STUDY

6.1 Hard, Bright, Microcracked BEP Chromium (DC)

6.2 Non-Cracked Milky Chromium (DC)

6.3 Duplex Chromium (DC)

7. CONCLUSIONS

REFERENCES 



\section{Executive Summary}

In early FY 84 the BEP Quality Control Group approached NIST to provide help with a "chromium wear" problem of currency printing plates. At that time the rate of plate wear exceeded plate production. A tour of the BEP facility identified a series of problems including: (1) lack of control of chromium thickness, (2) lack of control of electrolyte chemistry, particularly sulfate and specific gravity, and (3) problems in the sulfamate nickel plating process. A number of specific recommendations were made and within several weeks the crisis was not only over, but the quality improved to the extent that production was cut from 2400 plates/year in the fall of 1983 to the present production rate of 800 plates/year. We were told that in the past this problem was cyclical with a period of $1 / 2$ year, but for the last 3 years (1983-1986) the problem has not returned. (These recommendations are included in the section on failure analysis in this report).

In order to understand how structure affects wear, an accelerated wear tester was developed to rank electrodeposits for wear in a medium designed to simulate the press environment. Wear data obtained from this tester had a low standard deviation, indicating that the scatter between individual measurements was small and the test was at least precise.

In the course of this program, direct current deposited duplex and "transition" chromium coatings were found to have a lower wear rate than the presently used direct current deposited bright, hard, microcracked chromium. For direct current deposited duplex chromium, the problem of changing the electrolyte temperature or the transferring of samples 
between multiple plating tanks would have to be addressed. For the "transition" chromium, higher electrolyte temperature and current density must be provided, assuming that the satin finish of the deposit is suitable for currency plates.

It was also found that bright, low crack density chromium coatings as well as duplex coatings could be produced by pulsing the current. Coatings of this type were obtained at lower current densities than normally used in direct current deposition. The duplex coating was obtained by simply changing the pulsing parameters while maintaining a constant electrolyte temperature $\left(50^{\circ} \mathrm{C}\right.$ ) and peak current density (25 A/dm $\left.{ }^{2}\right)$. The pulse plated duplex chromium coating exhibited a factor of two increase in abrasive wear performance over the current chromium plating technology. Though we are still investigating this matter, it would appear that minor modification to the existing plating plant ( $\$ 30 \mathrm{~K}$ to $\$ 50 \mathrm{~K}$ ) would enable this new coating to be used not only for the intaglio plates but also for the rotary stamp presses.

of the various coatings investigated in this program, the nickelphosphorus-silicon carbide coating exhibited a factor of 12 improvement in abrasive wear performance over the present chromium coating as determined by the abrasive slurry tester. A drawback is that the surface may be too rough for use on currency plates. The pulse plated duplex chromium coating exhibited a factor of 2 improvement in wear performance. The direct current deposited chromium-aluminum oxide coating, "transition" chromium coating, and pulse plated bright chromium coating exhibited factors of 1.4 to 1.5 improvement in wear performance. The direct current deposited duplex chromium and chromium-vanadium coatings 
exhibited a factor of 1.2 to 1.3 increase in wear performance.

In situ wear testing of chromium plated $W-1$ wiper blades on the actual intaglio presses has exhibited a 10 to 15 fold increase in the blade life when compared to the currently used unplated blades. This effort would result in a conservative estimate of savings of $\$ 200,000$ per year.

\section{INTRODUCTION}

Electrodeposited coatings are widely used by industry to minimize or eliminate degradation caused by wear, corrosion, or fatigue and this is particularly true for the printing industry. Incorporation of coatings is an important strategy for critical or strategic materials conservation. For example, it has been estimated by the National Materials Advisory Board that up to $30 \%$ of the chromium presently in use (in stainless steels) could be saved by substituting appropriate coatings over low carbon steel substrates. Many of the properties of a part are required only near the functional surface. The use of coatings permits the use of inexpensive base material, allows the use of established designs and processes, and is inexpensive. New processes developed in the laboratory can be rapidly transferred directly to production with minimum expenditure of capital. Moreover, recent advances in coatings technology such as pulse electrodeposition and new understandings in particulate composites allow coatings to be tailored to a specific wear and corrosion environment. For example, corrosion inhibitors can be incorporated within teflon particles which can be co-deposited in a metal matrix, and further, control over the microdistribution of the coating is possible by pulsing the current. This latter process has proven to have significant advantages in the deposition of alloy coatings. 
Microcracking can also be controlled through appropriate pulsing parameters. As discussed below, the existence of cracks in chromium, for example, may act to promote wear in circumstances where corrosion processes are active; however, crack-free chromium by itself wears poorly. As will be shown in this report, a combination of microcracked chromium over crack-free chromium outperforms the traditional "hard" chromium in a simulated printing environment, and it is possible to produce both from the same electrolyte simply by changing the pulsing parameters.

Fracture, corrosion, and wear are the three principal degradative processes that affect materials and components in technological use. The yearly costs involved are very large: fracture costs in the U.S. are estimated at about $\$ 120 \mathrm{~B}$, corrosion costs at about $\$ 120 \mathrm{~B}$, and wear costs in excess of $\$ 50 \mathrm{~B}$, expressed in 1982 dollars. In each case, some of these costs can be avoided through the proper utilization of existing knowledge and materials, and some eliminated by further research and development to produce new materials.

In the case of wear, abrasion is the most prevalent mode of wear found in industrial service. The more severe forms of abrasive wear are associated with operations that mine, transport, or process hard particulate materials such as ores, minerals, and abrasives. However, many industrial wear problems such as those occurring in the printing industry involve milder forms of abrasive wear caused by low concentrations of abrasives or by relatively mildly abrasive materials. In many instances, wear may occur in a lubricated system because abrasives are present as a contaminant in the lubricant. Since the wear 
rate under mildly abrasive conditions can be several orders of magnitude greater than the typical value for lubricated conditions, this form of wear is a very serious problem. The wear processes are complicated in many operations by the presence of fluids or gases that cause a certain amount of corrosion to take place. The rate of corrosion alone may be acceptably low for the materials involved, but the simultaneous occurrence of wear creates a significant problem. Corrosion and wear are usually synergistic in their effect, and the rate of material loss can increase greatly. The occurrence of both processes at the same time must be considered when tailoring a coating system to survive in a particular environment.

\subsection{Objective}

Improvements in the wear performance of electrodeposited coatings require a complete investigation of the correlation of coating deposition parameters with wear performance. Understanding the wear mechanisms and the development of accurate, accelerated wear tests based on these mechanisms is necessary in order to test coatings in a realistic manner. Accordingly, the research described in this report consists of two parts: (1) a study of coating systems which may improve or substitute for hard chromium, and (2) a study of the wear modes involved in the printing process. Both portions of this research will proceed simultaneously and will interact closely. Due consideration will be given to the chemical effects of the particular environment; for example, the corrosive effects of the wiping fluids, inks, and constituents in the paper itself. For completeness, the analysis of premature plate failure by the Electrodeposition Group will be included in this final report. 


\section{ANALYSIS OF PREMATURE PLATE FAILURE}

The Electrodeposition Group was asked for advice and measurement assistance by the Bureau of Engraving and Printing (BEP) to help with premature plate failure problems which they had been periodically experiencing. We undertook to make microhardness, scratch hardness and chromium thickness measurements on several samples of printing plate sections supplied to us by BEP and in addition visited their plating shop where we made a number of on-the-spot recommendations.

\subsection{Thickness Measurements}

Measurements were made of the chromium thickness using a well calibrated Kocours thickness testing instrument in accordance with the procedures of ASTM B503. Measurements of chromium thickness are expected to vary over the surface area of the printing plates. As we were supplied only with small pieces of the plate (plate ends) cut from either the top or bottom (no information regarding orientations is available), the measurements were all made near the position where the plate number is stamped. The results are shown in Table 1 . No correlation could be made with chromium thickness and number of impressions to failure. The various plate ends came from different presses and were a mix of front and back plates of various bill denominations. It is apparent that there are large variations in chromium thickness of almost a factor of three. There does not seem to be an explanation for this extreme variation, except for possible variations in time of plating, variable current density, or electrolyte chemistry.

Lack of control of electrolyte chemistry can result in varjations in cathode current efficiency. 
In order to accurately correlate wear performance (number of impressions to failure) with a coating property, data can only be obtained from similar plates used on the same type presses for example all "faces" on "paper wipe" presses. Accordingly, face plates were suplied by BEP with accompanying data for the number of impressions made with each plate before failure, Table 2. The plates were of the same denomination and were run on the same press. Chromium thickness was determined for each plate using the Kocour test, Table 2. No correlation could be made with chromium thickness and number of impressions to failure, Figure 1. Results from other studies on engraved printing plates indicated that chromium thickness less than $0.20 \mathrm{mil}(5.08 \mu \mathrm{m})$ resulted in a low number of impressions to failure, whereas the number of impressions to failure seemed to level out at chromium thicknesses of $0.25 \mathrm{mil}(6.35 \mu \mathrm{m})$ and greater.

\subsection{Hardness Measurements}

Knoop hardness and scratch hardness measurements were made on several of the various plate ends first supplied. Again there exists some uncertainty in the orientation of the plate ends. The orientation of the plates may be important as the properties of the electrodeposit will depend on the current density which varies over the plate. Microhardness was determined for the as-received chrmium and nickel coatings normal to the surface. The results are shown in Table 1 where the specifications for hardness of the nickel and chromium given by the vendor of the plating electrolytes are also listed. The hardness of the chromium does not vary between plates that have failed prematurely and those which have worn normally; however, the chromium hardness is 
slightly lower than that specified by the vendor. It is by no means certain that a harder chromium would give better wear performance.

Scratch hardness is sensitive to the thickness of the chromium and to the surface finish. Accordingly, conclusions were not drawn due to nonuniformity in the thickness of the chromium.

The microhardness of the nickel measured on the surface of the plate ends of various samples, as shown in Table 1, appears to be high with respect to the vendor's specifications. These high values most likely are due to the rough, uneven nickel surface which can play a significant role when measuring at low loads, such as $50 \mathrm{~g}-\mathrm{f}$. Measurements on polished cross-sections should give more realistic values. The microhardness of the nickel, taken from va second set of various plate ends of the same denomination and run on the same press, was measured on the polished cross-sections using a Vickers indenter at $50 \mathrm{~g}$-f load, Table 3. These are the same plate ends used in determining chromium thickness in Table 2. There was no significant variation in hardness from plate to plate. The variation was no greater than that measured for an individual plate. The nominal hardness was 180 VHN which falls within the vendor's specified range, Table 1 . No correlation could be made between nickel hardness and number of impressions to failure for the various plates, Figure 2 .

\subsection{Wear Evaluation}

Preliminary scanning electron microscope (SEM) evaluation of color bar wear of an unidentified plate, Figure 3, was done by John Collins of BEP. The photos revealed that some of the peaks or lands were devoid of chromium, whereas others still had areas of chromium remaining. Some of 
the lands showed pits or voids that apparently were located in the nickel. Nodular areas around the pits may be a result of either the nickel or chromium deposition, Figure 4. If nickel is causing the problem, this kind of morphology can result when boric acid is low in the nickel electrolyte. If the nodulation is in the chromium, this morphology can result from low sulfate content in the electrolyte or from high localized current densities due to the sharp edge geometry of the engraved areas. SEM photos of the cross-section of the color bar area revealed what appeared to be fatigue cracking in the nickel under the chromium plate, Figure 5. The fatigue cracking and deformation of the nickel seemed more prominent on the edges of the lands.

SEM evaluation of wear was made at NIST in the engraved color bar areas of two plate ends, 50264 and 50265, from a set of plate ends of the same denomination and run on the same press, Table 2.

These plates were chosen since one, 50264, had a relatively high number of impressions, 139,000, before failure and the other, 50265, had a low number of impressions, 20,000, before failure. The low number of impressions of plate 50265 did not correlate with complete removal of chromium from the peaks or lands. Most of the lands were covered with chromium, if only partially, Figure 6. Whereas, the chromium was completely worn from most of the lands on plate 50264 which had a high number of impressions, Figure 7. This seems to be contradictory, but the rate of wear of each of these plates may be significantly different since there was no record of the appearance of the lands of 50264 after 20,000 impressions. The wear of the lands of the color bars of both plates was not even but seemed to start at one corner of the land and progress 
across the land with time. This is indicated by the remaining chromium left on some of the lands, Figure 6. This apperance of uneven wear may have resulted from the plate not mounted flat on the press. Pitting of the chromium plate, as well as corrosion products and/or ink residue, were noted in the grooves or valleys of the engraved color bars, Figure 8 .

Optical photomicrographs of the cross-section of the polished and etched plates revealed a slight difference in grain size of the nickel, being finer grained on the initial plated surface next to the master or just under the chromium overplate, Figure 9. This finer grain structure most likely results in a higher hardness which may not be detected at BEP since hardness is measured using a $15 \mathrm{~kg}-\mathrm{f}$ load on the Rockwell $15-\mathrm{T}$ tester. The depth of penetration of this indentation may be deeper than the thickness of the finer grained nickel. Hardness should be measured with either a Knoop or Vickers microhardness tester at loads of 50 to 100 g-f. This would provide a better monitor of nickel hardness just under the chromium over-plate. This initial fine grained nickel layer and the chromium overplate are experiencing the greater portion of the load during the printing operation. The grain size of the nickel for individual plates was not significantly different, Figure 10.

Several interesting features were noted while evaluating the cross-sections of the plates. A polished and etched section of a plate end revealed that during the course of electrodepositing the nickel, the current was interrupted as indicated by the boundary line (oxide) seen in Figure 11. Even though the structure of the subsequent deposit appeared to be epitaxial, the oxide included at this interface which could 
possibly be a site for delamination of the electroform when subjected to the stresses of printing. Cracking in the nickel was noted just under the chromium overplate, Figure 12. The cracks in the nickel electroform appear to result from the microcracking of the chromium. The cracks in the chromium probably act as stress risers from which the cracks in the nickel initiate. This cracking in the nickel may cause spalling of the chromium overplate or failure due to cracked plates. Another interesting feature was that corrosion of the nickel was occurring through the microcracks in the chromium, Figure 13. This may also be a cause of spalling of the chromium. It appears that the corrosion of the nickel through the microcracks in the chromium is occurring in stressed areas, probably during the various bending procedures of the flat plate or possibly during the printing process when the load is applied and released. These bending or flexing conditions apparently caused the microcracks to open.

\subsection{Electrolyte Analysis}

Sample aliquots of the BEP nickel electrolyte and chromium electrolyte were sent to Allied-Kelite for analysis. The analysis report for the nickel is shown in Table 4. This report indicated that the boric acid content was low which could explain the nodules present on the lands of the engraved color bars, Figure 4. The analysis report for the chromium is shown in Table 5. The report indicated that the chromium metal content was low, which could be conducive to poor coverage and burned deposits. The sulfate content was high, in fact, by a factor of two. This could also result in poor coverage. The trivalent chromium content was significant, probably due to a low anode to cathode ratio. Anode 
area should be a minimum of $1-1 / 2$ times the cathode area.

3.5 Conclusions from analysis of worn plates:

- There was no correlation between chromium thickness and number of impressions to failure with chromium thicker than $0.25 \mathrm{mil}$ ( 6.3 $\mu \mathrm{m})$.

Chromium thickness variation among different plates may be due to low cathode efficiency caused by high trivalent chromium content, impurities, or low sulfate content in the electrolyte. Thickness variation would also occur with varying plating times. There was no correlation between hardness of nickel and number of impressions to failure.

$\circ$ Uneven wear of engraved lands in color bars was observed, possibly due to the printing plate not being mounted flat in the press.

Nodules were observed on the engraved lands of color bars. These may be due to low boric acid content in the nickel electrolyte, if they were nickel nodules. If they were chromium nodules, low sulfate or impurities in the electrolyte could be the cause. Localized high current densities in the engraved areas could also result in nodulation.

- SEM and optical photos showed cracking in the nickel just under the chromium in both the engraved and smooth areas of the plate. This is most likely fatigue cracking. Corrosion of nickel was detected which occurred through the microcracks in the chromium. Plate failures may be a combination of abrasive wear, corrosion, 
and fatigue. The fatigue may be influenced by the large difference in hardness between the chromium and the nickel.

3.6 Recommendations:

\subsubsection{Chromium Process}

1. Measure the thickness of each sheet in several places to ensure that the minimum thickness exceeds 0.25 mils.

2. Purchase a new low ripple rectifier to allow deposition at a more normal current density (about $360 \mathrm{~A} / \mathrm{ft} .^{2}$ ).

3. Monitor the sulfate, iron, copper and trivalent chromium contents of the electrolyte at least weekly.

4. Use a filtered deionized water source for water make-up. This is rather important as tap water can be a major source of contamination.

5. Monitor the properties of each sheet: The most important parameter to check is the thickness of the chromium. The BEP already has the appropriate instrumentation to do this. The hardness of the chromium should be checked occasionally, perhaps once a day would be adequate.

6. The anode to cathode area ratio should be increased to $2: 1$ to prevent $\mathrm{Cr}^{+3}$ build-up.

\subsubsection{Nickel Process}

1. Maintain electrolyte chemistry either by in-house analysis or take advantage of vendor's analytical capabilities. The nickel and boric acid contents should be determined at least weekly and the $\mathrm{pH}$ maintained continuously.

2. Measure the hardness and perhaps the ductility of the nickel on 
each sheet.

3. Measure the internal stress of the nickel with a spiral contractometer, perhaps once a day would be adequate for each electrolyte.

\subsubsection{Safety}

1. Install appropriate ventilation for both the chromium and the nickel processes (see the 1983 Metal Finishing Guide book for recommendations or Graham's book on Electroplating Engineering.)

2. Institute annual health examinations for all employees to monitor blood chemistry for nickel and chromium levels, according to OSHA standards.

\subsubsection{Other Recommendations}

1. Care should be taken to uniformly stress the nickel during the grinding operation subsequent to plating. A pneumatic or electrical torque wrench should be purchased and the bolts tightened in an appropriate pattern.

2. The same care should also be practiced when mounting the plates on the presses.

\section{WEAR TEST DEVELOPMENT FOR COATINGS EVALUATION}

During the first phase of this project it was necessary to select and use a preliminary wear test to obtain data for use in evaluating coating systems of potential interest at the Bureau of Printing and Engraving (BEP). This step is necessary before optimizing coating properties based on wear performance.

The test selected was subject to change as more information concerning 
the wear modes associated with the printing process was acquired. The geometry selected is similar to that proposed by NBS for more accurate modeling of the wear conditions. It consists of a pin on disc system with the pin being a $3 / 8$ inch diameter 52100 steel ball bearing pressed with a force of $30.0 \mathrm{~N}(3100 \mathrm{~g}-\mathrm{f})$ against a rotating counterface, Figure 14. The path of the pin on the counter face surface describes a spiral. The surface speed varies from $\underline{8.1}$ to $\underline{48} \mathrm{~cm} / \mathrm{sec}$. Wear was measured by weight loss of the pin using a microbalance. It should be noted that wear could also be determined by measuring the diameter of the worn spot. The materials selected for the counterface were (1) Viton, (2) PVC, obtained from a portion of printing roller at BEP and (3) 1000 grit silicon carbide paper used without any lubrication. The polymeric counterfaces were used with an abrasive slurry whose composition is given in Table 6. This slurry was chosen to establish abrasive wear conditions using a convenient size and type of abrasive. While the slurry does not duplicate the conditions of service at BEP, it will permit obtaining wear data for use in preliminary ranking of coatings.

The coatings used for evaluation of this test included bright nickel, hard chromium, and a commercially available composite coating consisting of silicon carbide particles dispersed in nickel-5\% phosphorous matrix. The mean particle size for the silicon carbide was $3 \mu \mathrm{m}$ with the particle size reported by the supplier to vary from 1 to $5 \mu \mathrm{m}$. All of these coatings were plated to a thickness of $25 \mu \mathrm{m}$.

The wear data are summarized in Table 7. The Vitron counterface exhibited significant wear after only 5 runs of 1000 cycles each and in addition the metal wear scars were quite rounded. For these reasons 
Viton was not a very suitable counterface material. The lowest scatter in the data was for the 1000 grit SiC paper; however, it is not expected that the SiC would involve a wear mode similar to the wear process under study. The coating that exhibited the least wear was the composite of nickel-phosphorus with $3 \mu \mathrm{m}$ silicon carbide.

The preliminary wear test was further evaluated for conformance to abrasive wear experience by studying the effect of abrasive wear particle size on the wear rate of coatings. "Bright" nickel coatings were used as a baseline coating for determining the wear rate vs. particle size dependence. These results are shown in Figure 15. The results indicate that the abrasive slurry wear test is in agreement with prior abrasive wear experience [1]. This experience has shown that wear rate is low when the particle size is small, then increases to a plateau region, then further increases as the particle size becomes large. The BEP-PVC counterface is now used in combination with the abrasive slurry for obtaining preliminary wear data during the coating evaluation process. In connection with printing plate wear, it should be pointed out that by reducing the abrasive particle size, a very significant decrease in wear may be possible.

After evaluation of the intitial set of chromium deposits, it was determined that because of the degree to which the relatively soft PVC counterface conformed to the plated ball, a flat wear scar was not produced for the applied load of $30 \mathrm{~N}(3100 \mathrm{~g}-\mathrm{f})$. At this load only a small amount of the abrasive slurry was in contact with the counterface and the point of contact of the plated ball. This phenomena was not apparent when testing the softer bright nickel deposits since the nickel 
was much less wear resistant than the hard chromium. The load was then reduced to $14.7 \mathrm{~N}(1500 \mathrm{~g}-\mathrm{f})$ which resulted in a significantly flatter wear scar. It was noted that the amount of material removed for the same test time at the lower load increased nearly 5 times compared with tests at the higher load. Accordingly, the length of time for the wear tests had to be reduced to prevent penetration of the coating. All subsequent wear testing using the abrasive slurry tester was done at a load of 14.7 $N(1500 g-f)$.

5. MEASUREMENT OF CHROMIUM STRUCTURE, PROPERTIES, AND CORRELATION WITH WEAR

5.1 Chromium Deposition by Direct Current (DC):

Electrodeposition of chromium coatings is often undertaken with the purpose of increasing the wear resistance of the coated part. However, in practice, the operating conditions for the deposition process are chosen from tables and diagrams in which the hardness of the coating is given as a function of the operating conditions. The practical relationship between hardness and wear remains unclear and depends on the nature of the wear process active in the particular situation. The wear performance of the coating is influenced not only by hardness but also by toughness, adhesion to the substrate, internal stress, and substrate resistance to deformation and corrosion.

Wear resistance under metal-to-metal sliding conditions of hard chromium with 0.58 potassium chromate solution (lubricant) present was reported to be most sensitive to the temperature of the electrolyte and most insensitive to the current density [2]. The maximum wear performance of a coating produced in a $250 \mathrm{~g} / \mathrm{L}$ chromic acid electrolyte 
occurred when the electrolyte temperature was between 55 and $65^{\circ} \mathrm{C}$ and at a current density of $50 \mathrm{~A} / \mathrm{dm}^{2}$. There is some indication in the literature that coatings deposited from dilute electrolytes, e.g., 150 $\mathrm{g} / 1$, are somewhat superior in wear performance [2,3]. Surprisingly, when metal-to-metal wear resistance is correlated with microhardness, the performance maximum occurs at a microhardness of between 800 and 850 $\mathrm{kg} / \mathrm{mm}^{2}$. When the hardness is increased much beyond $900 \mathrm{~kg} / \mathrm{mm}^{2}$, the wear performance degrades. Even though the wear processes in printing may be much different than those in metal/metal sliding, it remains clear that hardness and wear are not expected to be linearly related.

The literature indicates that in wear of coated metal by yarn, multilayer chromium provides dramatically improved wear performance over a single component "hard" chromium coating [4]. The multilayer coating consists of (a) a "soft milky" chromium deposit whose purpose is to protect against corrosion and to provide a moderately hard substrate and (b) a normal hard chromium deposit. The nature of the wear process in this environment may approximate that occurring in the printing industry. In the second phase of the National Institute of Standards and Technology (NIST) investigation, the wear of a multilayer chromium coating will be investigated as a function of the deposition parameters and layer thicknesses. It is important from a practical point of view that both types of chromium can be deposited from the same electrolyte.

\subsubsection{Electrolytes Used}

The chromium and sulfamate nickel electrolytes used by BEP were used in this study. The nickel was deposited from a nickel sulfamate electrolyte of the following composition and operating parameters: 


\begin{tabular}{|c|c|c|}
\hline Nickel Sulfamate & - & $336.5 \mathrm{~g} / 1$ \\
\hline Nickel (as metal) & - & $78.8 \mathrm{~g} / 1$ \\
\hline Boric Acid & - & $49.9 \mathrm{~g} / 1$ \\
\hline Sodium Lauryl Sulf & fate - & $0.25 \mathrm{~g} / 1$ \\
\hline $\mathrm{pH}$ & - & 4.4 \\
\hline Current density & - & $6.1 \mathrm{~A} / \mathrm{dm}^{2}\left(57 \mathrm{~A} / \mathrm{ft}^{2}\right)$ \\
\hline Temperature & - & $50^{\circ} \mathrm{C}$ \\
\hline $\begin{array}{l}\text { Iromium was deposite } \\
\text { lectrolyte as follow }\end{array}$ & ed from a & a mixed-catalyst (fluoride-sulfate) \\
\hline Chromium Trioxide & 150 & $g / 1$ \\
\hline Sulfate Content & 0.9 & $g / 1$ \\
\hline Fluoride Content & prop & prietary \\
\hline Temperature & vari & iable \\
\hline Current density & vari & iable \\
\hline
\end{tabular}

\subsubsection{Sample Preparation}

Samples for evaluation of wear were prepared by depositing chromium directly on $9.5 \mu \mathrm{m}$ (0.375 in) diameter 52100 steel balls or on ball previously plated with sulfamate nickel, $150 \mu \mathrm{m}$ (6 mils) thick. This substrate geometry was chosen for wear testing in the pin on disk accelerated abrasive slurry tester, where the plated ball is the pin. The steel balls were plated with either nickel or chromium from a two liter electrolyte with mechanical agitation from a magnetic stirrer. The anodes were designed to conform to the substrate geometry. Before plating with nickel or chromium, the 52100 steel balls were anodically alkaline cleaned for 2 minutes at $5 \mathrm{~A} / \mathrm{dm}^{2}\left(50 \mathrm{~A} / \mathrm{ft}^{2}\right)$ and then pickled in 258 sulfuric acid at $50^{\circ} \mathrm{C}$ for 5 to 10 seconds. Prior to chromium 
plating, the nickel plated balls were treated in $25 \%$ sulfuric acid at $50^{\circ} \mathrm{C}$ for one minute.

\subsubsection{Chromium Evaluation - Wear and Hardness}

The hardness and wear of various wear resistant chromium coatings from the BEP electrolyte and three commercial electrolytes were measured. The hardness was measured using a knoop indenter.

The hardness value reported are an average of five measurements at a load of $0.5 \mathrm{~N}(50 \mathrm{~g}-\mathrm{f})$. The values for wear are an average of five measurements at a load of $39 \mathrm{~N}(4000 \mathrm{~g}-\mathrm{f})$ for either 250 or 500 cycle test duration. The wear was determined by measuring the weight loss after each test on a microbalance having an accuracy of \pm 2 micrograms. The wear is reported as weight loss/cycle. The results of these tests are shown in Table 8 and Figure 16. Corrosion of the 52100 steel could be seen through the cracks in the chromium for all the hard microcracked deposits, Figure 17. No corrosion of the 52100 steel was observed for the non-cracked milky chromium deposit, Figure 18. The majority of the various chromium deposits had similar wear $\left(15 \pm 2 \times 10^{-8} \mathrm{~g} /\right.$ cycles $)$. The exceptions were the deposits from the commercial "C" process and the noncracked milky deposits from the BEP electrolyte. "The deposits from the proprietary commercial "C" process (Armaloy) were marginally lower than the average of the majority of the deposits while the non-cracked milky deposits had a significantly lower wear rate, although having the lowest hardness. The milky deposits were semi-bright which may or may not be acceptable to BEP, but the wear results led to an investigation of noncracked chromium, multilayer chromium, and "transition" chromium (chromium deposited between bright and milky, Figure 19.) The crack- 
free or low crack density chromium deposits have been reported in the literature to have better wear properties than non-cracked chromium $[2,4,7]$. The rationale for studying this type of coating is to use the superior corrosion resistance of the non-cracked chromium while obtaining the wear resistance of microcracked hard chromium. This multilayer deposit can be prepared from a single electrolyte by changing the deposition conditions. In effect, the chromium deposit is a continuous coating of non-cracked and microcracked, not an overplate, Figure 20. It has been reported that the duplex or multilayer chromium provides a much longer service life in the textile industry, a tribo-chemical environment which is probably similar to that of the printing industry [4]. Chromium deposits from the "transition zone" between bright and milky chromium have a satin finish, are "crack-free," (or a low density of cracks), and have lower hardness than bright hard chromium. The rationale for studying this type of coating stems from several literature references which state that maximum wear resistance (abrasive wear) for chromium occurs for deposits from a "transition zone" between bright and milky chromium where the hardness of the chromium is in a range of 700-900 $\mathrm{kg} / \mathrm{mm}^{2} \quad[2,4]$.

After evaluating the wear of the first set of various chromium deposits, Table 8 and Figure 16, the abrasive slurry wear test instrument was modified to incorporate a second ball (52100 steel) for use as a reference and to add balance to the rotating holder which resulted in a more constant load on the plated sample during the test. Previous wear tests were run at a load of $4000 \mathrm{~g}-\mathrm{f}$, but the load was excessive and caused the ball to penetrate too deep into the PVC counterface. This 
caused an uneven wear scar since the abrasive particles could not reach the point contact area. The load was reduced to $1500 \mathrm{~g}-\mathrm{f}$ which resulted in a much flatter wear scar. These changes in the sample holder did not cause significant changes in the relative wear rate of various chromium deposits.

Various chromium deposits, such as milky crack-free, transition, and duplex coatings were prepared on sulfamate nickel plated 52100 steel balls, Table 9. The wear testing of the six sets of chromium deposits was conducted on $12.5 \mu \mathrm{m}(0.5 \mathrm{mil})$ deposits for a duration of 150 cycles. Wear rate is reported as weight loss/cycle. The results of wear tests on the various DC chromium deposits are shown in Table 10 and Fig. 21. The wear results are reported as an average of five tests plus and minus one standard deviation. The lowest wear rate for $12.5 \mu \mathrm{m}(0.5 \mathrm{mil})$ thick deposits was recorded for the "transition zone" chromium; whereas, the highest rate was for the bright, smooth, microcracked chromium which is presently being deposited at BEP. The two "Duplex" chromiums also revealed a significant reduction in wear compared with the presently used BEP chromium. The surface texture and crack density of these various deposits can be seen in Figure 22. The results of these wear tests were consistent with the reported literature in that the "transition" chromium and the duplex chromium had lower wear than bright, hard, microcracked chromium when subjected to a corrosive and abrasive environment. It was recently found that the transition type of chromium deposit also had the lowest coefficient of friction when compared to hard, microcracked and milky types of chromium. [5] This property and the low crack density may attribute to the higher abrasive wear resistance. The higher wear 
resistance of the duplex deposits may be attributed to the underlying crack free chromium deposit which prevents corrosion of the substrate, illustrating the synergistic effect of corrosion coupled with wear.

\subsection{Chromium Deposition by Pulse Plating (PP):}

Studies at NIST on the pulsed electrodeposition of hard chromium have confirmed existing theories of improvements in microthrowing power resulting from pulsing the current. In practice, this means that at the peaks in surface texture resulting, for example, from engravings, build up of chromium would be minimal and that, at the valleys, a deficit in chromium would not occur. A preferential build up of chromium at the engraving peaks is detrimental because it could lead to the following: (a) local anodic and cathodic sites on the surface which would tend to promote corrosion processes, and (b) a dendritic build up at the peaks of the engraving which would tend to concentrate stresses and fracture at the base of the dendrite, thereby preferentially removing chromium at the high spots where it is needed most.

Pulse plating may also provide a technique for depositing duplex chromium without having to change the operating parameters such as electrolyte temperature.

The literature was surveyed for operating parameters of pulse plated chromium that may yield wear resistant coatings for initial study. For crack-free, low hydrogen deposits that may have enhanced wear properties, the following conditions were used in the initial study: low chromium electrolyte concentrations (mixed catalyst type), low current densities, high plating temperatures, short on-off times, and high duty cycles $[6,7,8,9]$. 


\subsubsection{Sample Preparation}

Pulse plated chromium deposits were prepared on 52100 steel balls and on sulfamate nickel coated $(150 \mu \mathrm{m}) 52100$ steel balls. Pulse plating (PP) of chromium from the BEP electrolyte was done at the present BEP operating parameters for DC deposition of $24.8 \mathrm{~A} / \mathrm{dm}^{2}\left(230 \mathrm{~A} / \mathrm{ft}^{2}\right)$ at $50^{\circ} \mathrm{C}$ and $12.5 \mu \mathrm{m}(0.5 \mathrm{mil})$ thickness. The current density of $24.8 \mathrm{~A} / \mathrm{dm}^{2}$ is average current density reported for pulse plating. The peak current density depends on the duty cycle of the on/off pulse train, where the duty cycle is equal to the on time divided by the sum of the on and off times. The potential waveform for pulse plating was a square wave, Figure 23. Wear resistance, hardness, structure, and crack density were evaluated for various pulse parameters, such as on/off time, duty cycle, and current density.

\subsubsection{Pulse Plated Deposit Evaluation}

Wear results obtained from the abrasive slurry wear tester for pulse plated chromium deposits at various on/off times at a duty cycle of 83.38 are shown in Table 11 and Figure 24. The pulse plated deposits are compared with the DC deposit from the presently used BEP operating parameters. All deposits were $12.5 \mu \mathrm{m}(0.5 \mathrm{mil})$ thick. All tests were run at a load of $1500 \mathrm{~g}$ for 150 cycles. The wear results are reported as weight loss-cycle for the average of five tests, plus and minus one standard deviation. As can be seen from Figure 24, no significant effect was found on wear resulting from various on/off times at a duty cycle of 83.38. The best is comparable with the presently used BEP operating parameters for DC deposition. However, changes in duty cycle do have an apparent effect on wear rate as shown in Table 12 and Figure 25 . As the 
duty cycle decreases, the wear rate increases.

It was noted that none of the PP chromium deposits were as bright and smooth as the DC deposits. The deposits had a satin bright finish due to a nodular surface structure. The length of on/off times at the same duty cycle (83.38) did not affect the surface texture, Figure 26. Varying duty cycle affected the surface texture and the microcracking of the PP chromium deposits. As the duty cycle was incrementally increased from 628 to 838 , the deposit went from a frosted to a satin bright surface and from non-cracked to microcracked, Figure 27. These deposits were prepared at $50^{\circ} \mathrm{C}$ and an average current density of $25.0 \mathrm{~A} / \mathrm{dm}^{2}$, thus the peak current density increased significantly as the duty cycle decreased, i.e. at 508 duty cycle, the peak current density was $49.6 \mathrm{~A} / \mathrm{dm}^{2}$. These high peak current densities may be causing the frosted deposits when plating at lower duty cycles. This effect was further studied since it has been reported that pulse plated chromium has always resulted in matte grey deposits when the thickness was greater than several microns. $[8,9,10]$. These matte grey deposits were probably due to the fact that all prior processes equated average pulse plated current densities to DC conditions, where, in reality, the chromium being deposited during the on-time was deposited at a much higher current density (depending on the duty cycle), out of the bright range of chromium deposition. Another effect of pulse plating is that the normal bright range under DC conditions is not the same as for pulse plating. The range may be smaller or shifted with temperature and current density. It was found that by maintaining a peak current density of $25 \mathrm{~A} / \mathrm{dm}^{2}$ at a duty cycle of 62.58, a non-cracked PP chromium deposit could be produced at $50^{\circ} \mathrm{C}$ with a 
similar surface texture as that produced by $\mathrm{DC}$ deposition at $70^{\circ} \mathrm{C}$, Figure 28. A bright microcracked chromium deposit was also produced at duty cycles of $71 \%$ and higher once the peak current density was reduced to 25 $\mathrm{A} / \mathrm{dm}^{2}$ or lower, Figure 29. It is apparent that the peak current density or current during the on-time of pulse plating should be the controlling factor and not the average current density as reported in the literature references. It appears that the bright range for $\mathrm{PP}$ chromium is shifted to lower current densities when compared to the bright range for DC deposition. The bright range of PP chromium also may not be as broad as for DC deposition. Wear tests using the abrasive slurry tester, on the bright microcracked PP chromium, resulted in less wear than the bright microcracked DC chromium deposits, $17 \times 10^{-8} \mathrm{~g} /$ cycle and $24 \times 10^{-8} \mathrm{~g} / \mathrm{cycle}$ respectively. The crack density of the PP chromium deposit was lower than for the DC deposit, 21 and 38 cracks/mm respectively.

The lower wear rate of the bright PP chromium (which has a lower crack density than the bright DC chromium) led to an investigation on the effect of microcrack density on the wear rate. Crack density measurements were made on chromium electrodeposits from various operating parameters having the lowest wear when compared with the present BEP chromium deposits. These results are tabulated in Table 13. There does appear to be a trend of increasing wear with increasing crack density. The exception is the DC duplex chromium where a high crack density deposit exists over a lower crack density deposit. It must be noted that the measurement of crack density is not by itself sufficient for determining wear rate, but that other properties affect the abrasive wear resistance of chromium; such as ductility, hardness, internal stress, and 
adhesion of the deposit to the substrate.

Two modes may exist for the microcracking of chromium and most likely both are occurring at the same time. One is that cracking occurs from self-relief of internal stress in the deposit and the second is that cracking occurs from a volume change due to the decomposition of chromium hydride to chromium metal. The second hypothesis is based on opinion that chromium is initially deposited as a hydride which decomposes in a very short length of time depending on the temperature of the electrolyte and the rate of deposition [11]. On the basis of this hypothesis and the observed trend of lower wear with lower crack density deposits, pulse plating studies were continued to develop parameters that would result in: 1) a bright, hard, low crack density chromium deposit, and 2) a low crack density, duplex chromium deposit without having to change the electrolyte temperature.

Modification of a technique that was developed in the 1960's for electrodepositing chromium directly on aluminum by pulse plating resulted in the electrodeposition of a bright, hard, lower crack density deposit [10]. The prior technique involved the deposition of a monolayer of chromium (chromium hydride) by pulsing for a short on time and allowing enough time for the hydride to decompose before another layer of chromium is deposited. Our modification to the prior technique was to first adjust the peak current density, $25 \mathrm{~A} / \mathrm{dm}^{2}$ during pulse plating, to the same value used to obtain bright chromium under DC conditions. The pulse on-time was then adjusted to deposit a monolayer of chromium (chromium hydride) and the off-time adjusted to allow enough time for the hydride to decompose before another layer of chromium is deposited. These 
pulsing parameters, $5 \mathrm{~ms}$ on and $2 \mathrm{~ms}$ off, now enable the deposition of a bright, hard $900 \mathrm{~kg} / \mathrm{mm}^{2}$, lower crack density (7-10 cracks $/ \mathrm{mm}$ ) chromium deposit at an electrolyte temperature of $50^{\circ} \mathrm{C}$.

The ability to deposit thick bright pulse plated chromium makes possible the deposition of a pulse plated duplex coating similar, with the exception of having a lower crack density, to the DC plated duplex deposits produced by changing the electrolyte temperature from 50 to $70^{\circ} \mathrm{C}$. An optical micrograph of a sectioned pulse plated duplex chromium deposit is shown in Figure 30. The initial chromium deposit on the nickel was plated at parameters, $5 \mathrm{~ms}$ on and $3 \mathrm{~ms}$ off at a peak current density of $25 \mathrm{~A} / \mathrm{dm}^{2}$, resulting in a matte finish with a crack density of $1.2 \mathrm{cracks} / \mathrm{mm}$. The final deposit was plated at parameters $5 \mathrm{~ms}$ on and 2 ms off at a peak current density of $25 \mathrm{~A} / \mathrm{dm}^{2}$ resulting in a bright finish with a crack density of 7-10 cracks/mm. Cracks that penetrated through the entire chromium thickness to the nickel were present at a density of $1.3 \mathrm{cracks} / \mathrm{mm}$. The wear rate of the modified bright pulse plated chromium and the modified pulse plated duplex are compared with BEP chromium and various other DC and pulse plated deposits in Table 14 and Fig. 31. The wear rate of the modified pulse plated duplex chromium is approximately one-half the rate determined for the presently used BEP deposits using the abrasive slurry wear tester.

It was noted during the course of this study that the chromium structure was different when plated directly on steel compared with nickel on steel. The duplex structure took on another feature, a large columnar structure, when deposited directly on steel, Figure 32. Compare this to duplex chromium on nickel, on steel in Figure 30 . Since the 
steel is an alloy of iron, carbon, and chromium, an equipotential surface does not exist for the deposition of chromium with apparent resultant influence on the deposit structure through the duplex layers. This deposit surface was not as bright and smooth as when plated on nickel. This observation may prove to be significant when plating steel wiper blades as discussed in a later section. Smoother deposits may be applied to the wiper blades if an initial strike of copper or nickel is applied before chromium deposition so that the chromium deposit is initiated on an equipotential surface.

Although the goals of obtaining a bright chromium deposit and a duplex chromium deposit by pulse plating were attained, further work is needed to understand the chromium deposition mechanism during pulse plating and to characterize the resultant deposits.

\subsection{Chromium Alloys and Composites}

The initial studies on chromium alloys were concerned with alloying constituents such as vanadium, manganese, selenium, rhenium, and molybdenum. These alloying constituents may range in deposit composition from less than 1 weight percent to 30 weight percent. These alloys are deposited from the conventional sulfate catalyzed hexavalent chromium electrolyte, $250 \mathrm{~g} / 1 \mathrm{CrO}_{3}$ and $2.5 \mathrm{~g} / \mathrm{l}$ sulfate. Only one alloy, chromiumvanadium, was investigated for wear resistance when deposited at various operating parameters. Vanadium pentoxide was added to the electrolyte in the amount of $10 \mathrm{~g} / 1$. The wear data for various operating parameters both DC and PP were compared to the conventional chromium without vanadium and the BEP chromium, Table 15. Only one set of operating parameters, DC, $25 \mathrm{~A} / \mathrm{dm}^{2}$ @ $50^{\circ} \mathrm{C}$, resulted in a wear rate lower than the 
conventional or BEP chromium. This lower wear rate could be attributed to a lower crack density, Table 13. The surface texture and microcracking of the various chromium-vanadium deposits are shown in Figure 33.

A particulate composite coating of chromium and aluminum oxide $\left(\mathrm{Al}_{2} \mathrm{O}_{3}\right)$ was evaluated for wear using the abrasive slurry tester. This composite coating was deposited from the BEP chromium electrolyte containing $10 \mathrm{~g} / \mathrm{l}$ of $\mathrm{Al}_{2} \mathrm{O}_{3}$ in the form of $5 \mu \mathrm{m}$ size particles. Various DC operating parameters were evaluated for wear and compared to the BEP chromium deposits, Table 16. Lower wear was obtained for the chromium- $\mathrm{Al}_{2} \mathrm{O}_{3}$ composite when deposited at $50^{\circ} \mathrm{C}$ and current densities higher than are normally used in the present BEP chromium process. The lower wear value for the higher current density deposits is attributed to a larger volume of alumina being incorporated in the deposit. A significant reduction in wear was observed for the higher current density composite when compared to the BEP chromium.

\subsection{Other Metals, Alloys, and Composites}

Other metal coatings and composites were evaluated for wear and compared to the BEP chromium, Table 17. Electroless nickel (Ni-P) deposits were wear tested in the as-plated condition. These deposits had a hardness of $550 \mathrm{~kg} / \mathrm{mm}^{2}$. A $12.5 \mu \mathrm{m}$ thick deposit wore through during the normal 150 cycle test at a load of $1500 \mathrm{~g}-\mathrm{f}$. A wear rate was not determined once a coating was worn through to the substrate. Electrolytic nickel-cobalt-phosphorus (Ni-Co-P) alloys were wear tested in the as-plated condition. These deposits had a hardness of $500 \mathrm{~kg} / \mathrm{mm}^{2}$. A $35 \mu \mathrm{m}$ thick deposit had a wear rate eight times greater than the BEP 
chromium. Electrolytic bright nickel, a Watts nickel electrolyte with proprietary organic brighteners, was found to have a wear rate 5-1/2 times greater than BEP chromium. Two metallic composite coatings were evaluated for wear. One was an electrolytic nickel-cobalt-phosphorusTeflon composite. A composite thickness of $35 \mu \mathrm{m}$ wore through the coating to the steel substrate during the normal 150 cycle test at a load of $1500 \mathrm{~g}-\mathrm{f}$. The other composite coating was an electroless nickelphophorus-silicon carbide (Ni-P-SiC) coating. The size of the silicon carbide particulates were in the range of 1-3 $\mu \mathrm{m}$. The coating thickness was $18 \mu \mathrm{m}$. The wear rate of this coating was insignificant when tested at the normal 150 cycle, $1500 \mathrm{~g}-\mathrm{f}$ conditions. This composite coating had the lowest wear rate, as determined by the abrasive slurry tester, of any coating investigated in this program. This particular coating with the 3 um size particulates may have a surface too rough, $0.5 \mu \mathrm{m}$ (20 microinches) as shown in Figure 34, for use on printing plates due to the entrapment of ink, but warrants further investigation possibly with a smaller particulate size. The Ni-P-SiC composite coatings could have application in other areas of high wear in the printing industry, such as postage stamp perforators.

\section{PRIMARY WIPER BLADE COATINGS STUDY}

It would be very important to obtain a value for the wear rate of printing plates in actual service, and for a range of conditions. This information would provide a baseline for use in deciding whether subsequent wear experience is reasonable, or whether perhaps some part of the printing process is not under usual control. Such information would 
also permit a comparison between laboratory wear data and printing operation wear data; that would indicate the degree to which the laboratory wear test simulates the actual use. Several possibilities exist that might permit obtaining service wear data. Direct measurement of wear on the chromium printing plates would be best; however, security precautions have prevented us from following that course. Another approach recognizes that the steel wiper blades that bear on the wiping roll, Figure 35, experience very similar sliding conditions to the printing plates. Chromium plating on the wiper blades would permit an even closer comparison to be made, once the loads involved were determined. The blades could also serve to study other new materials for possible printing plate use.

Initially, the proposed plating of primary wiper blades involved the design and construction of a plating tank using the conforming anode. Chromium was deposited directly onto the steel blades along the length of one edge, $73 \mathrm{~cm}$, extending $10 \mathrm{~mm}$ back from the edge. The wiper blades were plated to a minimum thickness of $50 \mu \mathrm{m}(2.0 \mathrm{mils})$ on the flat sides of the blades. By taking advantage of the conforming anode and the high localized current density on the blade edge, the actual chromium thickness on the edge to be tested was doubled to $100 \mu \mathrm{m}$ ( $4.0 \mathrm{mils}$ ) for the same length of time to deposit $50 \mu \mathrm{m}(2.0 \mathrm{mils})$ on the sides, Figure 36. Once the uniformity of plating on the blade edge was established, primary wiper blades were plated with BEP chromium (normal operating conditions), non-cracked (milky) chromium, duplex chromium (cracked over non-cracked), and "transition" chromium. These blades were to be forwarded to BEP for evaluation in the water-wipe presses. A program was 
developed at BEP to track the plated wiper blades as they were used in the presses.

The process for plating the wiper blades consisted of polishing off the blue temper oxide, pumice scrubbing, reverse etching in the chromium plating solution at $5-7 \mathrm{~A} / \mathrm{dm}^{2}$ for 30 seconds, and chromium plating. After plating, the blades were hydrogen relieved by heat treating at $185^{\circ} \mathrm{C}$ for two hours. The blades were identified by scribing a number which indicates the electrolyte operating temperature, ${ }^{\circ} \mathrm{C}$, and current density in amp/ft ${ }^{2}$. Wear was determined by total weight loss and photographic comparison of blade edge before and after testing.

Three of the original four sets of the various types of chromium plated blades have been sent to BEP for evaluation, but only two types have been tested, the BEP chromium (normal operating conditions) and the non-cracked (milky) chromium. The results of in situ testing on the printing presses are described in the following section.

6.1 Hard, Bright, Microcracked Chrmoium (BEP) - - $25 \mathrm{~A} / \mathrm{dm}^{2}\left(230 \mathrm{~A} / \mathrm{ft}^{2}\right)$ at $50{ }^{\circ} \mathrm{C}$.

Primary wiper blade \#50230-1. The average chromium thickness on the edge was $94 \mu \mathrm{m}(3.7 \mathrm{mils})$. The wiper blade was run for 706,345 impressions to failure (fracture). The PVC wiper roll cover was also destroyed when the blade fractured. Only one chromium plated edge was tested. This blade ran for 16 shifts. Representative photos of the chromium plated edge, before and after testing, are shown in Figure 37. Primary wiper blade \#50230-2. The average chromium thickness on the 
edge was $96.5 \mu \mathrm{m}$ ( $3.8 \mathrm{mils})$. The wiper blade was run for $1,113,400$ impressions. The blade was removed due to wear, nicks, and scratches. The PVC wiper roll was also ruined. Both sides of the chromium plated edge were tested. One side appeared to run longer than the other (determined by the width of the exposed steel). This blade was run on press 501 (back plates and green ink) for 26 shifts. Total weight loss was $1.01 \mathrm{~g}$. Wear rate determined as weight loss/impression as $0.91 \times 10^{-}$ 6 g/impression. Representative photos of the chromium plated edge, before and after testing, are shown in Figure 38.

Primary wiper blade \#50230-3. The average chromium thickness on the edge was $96.5 \mu \mathrm{m}(3.8 \mathrm{mils})$. The wiper blade was run for 800,093 impressions. The blade was removed due to wear, nicks, and scratches. Both sides of the chromium plated edge were tested and were worn through to the steel. The blade was run on press 501 (back plates and green ink) for 20 shifts. Total weight loss was $0.72 \mathrm{~g}$ which resulted in a wear rate of $0.90 \times 10^{-6} \mathrm{~g} /$ impression. Representative photos of the chromium plated edge, before and after testing, are shown in Figure 39.

Primary wiper blade \#50230-4. The average chromium thickness on the edge was $114 \mu \mathrm{m}(4.5 \mathrm{mils})$. Only one side of the chromium plated edge was tested. The reason for the removal of the blade from the test was not known. The weight loss was $0.23 \mathrm{~g}$. Number of impressions, press number, and number of shifts were not reported. Representative photos of the plated blade, before and after testing, are shown in Figure 40 .

6.2 Non-Cracked Milky Chromium $30 \mathrm{~A} / \mathrm{dm}^{2}\left(278 \mathrm{~A} / \mathrm{ft}^{2}\right)$ at $70^{\circ} \mathrm{C}$. 
Primary wiper blade \#70278-1. The average chromium thickness on the edge was $135 \mu \mathrm{m}(5.3 \mathrm{mils})$. The only data available on the testing of this blade is that it was run for 492,907 impressions. The blade was lost at BEP.

Primary wiper blade $\# 70278-2$. The average chromium thickness on the edge was $119 \mathrm{um}(4.7 \mathrm{mils})$. The wiper blade was run for $\sim 840,000$ impressions (determined from the number of impressions per shift from other blades, $\sim 2,000$ impressions/shift). The blade was run on press 503 (back plates and green ink) for 20 shifts. Both sides of the chromium plated edge were tested, but only one side had worn through to the steel. It was not known why the blade was removed from the test. Total weight loss was $0.43 \mathrm{~g}$, which resulted in a wear rate of $0.51 \times 10^{-6}$ g/impression. Representative photos of the chromium plated edge, before and after testing, are shown in Figure 41.

Primary wiper blade \#70278-3. The average chromium thickness on the edge was $127 \mu \mathrm{m}(5.0 \mathrm{mils})$. The wiper blade was run for $\sim 462,000$ impressions (determined from the average number of impressions per shift). The blade was run for 11 shifts on an unknown press for front plates and black ink. Only one side of the chromium plated edge was tested. When turning the blade over for testing the other side, the unplated edge was inadvertently tested. The test was stopped when the unplated edge wore to a knife edge. Total weight loss was $0.56 \mathrm{~g}$ which included the unplated edge and resulted in a wear rate of $1.2 \times 10^{-6}$ g/impression. Representative photos of the chromium plated edge, before and after testing, are shown in Figure 42. 


\subsection{Duplex Chromium (Cracked over Non-cracked)}

A set of three duplex chromium plated blades have been sent to BEP but have not been evaluated.

\section{CONCLUSIONS}

$\circ$

An accelerated wear test was developed to rank electrodeposits for wear in a medium designed to simulate the press environment. Wear data obtained from the test had a low standard deviation, indicating that the scatter between individual measurements was small and the test was precise.

of the many metal, metal alloy, and composite coatings that were investigated for wear performance, seven types of coatings exhibited an improvement in abrasive wear performance over the current chromium technology. The results of wear tests on these coatings as determined by the accelerated abrasive slurry wear tester are summarized in Table 18 and Figure 43. The coating that exhibited the lowest rate of wear was a composite coating of nickel-phosphorus-silicon carbide. This particular coating may have a surface too rough for use on printing plates due to the entrapment of ink, but warrants further investigation possibly with a smaller particulate size. The Ni-P-SiC composite coatings could have applciation in other areas of high wear in the printing industry, such as postage stamp perforators. 
The majority of the coatings investigated were chromium or chromium based coatings of which six types exhibited an increase in wear performance. One of the new kinds of chromium (pulse plated duplex) exhibited a factor of two increase in abrasive wear performance. This coating will most likely be patented. Other types of chromium coatings such as composites of chromium and aluminum oxide, "transition" chromium, pulse plated bright chromium, DC deposited duplex, and a chromium-vanadium alloy have exhibited a factor of 1.2 to 1.5 increase in wear performance over the current chromium technology.

The most significant result of the in situ wear testing of chromium plated wiper blades has been the extended life of the blade compared to the presently used unplated blade. The life of the plated blade is 15-20 shifts, whereas the unplated blades have a normal life of only $1-2$ shifts. The results of the in situ wear testing is summarized in Table 19. A conservative estimate of savings in dollars to BEP for the extended life of the plated wiper blades is $\$ 200,000 /$ year. As far as the ranking of various chromium coatings for wear in the in situ test, not enough data has been accumulated and the tracking control of the tests at BEP must be improved to prevent such occurrences as lost blades, no reported data on history of test, and the use of different presses with either front or back plates (black or green inks) for blades from same set. 


\section{ACKNOWLEDGEMENTS}

The authors are grateful to the Bureau of Engraving and Printing for the financial support of this program. The authors would also like to thank Mr. Wayne Anderson of Harper-Thiel, Incorporated, and Mr. Leo Lee of Armoloy International for supplying electrodepostied chromium samples for wear evaluation. 
TABLE 1

PLATE NUMBER, CHROMIUUM THICKNESS, IMPRESSIONS TO FAILURE, HARDNESS (MEASURED AND SPECIFIED)

\begin{tabular}{|c|c|c|c|c|c|c|c|}
\hline \multirow[t]{2}{*}{ Plate } & \multirow[t]{2}{*}{ No. } & \multirow{2}{*}{\multicolumn{2}{|c|}{$\begin{array}{l}\text { Thickness } \\
\mu \mathrm{m} \text { (mil) }\end{array}$}} & \multirow{2}{*}{$\begin{array}{l}\text { Impressions } \\
\text { X1000 }\end{array}$} & \multirow[b]{2}{*}{$\mathrm{Cr}$} & \multicolumn{2}{|c|}{ Microhardness } \\
\hline & & & & & & $\mathrm{Ni}$ KHN50 & Specs., VHN100 \\
\hline 11438 & 101 & 5.97 & $(0.235)$ & 185 & 1025 & 354 & $\mathrm{Ni}: 175-230$ \\
\hline 11533 & 502 & 4.50 & $(0.177)$ & 78 & 920 & 309 & $\mathrm{Cr}: 1000-1100$ \\
\hline 11597 & 502 & 6.10 & $(0.240)$ & 175 & 1051 & 291 & \\
\hline 11264 & 205 & 7.19 & $(0.283)$ & $?$ & & & \\
\hline 11446 & 101 & 7.62 & $(0.300)$ & 181 & & & \\
\hline 12054 & 101 & 8.64 & $(0.340)$ & 513 & & & \\
\hline 46960 & 101 & 8.95 & $(0.352)$ & 271 & & & \\
\hline 47050 & 205 & 6.93 & $(0.273)$ & 91 & & & \\
\hline 46924 & 205 & 6.10 & $(0.240)$ & $?$ & & & \\
\hline 46957 & 101 & 14.60 & $(0.575)$ & 77 & & & \\
\hline 47058 & 220 & 8.64 & $(0.340)$ & 51 & & & \\
\hline 47038 & 220 & 4.57 & $(0.180)$ & $?$ & & & \\
\hline 47059 & 220 & 8.38 & $(0.330)$ & $?$ & & & \\
\hline $8(4 ?) 7$ & 7964101 & 111.3 & $(0.443)$ & $?$ & & & \\
\hline
\end{tabular}


TABLE 2

CHROMIUM THICKNESS VS. NUMBER OF IMPRESSIONS TO FAILURE

Number of Impressions

Plate Number

$50230-110$

$50264-110$

$50169-110$

$50229-110$

$50301-110$

$50168-110$

$50265-110$
To Failure

140,000

139,000

129,000

106,000

100,000

88,000

20,000
Chromium Thickness

$(\mu \mathrm{m}) \mathrm{mil}$

$0.270(6.86)$

$0.270(6.86)$

$0.225(5.72)$

$0.328(8.33)$

$0.250(6.35)$

$0.243(6.17)$

$0.223(5.66)$ 
TABLE 3

MICROHARDNESS OF ELECTRODEPOSITED NICKEL ENGRAVING PLATES

Plate No. Hardness Values of Five Indentations Avg. Vickers Hardness

\begin{tabular}{llllllll}
$50230-110$ & 167.8 & 180.7 & 183.9 & 195.2 & 194.2 & 184.1 & VHN \\
& 167.1 & 180.7 & 182.3 & 194.2 & 194.2 & & \\
& 169.3 & 180.7 & 183.1 & 194.2 & 193.3 & SD=10.15 \\
\hline
\end{tabular}

\begin{tabular}{rrrrrrr}
$50264-110$ & 191.5 & 190.6 & 175.2 & 194.2 & 185.6 & 187.3 VHN \\
& 189.8 & 188.9 & 173.7 & 195.9 & 186.4 & \\
& 189.8 & 190.6 & 174.5 & 195.9 & 187.2 & SD $=7.31$ \\
\hline
\end{tabular}

\begin{tabular}{|c|c|c|c|c|c|c|}
\hline $50169-110$ & $\begin{array}{l}170.7 \\
172.2 \\
170.7 \\
\end{array}$ & $\begin{array}{l}172.2 \\
172.2 \\
172.2 \\
\end{array}$ & $\begin{array}{l}163.6 \\
161.6 \\
164.0 \\
\end{array}$ & $\begin{array}{l}189.8 \\
188.1 \\
185.6 \\
\end{array}$ & $\begin{array}{l}184.7 \\
183.9 \\
183.1 \\
\end{array}$ & $\begin{array}{l}175.5 \mathrm{VHN} \\
\mathrm{SD}=9.48\end{array}$ \\
\hline $50229-110$ & $\begin{array}{l}250.2 \\
250.2 \\
248.9 \\
\end{array}$ & $\begin{array}{l}208.2 \\
206.2 \\
205.3\end{array}$ & $\begin{array}{l}181.5 \\
180.7 \\
181.5 \\
\end{array}$ & $\begin{array}{l}158.9 \\
158.9 \\
160.3 \\
\end{array}$ & $\begin{array}{l}188.9 \\
188.9 \\
189.8 \\
\end{array}$ & $\begin{array}{l}197.2 \quad \mathrm{VHN} \\
\mathrm{SD}=31.40\end{array}$ \\
\hline $50301-110$ & $\begin{array}{l}197.8 \\
199.6 \\
195.0 \\
\end{array}$ & $\begin{array}{l}179.1 \\
178.3 \\
177.5 \\
\end{array}$ & $\begin{array}{l}191.5 \\
193.3 \\
193.3 \\
\end{array}$ & $\begin{array}{l}195.9 \\
195.0 \\
194.2 \\
\end{array}$ & $\begin{array}{l}179.9 \\
180.7 \\
179.9 \\
\end{array}$ & $\begin{array}{l}188.7 \quad \mathrm{VHN} \\
\mathrm{SD}=8.27\end{array}$ \\
\hline $50168-110$ & $\begin{array}{l}171.5 \\
170.7 \\
170.7\end{array}$ & $\begin{array}{l}156.3 \\
155.7 \\
157.0 \\
\end{array}$ & $\begin{array}{l}168.6 \\
168.6 \\
169.3 \\
\end{array}$ & $\begin{array}{l}167.8 \\
167.8 \\
167.8 \\
\end{array}$ & $\begin{array}{l}167.1 \\
168.6 \\
167.1 \\
\end{array}$ & $\begin{array}{l}166.3 \text { VHN } \\
\mathrm{SD}=5.33\end{array}$ \\
\hline $50265-110$ & $\begin{array}{l}183.9 \\
186.4 \\
183.1\end{array}$ & $\begin{array}{l}179.1 \\
177.5 \\
177.5\end{array}$ & $\begin{array}{l}176.8 \\
177.5 \\
176.8\end{array}$ & $\begin{array}{l}157.0 \\
155.0 \\
155.0\end{array}$ & $\begin{array}{l}195.0 \\
195.0 \\
195.0\end{array}$ & $\begin{array}{l}178.0 \quad \mathrm{VHN} \\
S D=13.36\end{array}$ \\
\hline
\end{tabular}

Microhardness measured on Leco DME at $50 \mathrm{~g}-\mathrm{f}$. 


\begin{tabular}{|c|c|c|}
\hline & $\begin{array}{l}29111 \text { MILFORO ROAD } \\
\text { NEW HUDSON, M11 } 48165 \\
\end{array}$ & $\begin{array}{l}1250 \text { N. MAIN STREET } \\
\text { LOS ANGELES. CA } 90012\end{array}$ \\
\hline & $\begin{array}{l}81 \text { INOUSTRIAL QOOAO } \\
\text { BERKELEY HEIGHTS, NJ } 07922\end{array}$ & $\begin{array}{l}2054 \text { CONCOURSE ORIVE } \\
\text { ST. LOUIS, MOO } 63141\end{array}$ \\
\hline & $\begin{array}{l}2700 \text { W. LAKE ST. } \\
\text { MELROSE PARK, IL } 60160\end{array}$ & \\
\hline
\end{tabular}

\begin{tabular}{|l|l|l|l|l|}
\hline TANK IOENTIFICATION & NUMBER & OPERATING TEMP. & CAPACITY & DATE RECEIVED \\
\hline
\end{tabular}

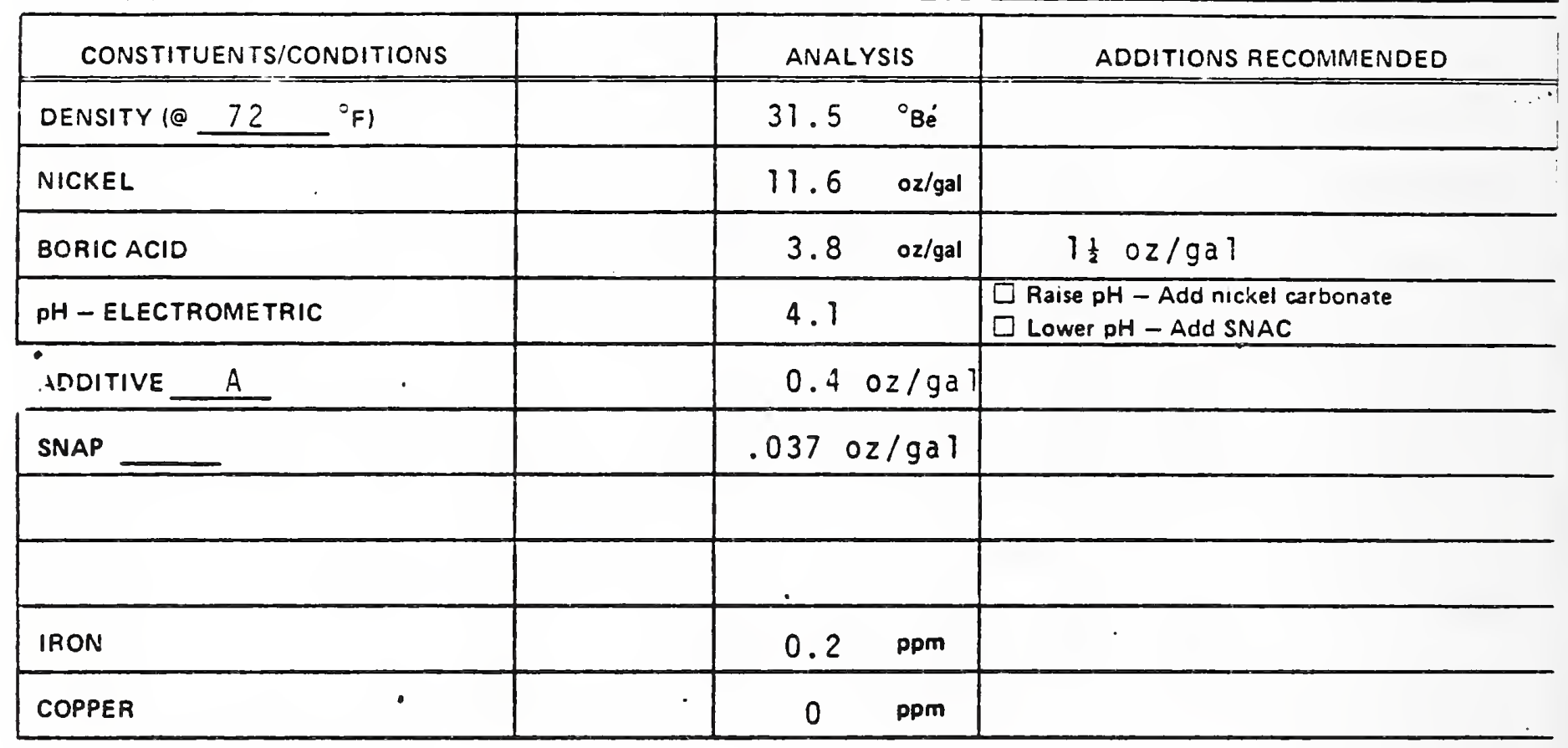

DEPOSIT CHARACTERISTICS

\begin{tabular}{|l|l}
\hline HULL CELL & Good Panel \\
\hline DUCTILITY & \\
\hline STRESS* [TENSILE \\
$\square$ COMPRESSIVE
\end{tabular}
REMARKS AND FURTHER RECONMENDATIONS:

\begin{tabular}{|c|c|c|c|}
\hline DATE & $\begin{array}{c}\text { SMLES (SERIVILE) REI AESENTATIVE } \\
\text { B. Smith }\end{array}$ & FNALYST & CHECKED BY \\
\hline
\end{tabular}


ANALYSIS REPORT

ISOBRITE ${ }^{\circledR}$ CHROMIUM SOLUTION

National Bureau of Standards

ATTN:

\begin{tabular}{|l|l|l|l|}
\hline $\begin{array}{l}\text { ISOBRITE SYSTEM } \\
\text { No. }\end{array}$ & TANS IDENTIFICATION & CAPACITY & $\begin{array}{c}\text { DATE RECEIVED } \\
11-28-83\end{array}$ \\
\hline
\end{tabular}

\begin{tabular}{|c|c|c|}
\hline CONSTITUENTS/CONDITIONS & ANALYSIS & ADDITIONS RECOMMENDED \\
\hline TOTAL CHROMIC ACID $\left(\mathrm{CrO}_{3}\right)$ & $18.0 \quad$ oz/gal & 12 lbs $920 S F / 100$ gal. capaci \\
\hline FREE CHROMIC ACID & oz/gal & \\
\hline TRIVALENT CHROME & $0.3 \mathrm{oz} / \mathrm{gal}$ & \\
\hline SULFATE $\left(\mathrm{SO}_{4}{ }^{\circ}\right)$ & $0.25 \mathrm{oz} / \mathrm{gal}$ & $1.5 \mathrm{lbs} \mathrm{BaCO}_{3} / 100 \mathrm{gal}$. capac \\
\hline OTALCrO ${ }_{3} / \mathrm{SO}_{4}=\mathrm{RATIO}$ & $72: 1$ & \\
\hline \multicolumn{3}{|l|}{ TOTAL $\mathrm{CrO}_{3} / \mathrm{FREE} \mathrm{CrO} 3$ RATIO } \\
\hline ISOBRITE NO. 923 & $0.5 \mathrm{~g} / 1$ & $1.51 \mathrm{bs} / 100 \mathrm{gal}$. capacity \\
\hline \multicolumn{3}{|l|}{ ISOBRITE No. } \\
\hline \multicolumn{3}{|l|}{ ISOBRITE No. } \\
\hline Iron & $600 \mathrm{ppm}$ & \\
\hline Copper & $220 \mathrm{ppm}$ & \\
\hline Nickel & $20 \mathrm{ppm}$ & \\
\hline
\end{tabular}

REMARKS AND FURTHER RECOMMENDATIONS:

\begin{tabular}{|l|c|c|c|}
\hline DATE & SALES ISERVICE) REPRESENTATIVE & ANALYST & JHECKED BY \\
$11-30-83$ & B. Smith & JB & \\
\hline
\end{tabular}


TABLE 6

COMPOSITION OF THE ABRASIVE SLURRY USED IN ACCELERATED WEAR TESTER

\author{
$100 \mathrm{cc}$ distilled water \\ $10 \mathrm{~g} \mathrm{Al}_{2} \mathrm{O}_{3}(5.0 \mathrm{~mm}$ diameter $)$ \\ 5 g Cab-0-Sil silica (thickening agent) \\ $\mathrm{pH}=4$, adjusted with ferric chloride
}


TABLE 7

A SUMMARY OF THE WEAR DATA FROM WEAR TESTER DEVELOPMENT

\begin{tabular}{|c|c|c|c|}
\hline Substrate & Counterface & $\begin{array}{l}\text { Wear (SD) *** } \\
\left(\mathrm{g} \times 10^{-5}\right)\end{array}$ & $\begin{array}{l}\text { Hardness }(200 \mathrm{~g}) \\
\text { Vickers }\end{array}$ \\
\hline \multirow[t]{3}{*}{ Steel } & Viton & $247(60)$ & 832 \\
\hline & PVC-BEP & $307(128)$ & \\
\hline & 1000 grit $\mathrm{SiC}$ & $218(4)$ & \\
\hline \multirow[t]{3}{*}{ Nickel } & Viton & $322(41)$ & 590 \\
\hline & PVC-BEP & $126(39)$ & \\
\hline & 1000 grit $\mathrm{SiC}$ & 749 (13) & \\
\hline \multirow[t]{3}{*}{ Chromium } & Viton & $39(5)$ & $900+$ \\
\hline & PVC-BEP & $27(5)$ & \\
\hline & $1000 \mathrm{grit} \mathrm{SiC}$ & $32(3)$ & \\
\hline \multirow{3}{*}{$\begin{array}{l}\text { Nickel-Phosphorus } \\
\text { and Silicon Carbide }\end{array}$} & Viton & $2.3(4)$ & $2600 *$ \\
\hline & PVC-BEP & $0(1)$ & \\
\hline & 1000 grit SiC & $\begin{array}{l}\text { No measureable } \\
\text { loss }\end{array}$ & \\
\hline
\end{tabular}

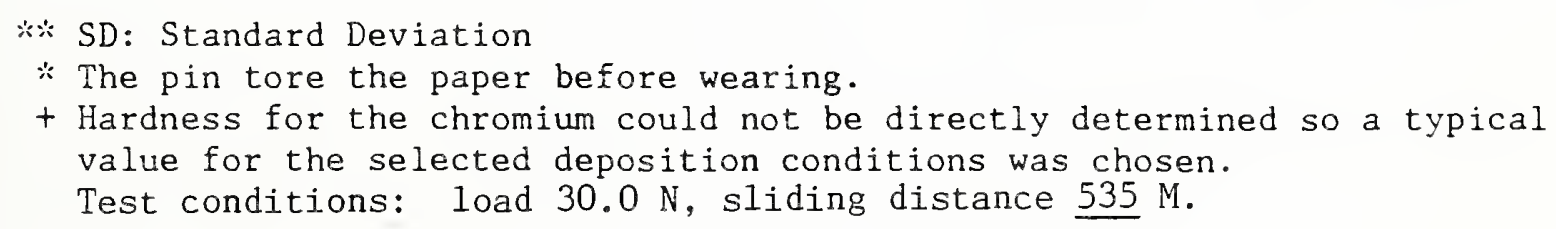


TABLE 8

WEAR AND HARDNESS OF VARIOUS CHROMIUM DEPOSITS

Wear Rate, g/cycle Hardness, KHN 50

\begin{tabular}{|c|c|c|}
\hline 6 um BEP Cr, $50^{\circ} \mathrm{C}-25 \mathrm{~A} / \mathrm{dm}^{2}$ & $15.2 \pm 3.4 \times 10^{-8}$ & 973 \\
\hline $2.5 \mathrm{um}$ BEP $\mathrm{Cr}, 50^{\circ} \mathrm{C}-25 \mathrm{~A} / \mathrm{dm}^{2}$ & $17.0 \pm 2.0 \times 10^{-8}$ & 1034 \\
\hline $\begin{array}{l}7.5 \text { um Non-Crack BEP Cr, } \\
70^{\circ} \mathrm{C}-30 \mathrm{~A} / \mathrm{dm}^{2}\end{array}$ & $9.2 \pm 1.7 \times 10^{-8}$ & 700 \\
\hline 0.6 un Comm. "A" $\mathrm{Cr}$, & $13.2 \pm 4.0 \times 10^{-8}$ & 1002 \\
\hline $\begin{array}{l}5 \text { um Comm. "A" } \mathrm{Cr} \text {, } \\
54^{\circ} \mathrm{C}-39 \mathrm{~A} / \mathrm{dm}^{2}\end{array}$ & $13.6 \pm 2.4 \times 10^{-8}$ & 1064 \\
\hline $\begin{array}{l}8.5 \text { um Comm. "A" } \mathrm{Cr} \text {, } \\
54^{\circ} \mathrm{C}-46 \mathrm{~A} / \mathrm{dm}^{2}\end{array}$ & $15.0 \pm 4.0 \times 10^{-8}$ & 1085 \\
\hline 2.5 um Comm. "B" $\mathrm{Cr}$, & $16.2 \pm 1.5 \times 10^{-8}$ & 960 \\
\hline $\begin{array}{l}6 \text { um Comm. "B" } \mathrm{Cr} \text {, } \\
54^{\circ} \mathrm{C}-46 \mathrm{~A} / \mathrm{dm}^{2}\end{array}$ & $14.2 \pm 4.0 \times 10^{-8}$ & 999 \\
\hline 6 um Comm. "C" $\mathrm{Cr}$ & $12.8 \pm 4.0 \times 10^{-8}$ & 1050 \\
\hline
\end{tabular}

Load: $39 \mathrm{~N}(4000 \mathrm{~g}-\mathrm{f}) \quad$ Test Duration: 250 or 500 cycles 
TABLE 9

DC PLATING PARAMETERS OF BEP CHROMIUM ELECTROLYTE

Electrolyte Temp. ${ }^{\circ} \mathrm{C}$ Current Density, $\mathrm{A} / \mathrm{dm}^{2} \quad$ Nomenclature

50

70

70

70

70

50

70

70
110

24.8

30

65

110

30

24.8

30

65
Standard BEP Plating Parameters. Bright, smooth, microcracked deposits.

"Milky" chromium deposits. "Crack free."

"Transition" chromium (zone between bright and milky deposits).

Low crack density, semi-bright.

"Bright," lower crack density, not as smooth as bright microcracked. Some surface texture.

Duplex Chromium I--Layer of bright, microcracked over milky.

Duplex Chromium II--Layer of transition over milky. 
TABLE 10

WEAR RESULTS OF VARIOUS BEP CHROMIUM DEPOSITS

$\underline{\text { Deposit }}$

Wear Rate, g/cycle

Transition $\mathrm{Cr}$ on $\mathrm{Ni}$ : $12.5 \mathrm{um}$ @ $70^{\circ} \mathrm{C}-65 \mathrm{~A} / \mathrm{dm}^{2} 16.7 \pm 4.0 \times 10^{-8}$ Duplex $\mathrm{Cr}$ I on $\mathrm{Ni}: 6 \mathrm{um}$ a $50^{\circ} \mathrm{C}-25 \mathrm{~A} / \mathrm{dm}^{2} 18.0 \pm 4.0 \times 10^{-8}$ Duplex $\mathrm{Cr}$ II on $\mathrm{Ni}: \begin{gathered}6 \mathrm{um} @ 70^{\circ} \mathrm{C}-65 \mathrm{~A} / \mathrm{dm}^{2} \\ \text { over } 6 \text { um } 18.7 \pm 40^{\circ} \mathrm{C}-30 \mathrm{~A} / \mathrm{dm}^{2}\end{gathered}$ High Temp Bright $\mathrm{Cr}$ on $\mathrm{Ni}$ : 12.5 um a $22.0 \pm 4.0 \times 10^{-8}$ Milky $\mathrm{Cr}$ on $\mathrm{Ni}: 12.5$ um $70^{\circ} \mathrm{C}-30 \mathrm{~A} / \mathrm{dm}^{2}$ $22.0 \pm 4.0 \times 10^{-8}$ Standard BEP on $\mathrm{Ni}: \quad 12.5$ um $950^{\circ} \mathrm{C}-25 \mathrm{~A} / \mathrm{dm}^{2} 24.0 \pm 4.0 \times 10^{-8}$ 
WEAR RESULTS OF PULSE PLATED BEP CHROMIUM DEPOSITS AT VARIOUS ON/OFF TIMES AT A CONSTANT DUTY CYCLE

\section{Deposit}

$\mathrm{PP} \mathrm{Cr}$ on $\mathrm{Ni}: 2.5 \mathrm{~ms}$ on, $0.5 \mathrm{~ms}$ off

$\mathrm{PP} \mathrm{Cr}$ on $\mathrm{Ni}$ : $5 \mathrm{~ms}$ on, $1 \mathrm{~ms}$ off

$\mathrm{PP} \mathrm{Cr}$ on $\mathrm{Ni}: 10 \mathrm{~ms}$ on, $2 \mathrm{~ms}$ off

$\mathrm{PP} \mathrm{Cr}$ on $\mathrm{Ni}$ : $15 \mathrm{~ms}$ on, $3 \mathrm{~ms}$ off

$\mathrm{PP} \mathrm{Cr}$ on $\mathrm{Ni}: 0.5 \mathrm{~ms}$ on, $0.1 \mathrm{~ms}$ off

$\mathrm{PP} \mathrm{Cr}$ on $\mathrm{Ni}: 1 \mathrm{~ms}$ on, $0.2 \mathrm{~ms}$ off

DC BEP $\mathrm{Cr}$ on $\mathrm{Ni}$
Wear Rate, g/cycle

$23.3 \pm 4 \times 10^{-8}$

$25.2 \pm 4.5 \times 10^{-8}$

$25.3 \pm 3.5 \times 10^{-8}$

$25.9 \pm 4.5 \times 10^{-8}$

$26.3 \pm 4.0 \times 10^{-8}$

$28.0 \pm 4.0 \times 10^{-8}$

$24.0+4.0 \times 10^{-8}$

Pulse Plated Samples Deposited at $50^{\circ} \mathrm{C}$, current density of $25 \mathrm{~A} / \mathrm{dm}^{2}$, and a duty cycle of $83.3 \%$.

Load: $1500 \mathrm{~g}-\mathrm{f} \quad$ Test Duration: 150 cycles 
TABLE 12

WEAR RESULTS OF PULSE PLATED BEP CHROMIUM DEPOSITS

AT VARIOUS DUTY CYCLES

\section{Deposits}

PP $\mathrm{Cr}$ on $\mathrm{Ni}: 5 \mathrm{~ms}$ on, $1 \mathrm{~ms}$ off 83.3\% duty

$\mathrm{PP} \mathrm{Cr}$ on $\mathrm{Ni}: 5 \mathrm{~ms}$ on, $2 \mathrm{~ms}$ off $71.4 \%$ duty

$\mathrm{PP} \mathrm{Cr}$ on $\mathrm{Ni}: 5 \mathrm{~ms}$ on, $3 \mathrm{~ms}$ off $62.5 \%$ duty

DC BEP $\mathrm{Cr}$ on $\mathrm{Ni}$
Wear Rate, g/cycle

$25.2 \pm 4.5 \times 10^{-8}$

$31.8 \pm 4.0 \times 10^{-8}$

$34.8 \pm 3.0 \times 10^{-8}$

$24.0 \pm 4.0 \times 10^{-8}$

Pulse Plated Samples Deposited at $50^{\circ} \mathrm{C}$, average current density of $25 \mathrm{~A} / \mathrm{dm}^{2}$.

Load: $\quad 14.7 \mathrm{~N}(1500 \mathrm{~g}-\mathrm{f})$

Test Duration: 150 cycles 
TABLE 13

WEAR RATE VS CRACK DENSITY OF VARIOUS CHROMIUM DEPOSITS

Deposits

DC Transition $\mathrm{Cr}$

$70^{\circ} \mathrm{C}-65 \mathrm{~A} / \mathrm{dm}^{2}$

DC Duplex $\mathrm{Cr}$

$70^{\circ} \mathrm{C}-30 \mathrm{~A} / \mathrm{dm}^{2}$

$50^{\circ} \mathrm{C}-25 \mathrm{~A} / \mathrm{dm}^{2}$

DC Cr - V Alloy

$50^{\circ} \mathrm{C}-21.5 \mathrm{~A} / \mathrm{dm}^{2}$

PP $\mathrm{Cr}$

$50^{\circ} \mathrm{C}-25 \mathrm{~A} / \mathrm{dm}^{2}$ (Peak)

$\mathrm{PP} \mathrm{Cr}$

$50^{\circ} \mathrm{C}-25 \mathrm{~A} / \mathrm{dm}^{2}(\mathrm{Avg})$

DC BEP Cr

$50^{\circ} \mathrm{C}-25 \mathrm{~A} / \mathrm{dm}^{2}$
Wear rate, g/cycle Crack Density, crack/mm

$16.7 \pm 4.0 \times 10^{-8}$

2

$18.0 \pm 4.0 \times 10^{-8}$

26

17

21

26

38 
WEAR RATE OF MODIFIED PULSE PLATED CHROMIUM DEPOSITS VS OTHER DC AND BEP CHROMIUM DEPOSITS

$$
1500 \mathrm{~g} \text { Load }
$$

\section{Deposits}

Modified PP Duplex $\mathrm{Cr}$

$50^{\circ} \mathrm{C}-25 \mathrm{~A} / \mathrm{dm}^{2}$ (Peak)

Modified PP Bright $\mathrm{Cr}$

$50^{\circ} \mathrm{C}-25 \mathrm{~A} / \mathrm{dm}^{2}$ (Peak)

DC Transition $\mathrm{Cr}$

$70^{\circ} \mathrm{C}-65 \mathrm{~A} / \mathrm{dm}^{2}$

DC Duplex $\mathrm{Cr}$

$70^{\circ} \mathrm{C}-30 \mathrm{~A} / \mathrm{dm}^{2} \& 50^{\circ} \mathrm{C}-25 \mathrm{~A} / \mathrm{dm}^{2}$

PP Semi-bright $\mathrm{Cr}$

$50^{\circ} \mathrm{C}-25 \mathrm{~A} / \mathrm{dm}^{2}$ (Avg)

DC BEP Cr

$50^{\circ} \mathrm{C}-25 \mathrm{~A} / \mathrm{dm}^{2}$
150 Cycle Test

Wear Rate, g/cycle

$12.5 \pm 2.0 \times 10^{-8}$

$17.2 \pm 2.5 \times 10^{-8}$

$16.7 \pm 4.0 \times 10^{-8}$

$18.0 \pm 4.0 \times 10^{-8}$

$23.0 \pm 5.0 \times 10^{-8}$

$24.0 \pm 4.0 \times 10^{-8}$ 


\section{TABLE 15}

WEAR RESULTS OF VARIOUS CR-V DEPOSITS COMPARED TO BEP CHROMIUM

\section{Operating Parameters}

DC, $21.5 / \mathrm{dm}^{2}$ a $50^{\circ} \mathrm{C}$

DC, $32 \mathrm{~A} / \mathrm{dm}^{2}$ a $50^{\circ} \mathrm{C}$

DC, $43 \mathrm{~A} / \mathrm{dm}^{2}$ @ $50^{\circ} \mathrm{C}$

$\mathrm{DC}, 65 \mathrm{~A} / \mathrm{dm}^{2}$ ? $70^{\circ} \mathrm{C}$

$\mathrm{PP}, 25 \mathrm{~A} / \mathrm{dm}^{2}(\mathrm{Avg})$ a $50^{\circ} \mathrm{C}$

$\mathrm{PP}, 65 \mathrm{~A} / \mathrm{dm}^{2}(\mathrm{Avg})$ a $70^{\circ} \mathrm{C}$

DC, Conv. Cr. $25 \mathrm{~A} / \mathrm{dm}^{2}$ @ $50^{\circ} \mathrm{C}$

DC, BEP Cr $25 \mathrm{~A} / \mathrm{dm}^{2}$ C $50^{\circ} \mathrm{C}$

Load: $\quad 14.7 \mathrm{~N}(1500 \mathrm{~g}-\mathrm{f})$
Wear Rate, g/cycle

$19.8 \pm 2.5 \times 10^{-8}$

$26.0 \pm 4.0 \times 10^{-8}$

$24.0 \pm 2.7 \times 10^{-8}$

$26.0 \pm 4.0 \times 10^{-8}$

$22.7 \pm 1.1 \times 10^{-8}$

$22.7 \pm 4.0 \times 10^{-8}$

$29.7 \pm 2.5 \times 10-8$

$24.0 \pm 4.0 \times 10^{-8}$

Test Duration: 150 cycles 
WEAR OF $\mathrm{Cr}-\mathrm{Al}_{2} \mathrm{O}_{3}$ COMPOSITES OF VARIOUS OPERATING PARAMETERS COMPARED TO BEP CHROMIUM

Operating Parameters

$$
\begin{gathered}
50^{\circ} \mathrm{C}-40 \mathrm{~A} / \mathrm{dm}^{2} \\
70^{\circ} \mathrm{C}-30 \mathrm{~A} / \mathrm{dm}^{2} \\
50^{\circ} \mathrm{C}-25 \mathrm{~A} / \mathrm{dm}^{2} \\
70^{\circ} \mathrm{C}-65 \mathrm{~A} / \mathrm{dm}^{2} \\
\text { BEP } \mathrm{Cr}-50^{\circ} \mathrm{C}, 25 \mathrm{~A} / \mathrm{dm}^{2}
\end{gathered}
$$

Load: 14.7 (1500 g-f)

\section{Wear Rate, g/cycle}

$$
\begin{aligned}
& 15.9 \pm 2.2 \times 10^{-8} \\
& 20.4 \pm 1.6 \times 10^{-8} \\
& 21.6 \pm 2.0 \times 10^{-8} \\
& 27.5 \pm 2.5 \times 10^{-8} \\
& 24.0 \pm 4 \times 10^{-8}
\end{aligned}
$$

Test Duration: 150 cycles 


\section{TABLE 17}

WEAR RESULTS OF VARIOUS METALLIC COATINGS COMPARED TO BEP CHROMIUM

\section{Coating}

$\mathrm{Ni}-\mathrm{P}-\mathrm{SiC}$ (As plated)

Bright $\mathrm{Ni}$

$\mathrm{Ni}-\mathrm{Co}-\mathrm{P}$ (As-plated)

Ni-P (As plated)

$\mathrm{Ni}-\mathrm{Co}-\mathrm{P}-\mathrm{Tef}$ ion (As plated)

BEP Cr

Load: $14.7 \mathrm{~N}(1500 \mathrm{~g}-\mathrm{f})$
Wear Rate, g/cycle

Insignificant $\left(0-2 \times 10^{-8}\right)$

$137 \pm 21 \times 10^{-8}$

$192 \pm 17 \times 10^{-8}$

Wore Thru Coating

Wore Thru Coating

$24+4 \times 10$

Test Duration: 150 cycles 
TABLE 18

SUMMARY OF LOW WEAR RATE DEPOSITS COMPARED TO THE PRESENTLY USED DC DEPOSITED CHROMIUM AS DETERMINED BY THE ABRASIVE SLURRY ACCELERATED WEAR TESTER

\section{Coating}

Electroless $\mathrm{Ni}-\mathrm{P}-\mathrm{SiC}$

PP Duplex $\mathrm{Cr}$

$50^{\circ} \mathrm{C}-25 \mathrm{~A} / \mathrm{dm}^{2}$ (peak)

$\mathrm{DC} \mathrm{Cr}-\mathrm{Al}_{2} \mathrm{O}_{3}$

$50^{\circ} \mathrm{C}-40 \mathrm{~A} / \mathrm{dm}^{2}$

DC "Transition" $\mathrm{Cr}$

$70^{\circ} \mathrm{C}-65 \mathrm{~A} / \mathrm{dm}^{2}$

PP Bright $\mathrm{Cr}$

$50^{\circ} \mathrm{C}-25 \mathrm{~A} / \mathrm{dm}^{2}$ (peak)

DC Duplex Cr

$70^{\circ} \mathrm{C}-30 \mathrm{~A} / \mathrm{dm}^{2} \& 50 \circ \mathrm{C}-25 \mathrm{~A} / \mathrm{dm}^{2}$

DC $\mathrm{Cr}-\mathrm{V}$

$50^{\circ} \mathrm{C}-21.5 \mathrm{~A} / \mathrm{dm}^{2}$

DC BEP Cr

$50^{\circ} \mathrm{C}-25 \mathrm{~A} / \mathrm{dm}^{2}$

Load: $14.7 \mathrm{~N}(1500 \mathrm{~g}-\mathrm{f})$
Wear Rate, g/cycle*

$(0-2) \times 10^{-8}$

$12.5 \pm 2.0 \times 10^{-8}$

$15.9 \pm 2.2 \times 10^{-8}$

$16.7 \pm 4.0 \times 10^{-8}$

$17.2 \pm 2.5 \times 10^{-8}$

$18.0 \pm 4.0 \times 10^{-8}$

$19.8 \pm 2.5 \times 10^{-8}$

$24.0 \pm 4.0 \times 10^{-8}$

Test Duration: 150 cycles

*Wear rate was determined as an average of five measurements plus and minus one standard deviation. 


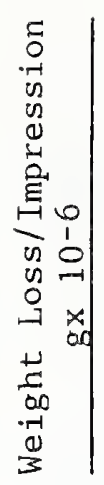

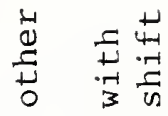

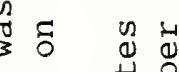

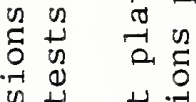

in $+\cdots$

ำ

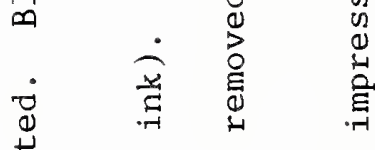

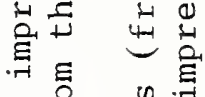

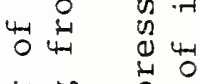

मे

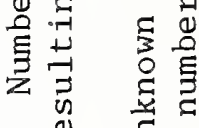

$\therefore \stackrel{\square}{\Xi}$

븡 छ

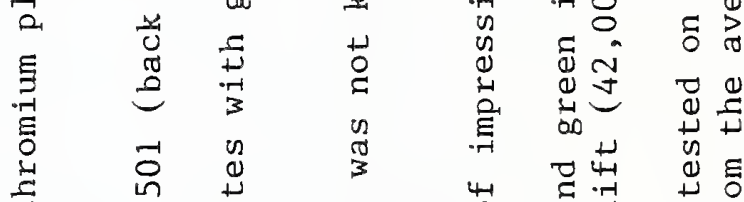

놀

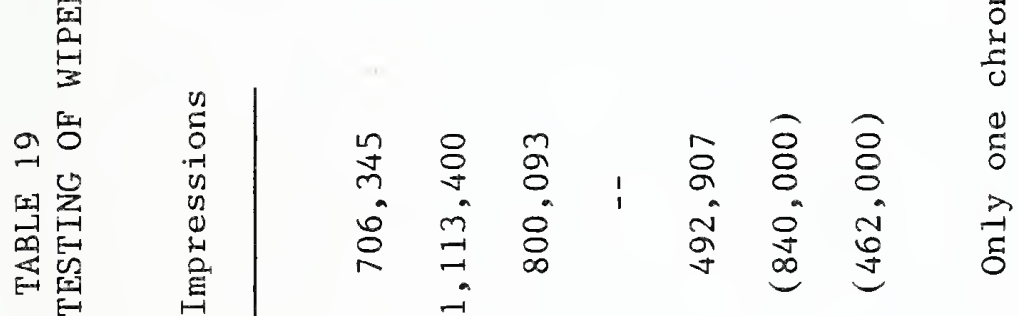

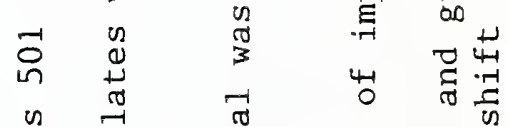

is

옹

3 वृ

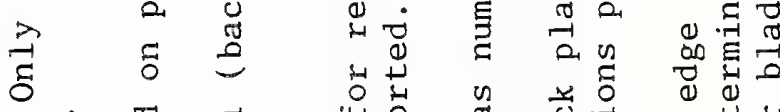

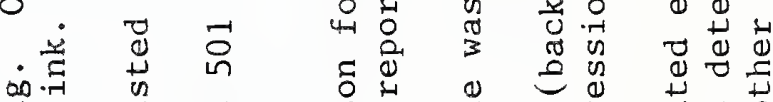

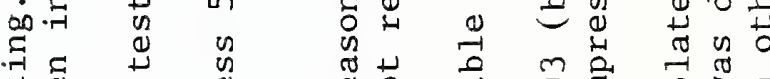

畓

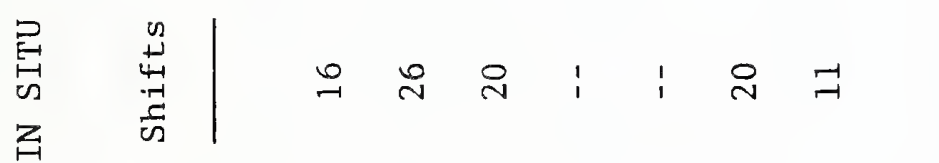

क⿺⿻一⿰冫⿰亅⿱丿丶丶⿱⿰㇒一乂

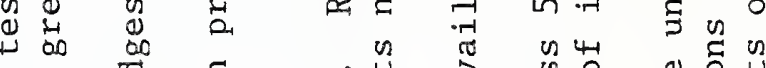

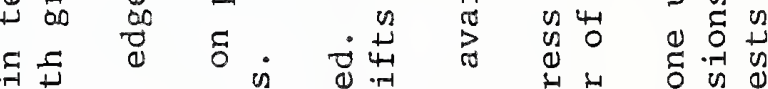

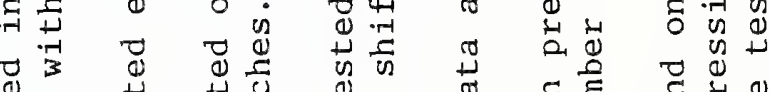

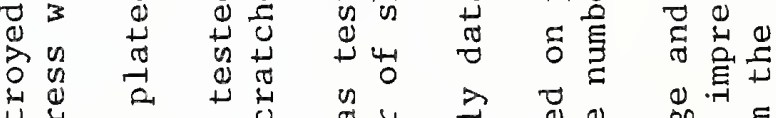

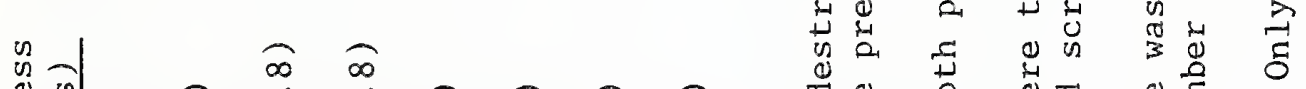

$\stackrel{1}{\perp}$

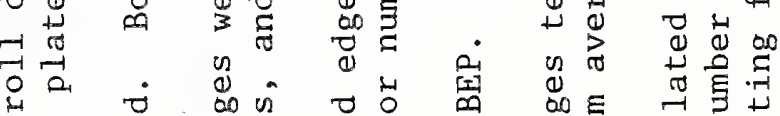

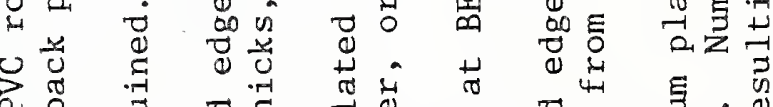

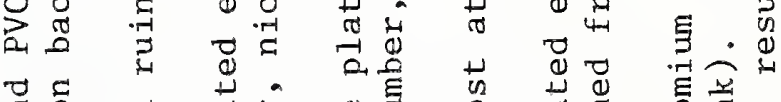

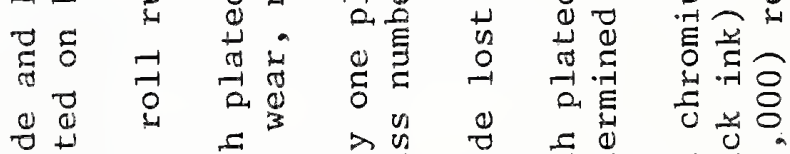

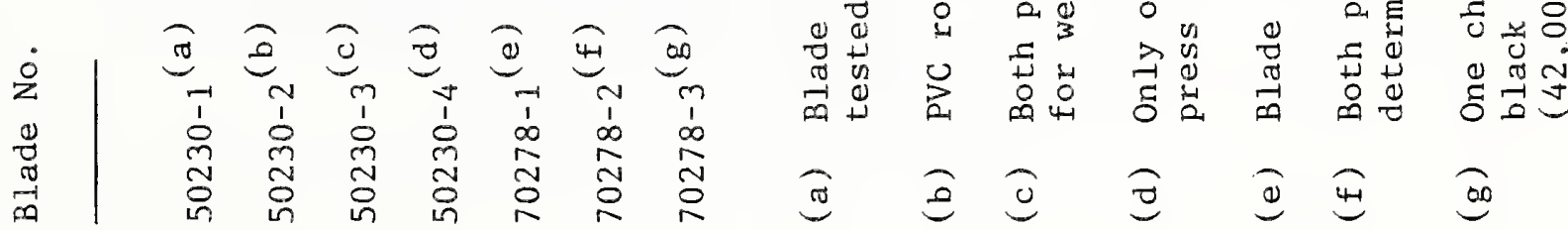




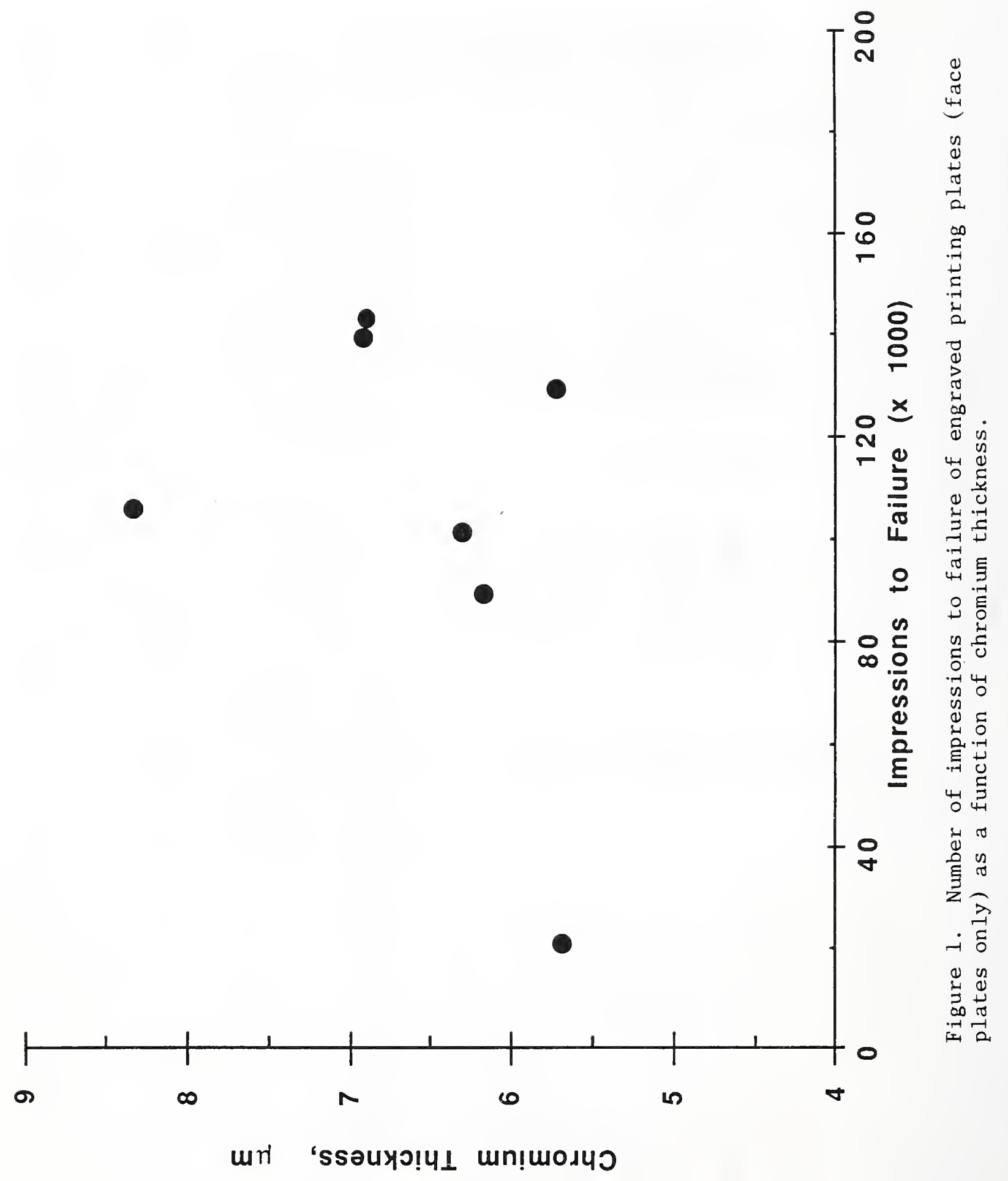




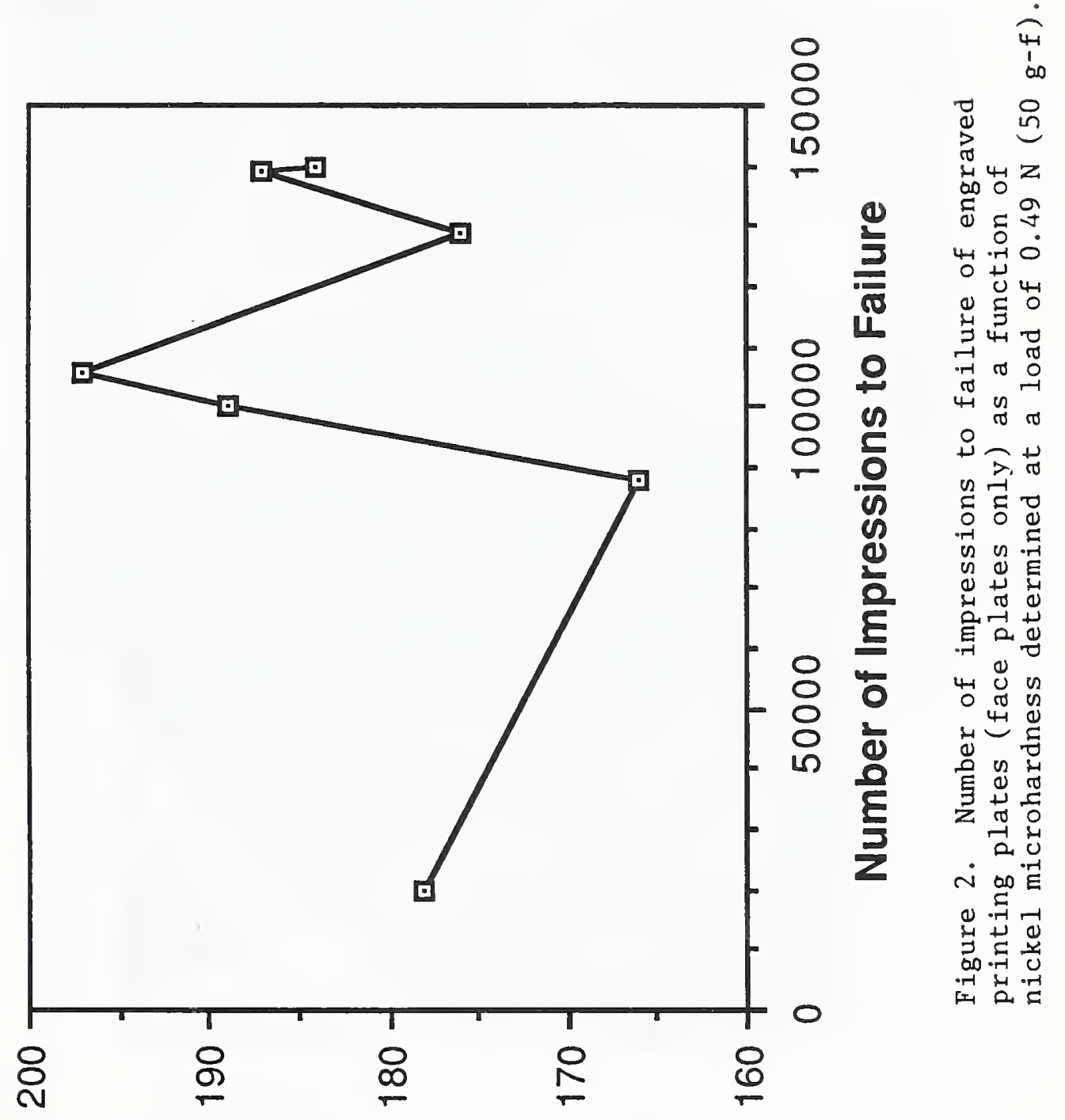

(60s) NH^ 'ssәupден |әуग!N 

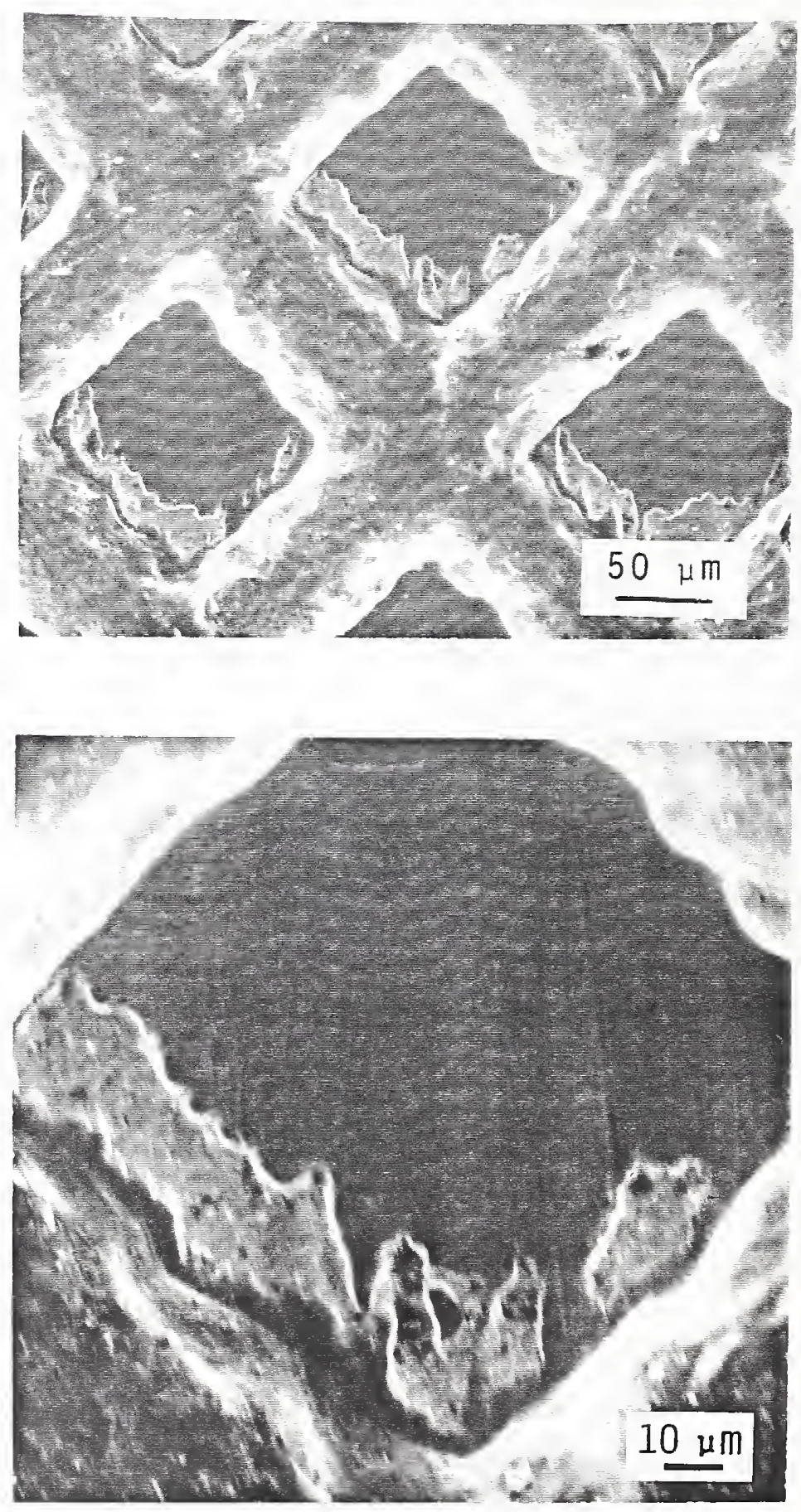

Figure 3. Scanning electron micrographs of chromium wear on an engraved area of a printing plate. Note the uneven wear and patches of chromium left on surface of nickel electroform. 


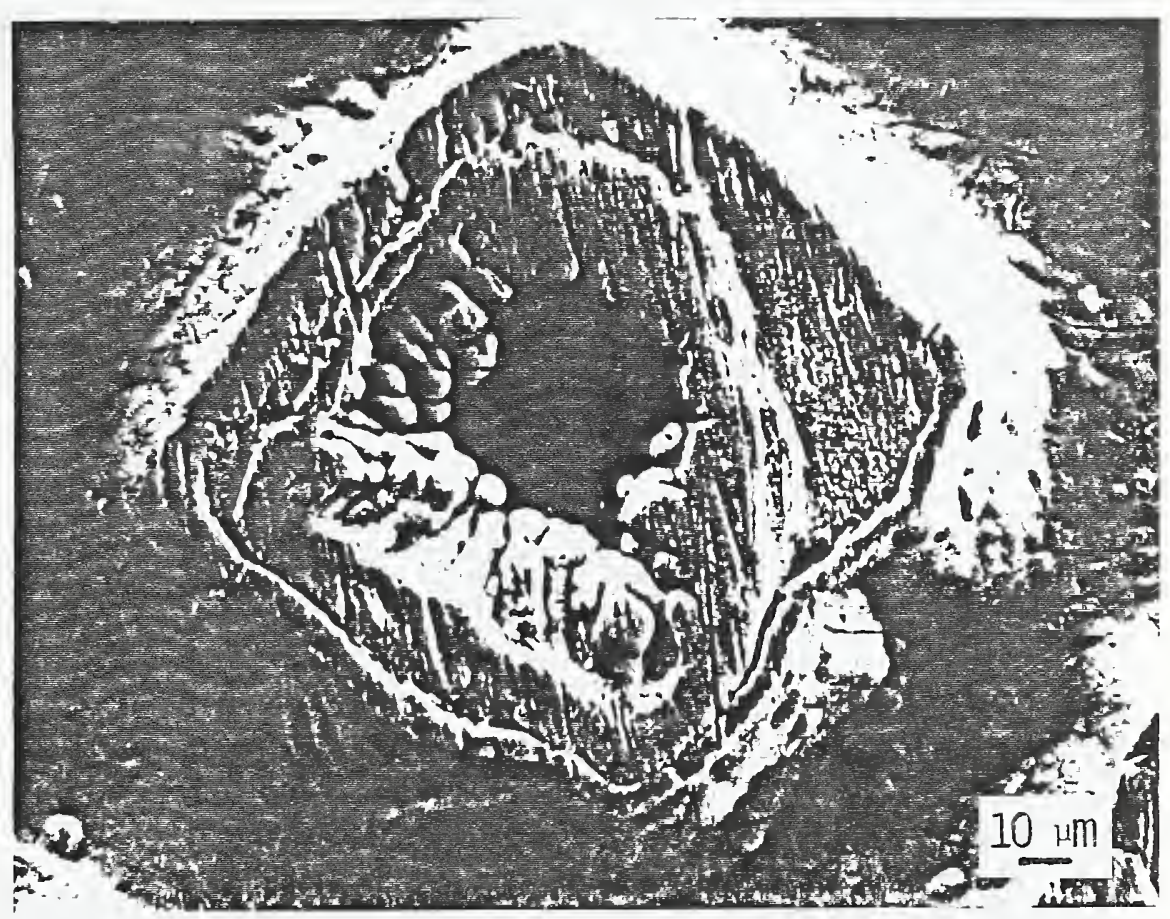

Figure 4. Scanning electron micrograph of modular growth on the engraved land area of a color bar. The modulation may either be in the nickel or chromium. 


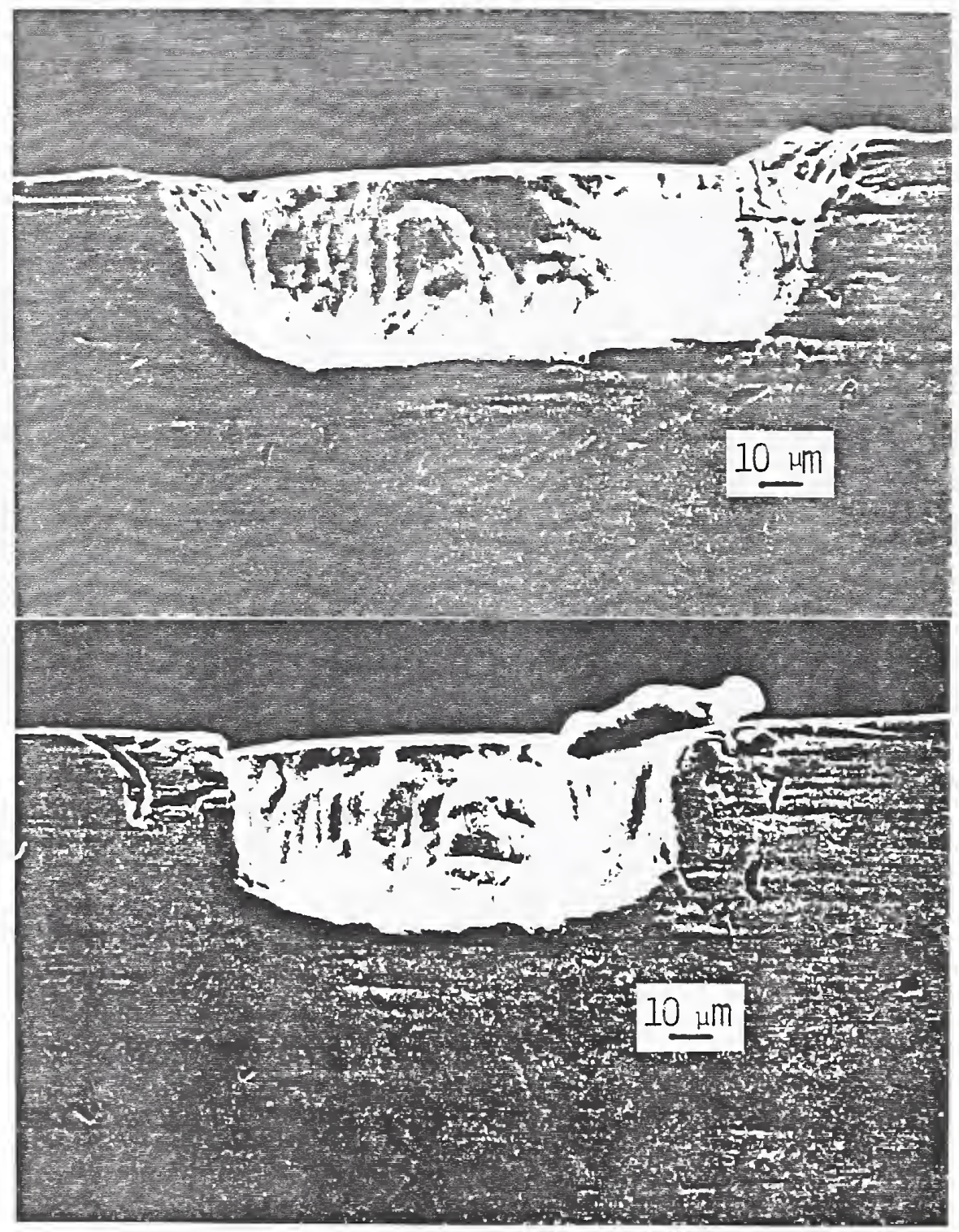

Figure 5. Scanning electron micrograph of a sectioned color bar area of a printing plate revealing the apparent fatigue cracking in the nickel electroform under the chromium plate. 


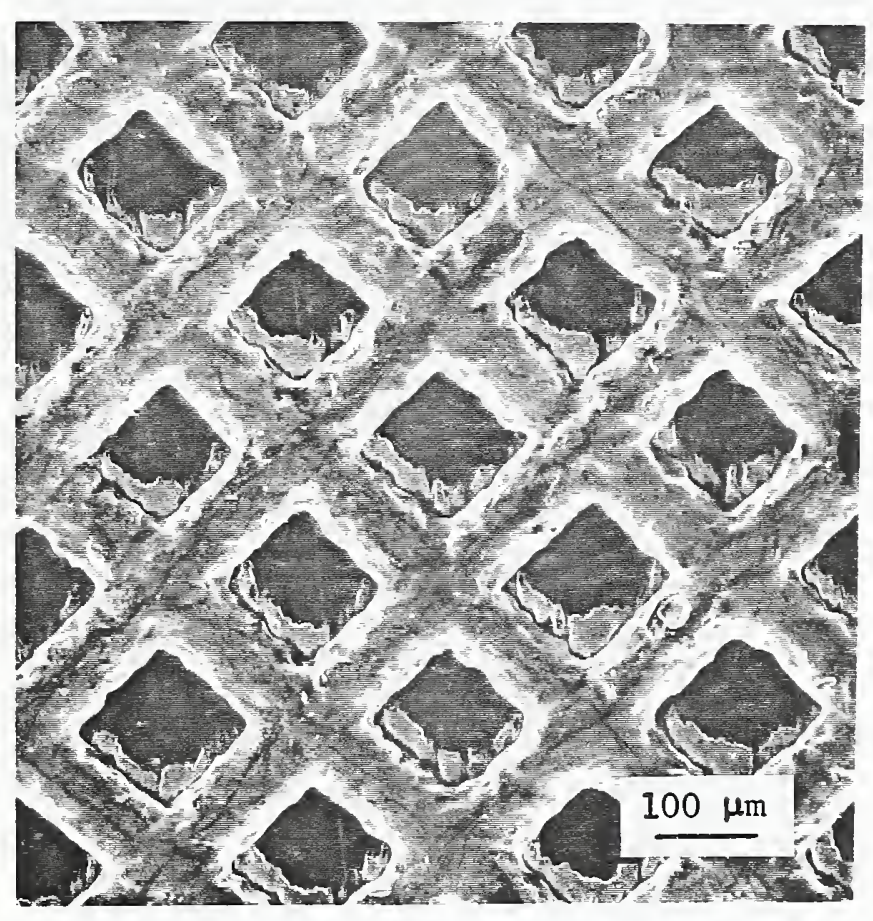

Figure 6. Scanning electron micrograph of color bar area from plate 50265. Number of impressions to failure $=20,000$. 


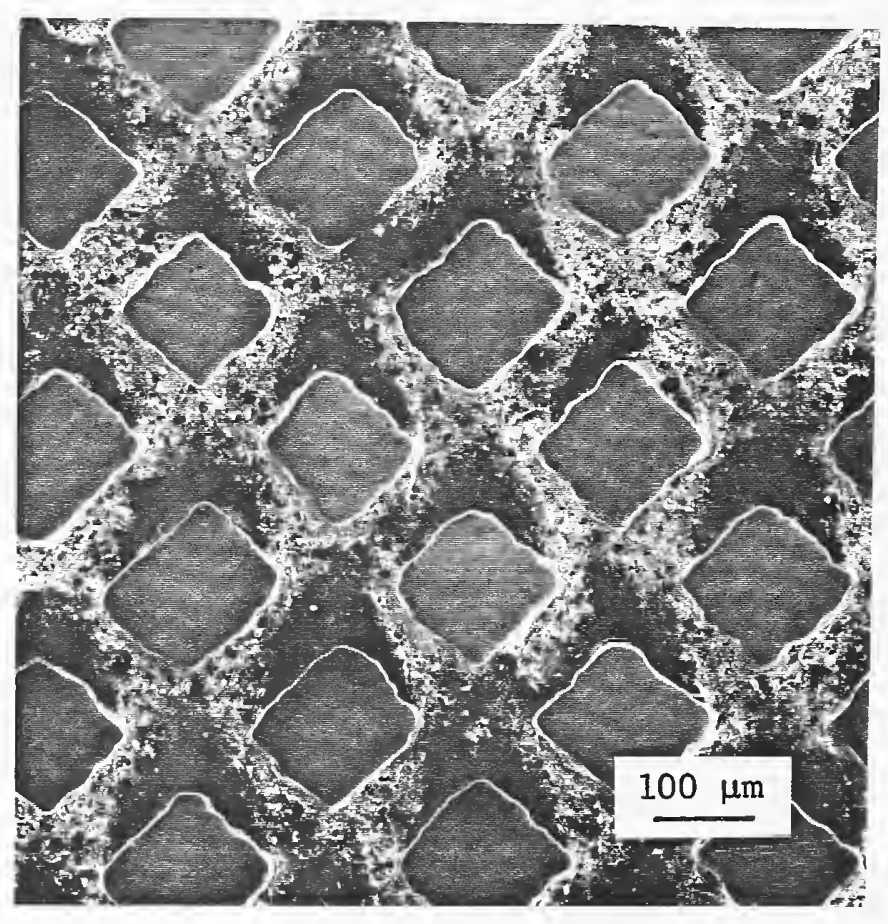

Figure 7. Scanning electron micrograph of color bar area from plate 50264. Number of impressions to failure $=139,000$. 

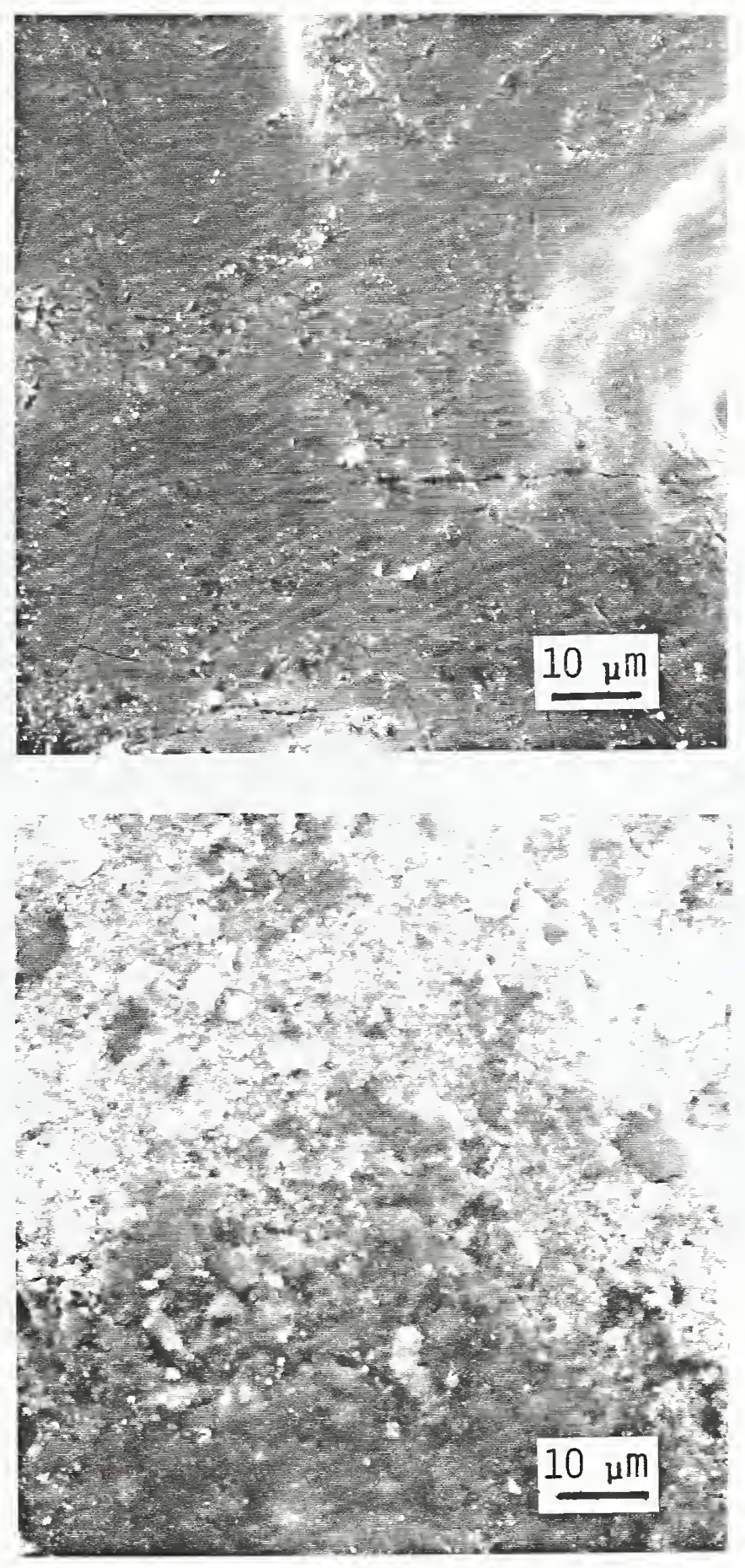

Figure 8. Scanning electron micrographs of grooves or valleys in color bar area from plates 50265 and 50264 revealing the pitting of the chromium and the accumulation of ink residue and/or corrosion products. 


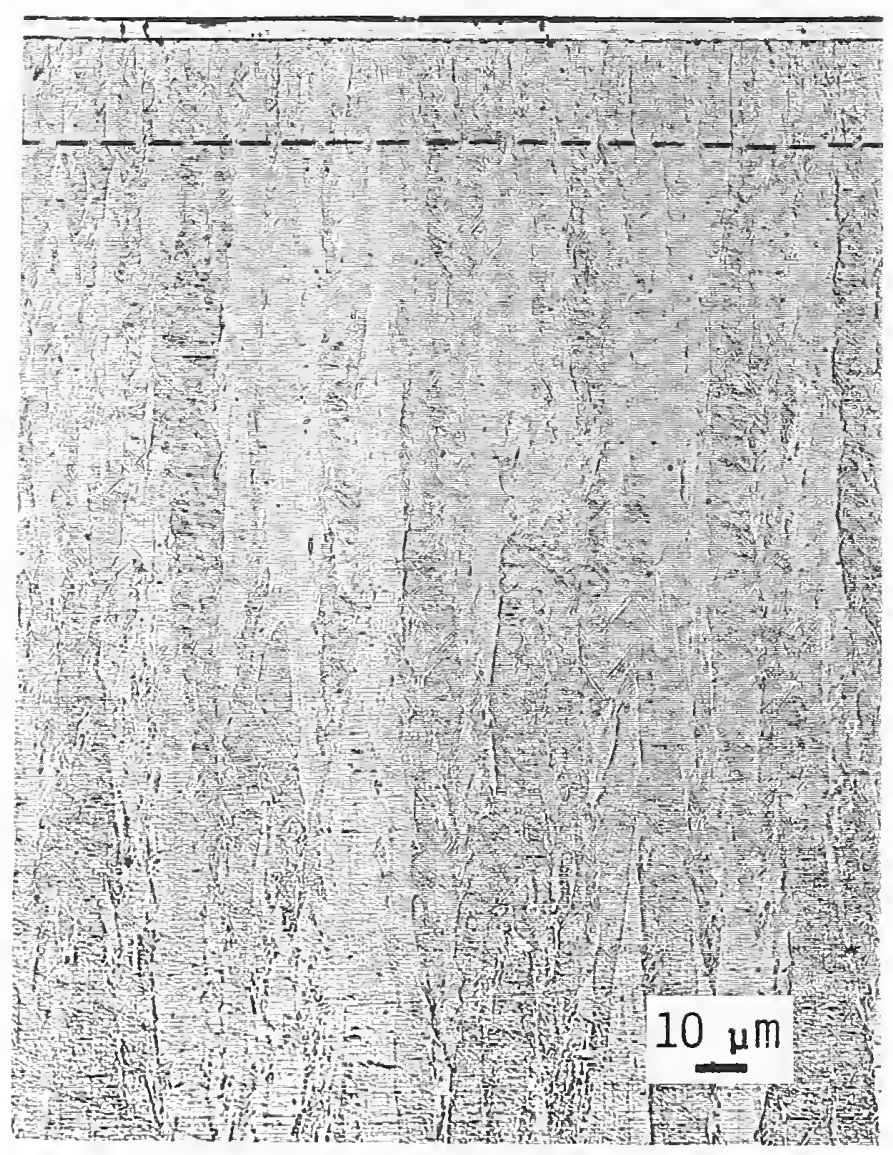

Figure 9. Optical micrograph of polished and etched section of plate 50168 revealing grain structure of the nickel. Note the finer grain size just under the chromium overplate. 


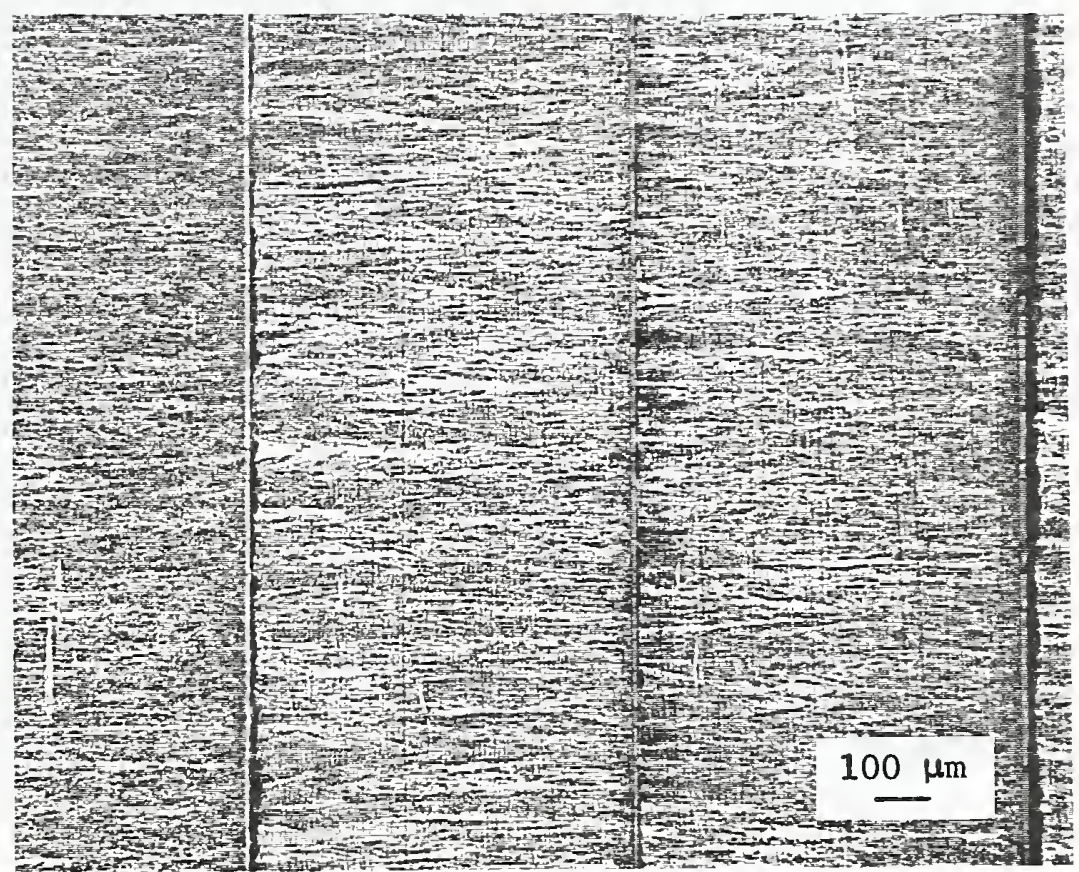

Figure 10. Optical micrograph of polished and etched sections of plates 50301, 50168, and 50264 revealing very little differences in grain size of the nickel from plate to plate. 


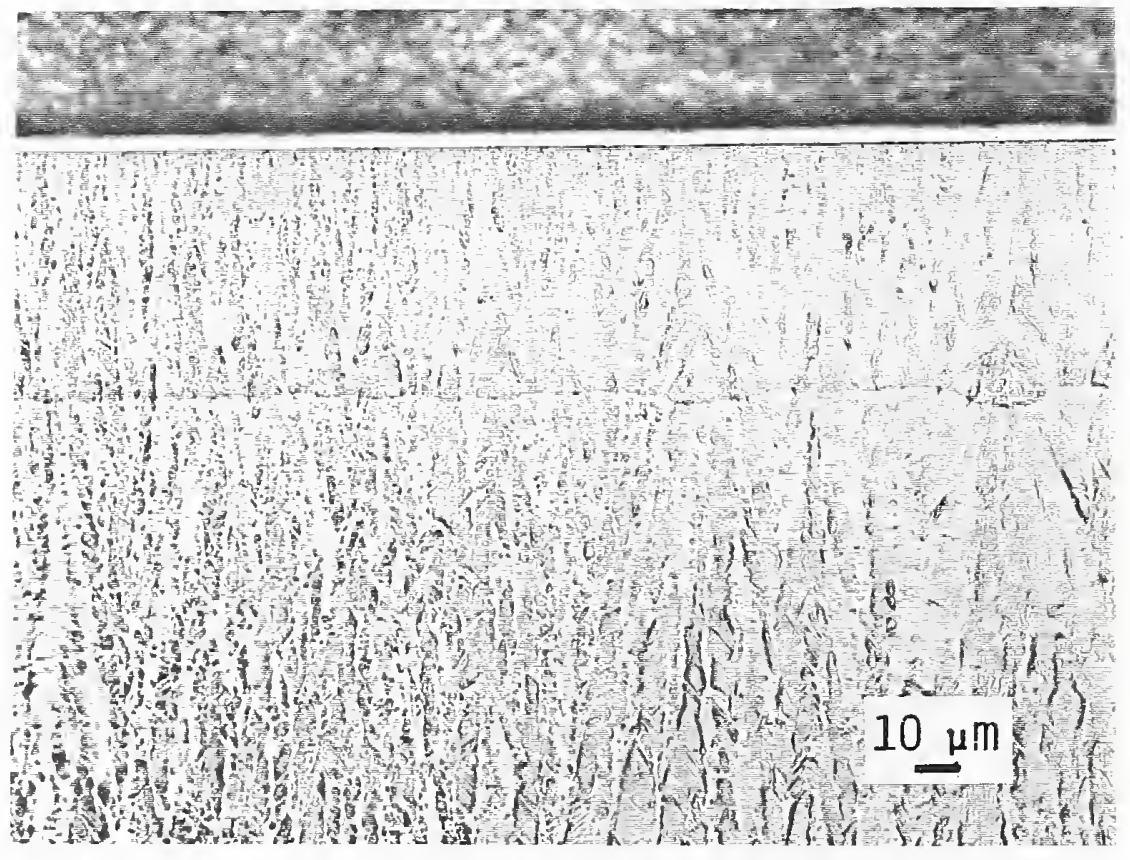

Figure 11. Optical micrograph of polished and etched section of a plate end revealing a boundary line in the nickel electroform indicative of a current interruption. 


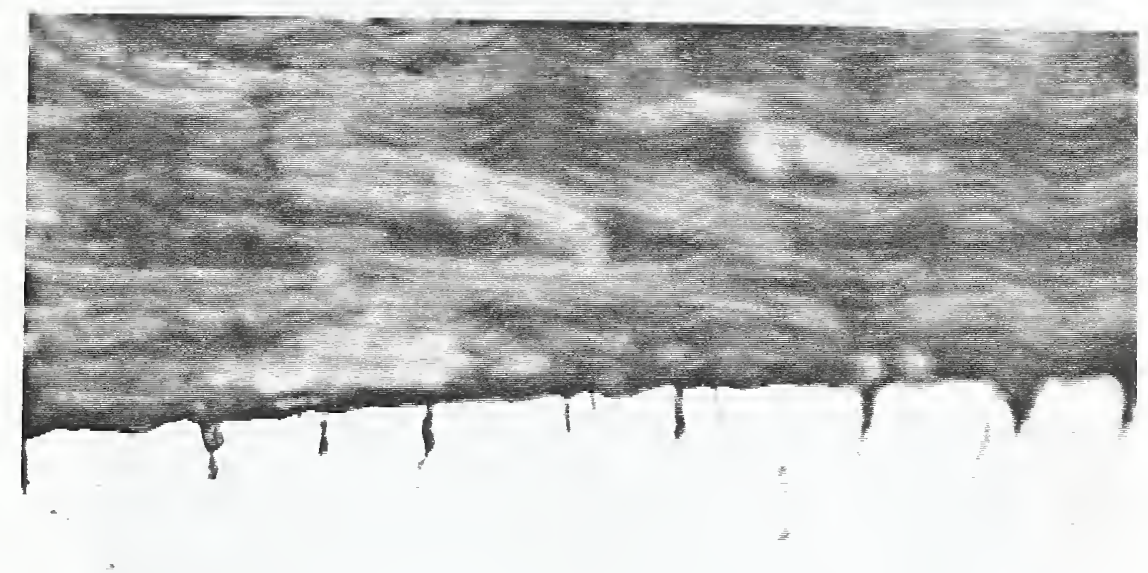

$10 \mu \mathrm{m}$

Figure 12. Optical micrograph of a polished section of a plate end revealing the cracking of the nickel at the site of a microcrack in the chromium. 


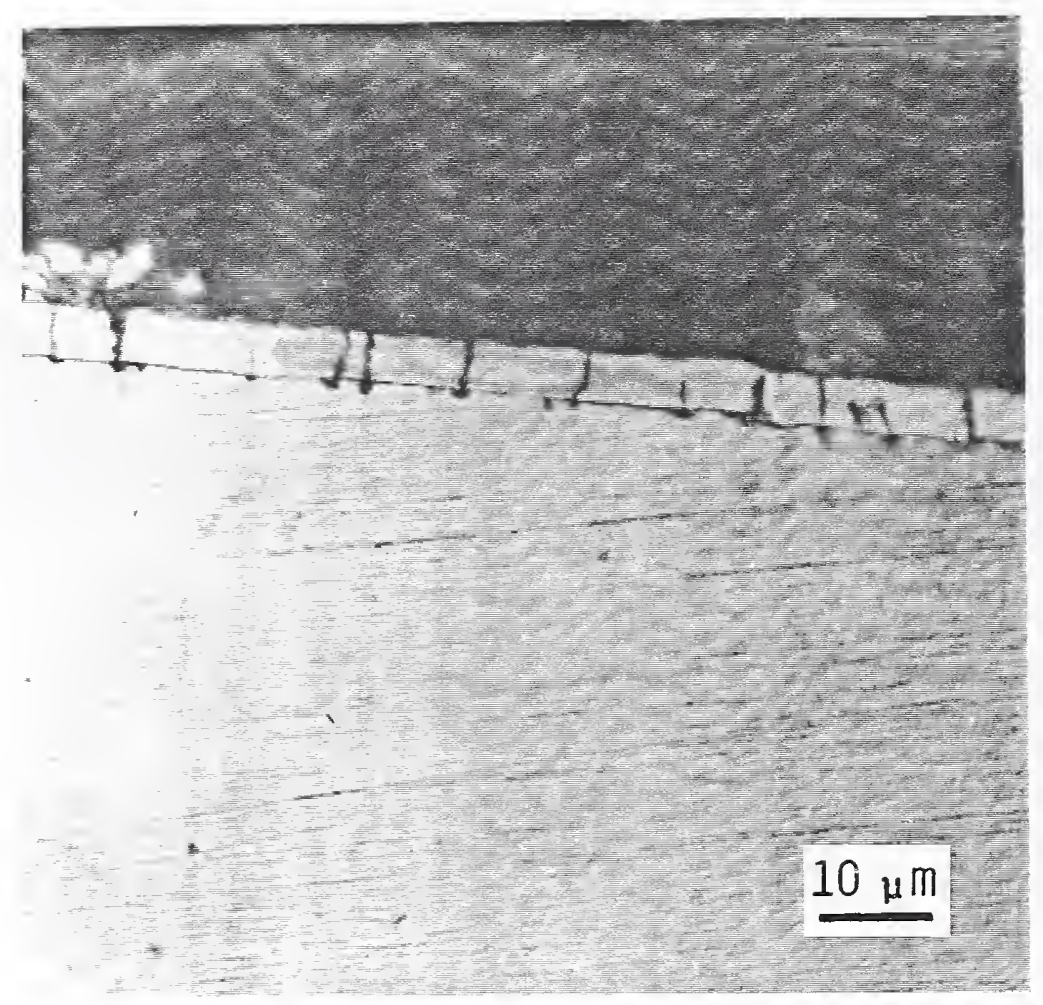

Figure 13. Optical micrograph of a polished and very lightly etched section of the plate end from plate $\$ 50264$ revealing the corrosion of the nickel occurring through the microcracks in the chromium. 

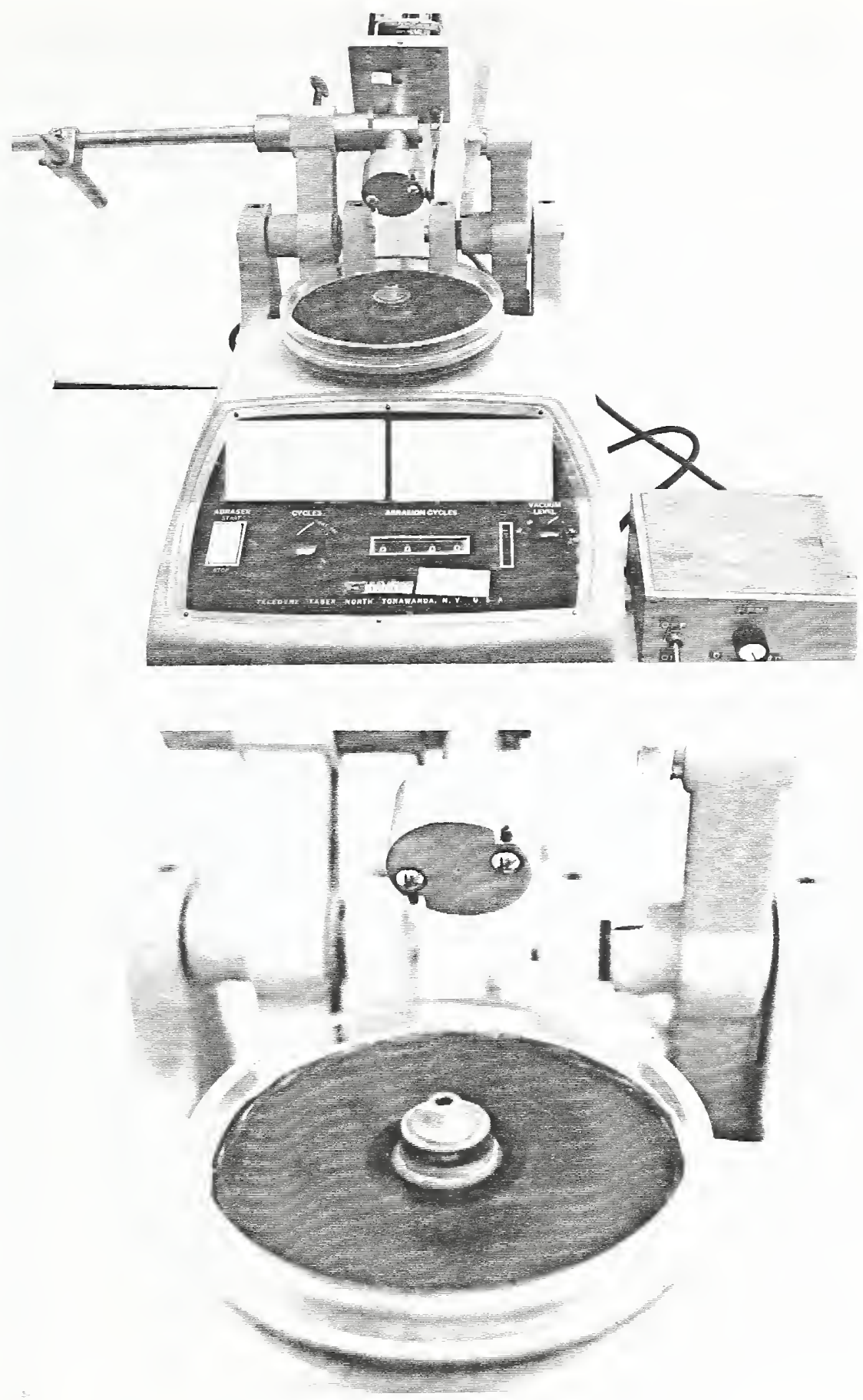

Figure 14. Photos of abrasive slurry wear tester used for the accelerated wear testing of chromium and other metal coatings. 


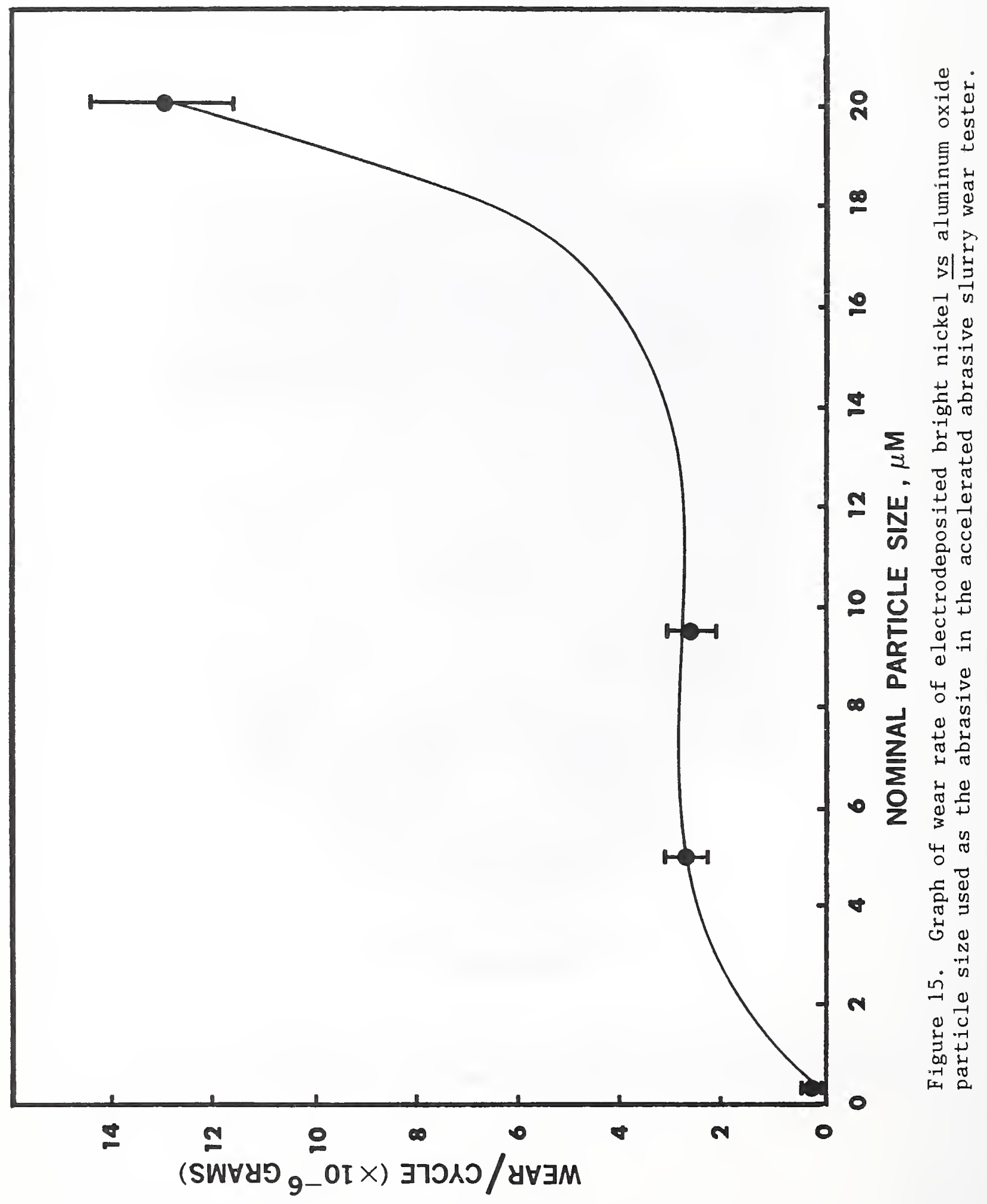



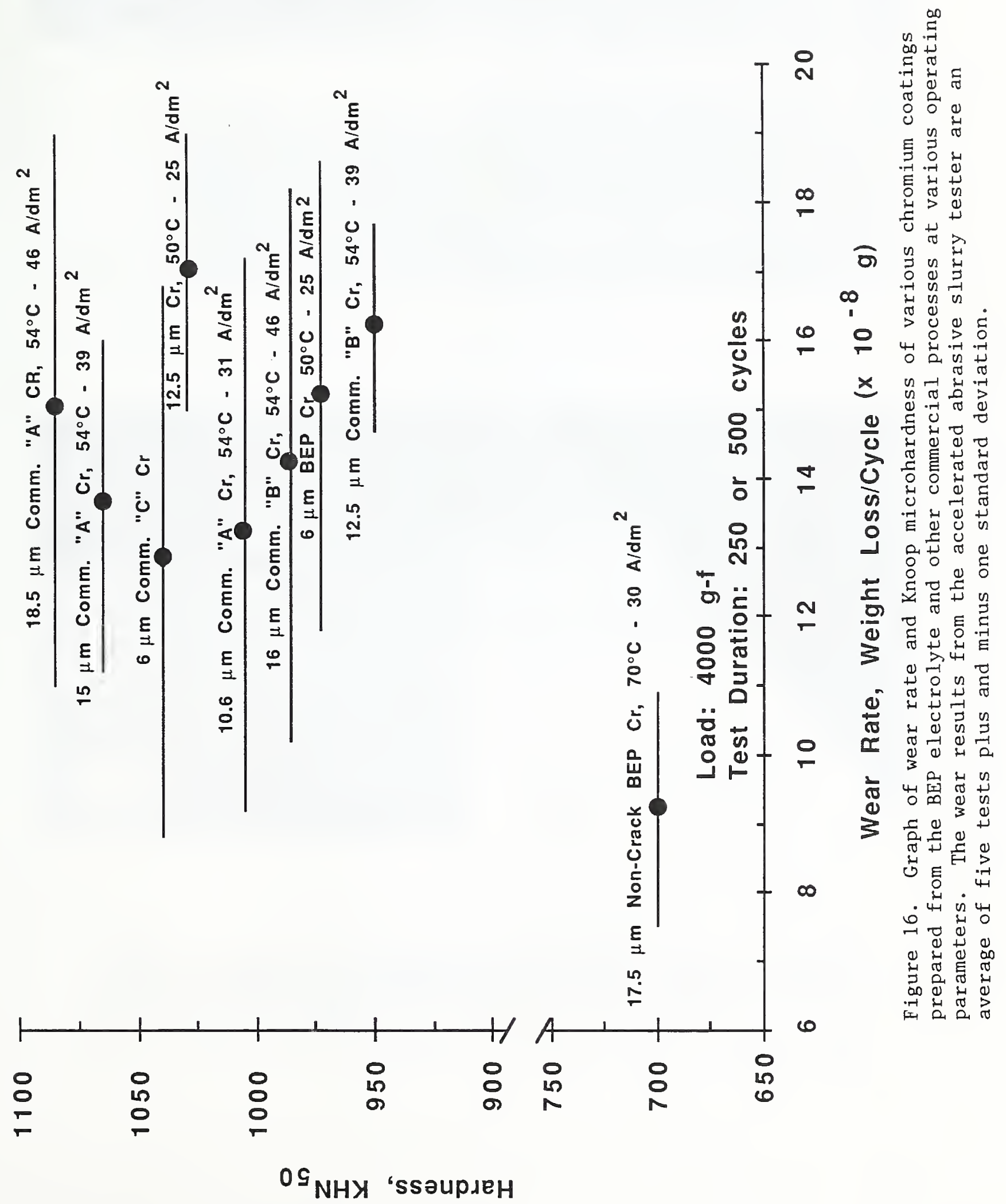

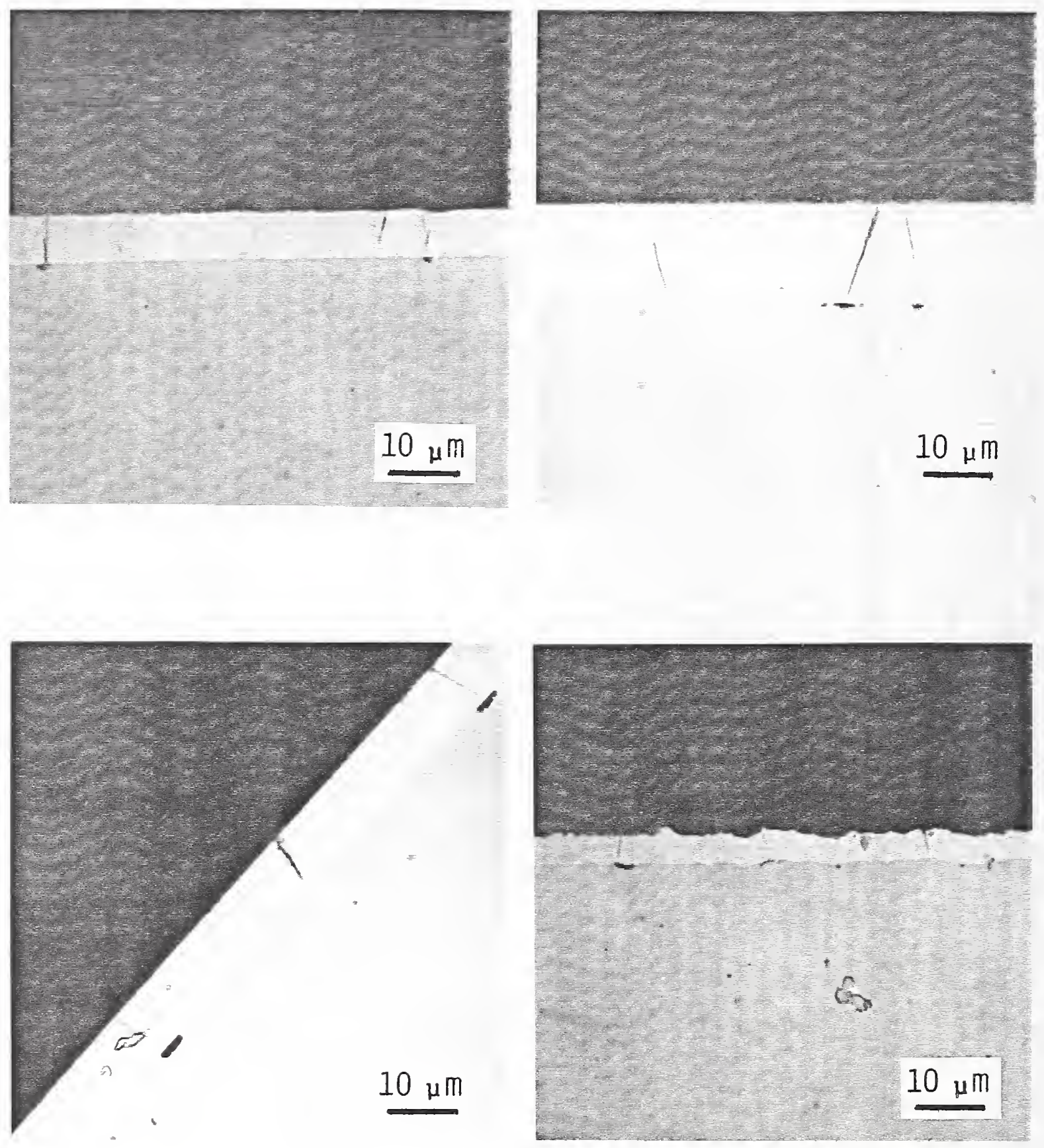

Figure 17. Optical micrographs of polished sections of various chromium coatings on 52100 steel revealing the corrosion of the steel occurring through the microcracks in the chromium coatings after wear testing on the abrasive slurry tester (a) BEP chromium, (b) commercial "A" chromium, (c) commercial "B" chromium, (d) commercial "C" chromium. 

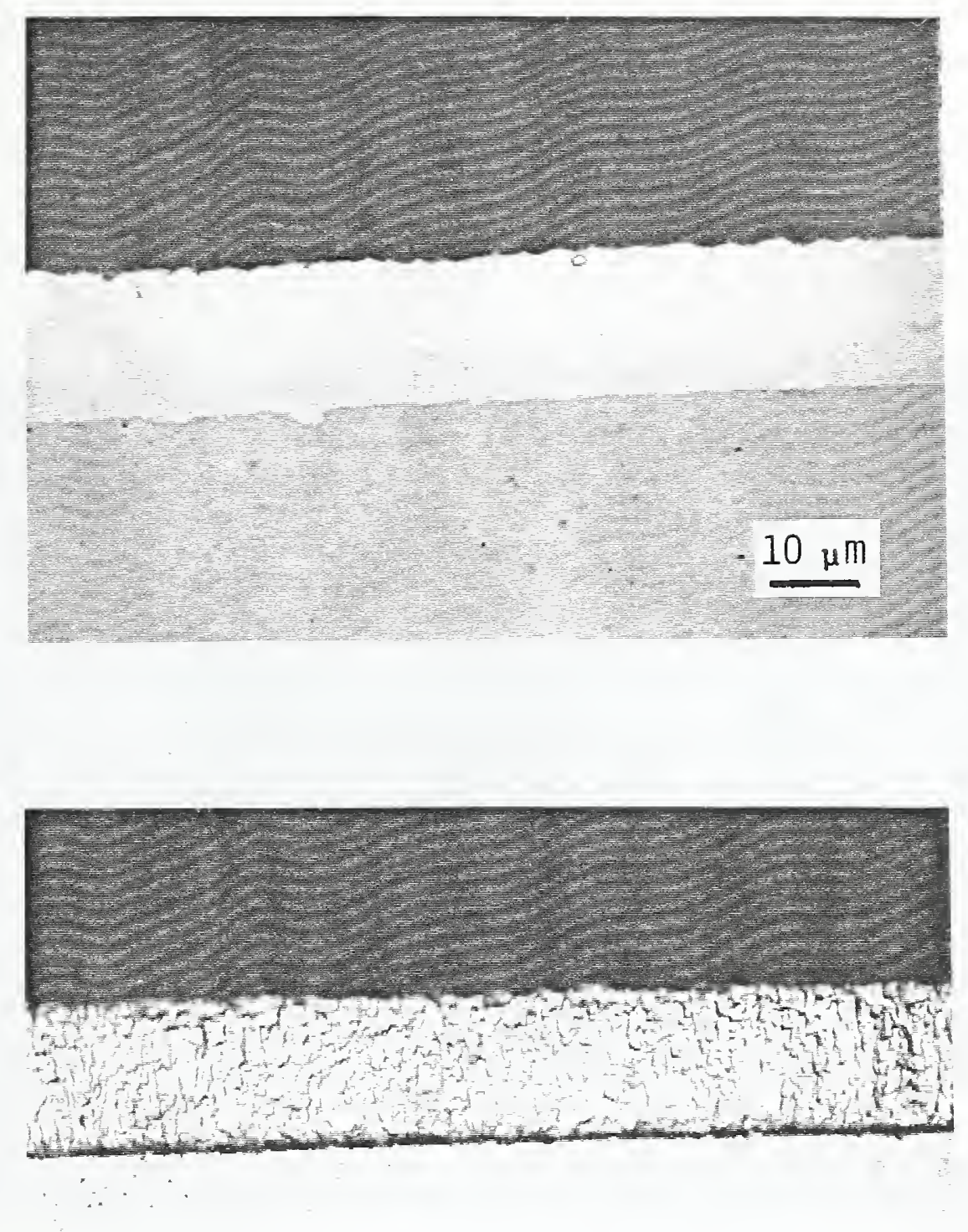

$10 \mu \mathrm{m}$

Figure 18. Optical micrographs of a polished and etched section of the non-cracked milky chromium coating on 52100 steel. (a) polished; (b) polished and etched. 


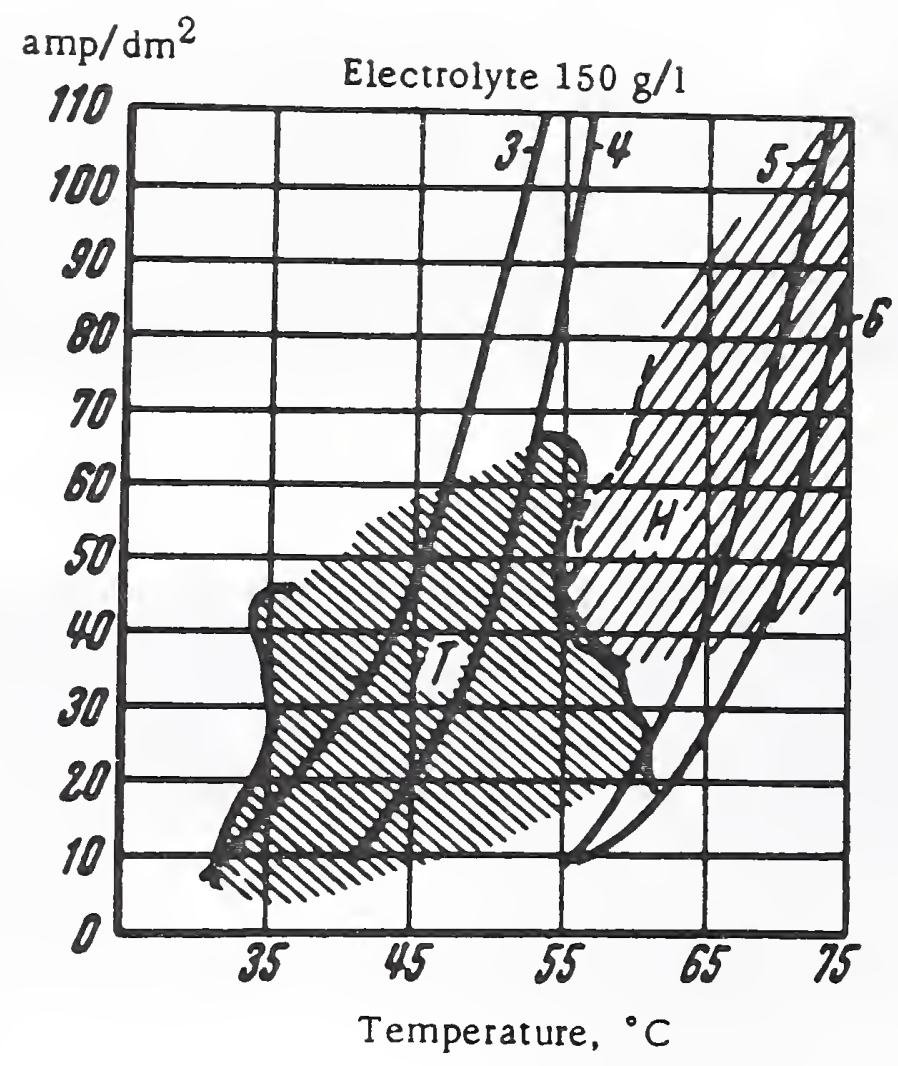

Figure 19. Graph of operating parameters for plating various chromium deposits from a dilute electrolyte. Curves 3 and 4 enclose the zone of transition from gray to bright deposits; curves 5 and 6 enclose the zone of transition from bright to milky deposits. 


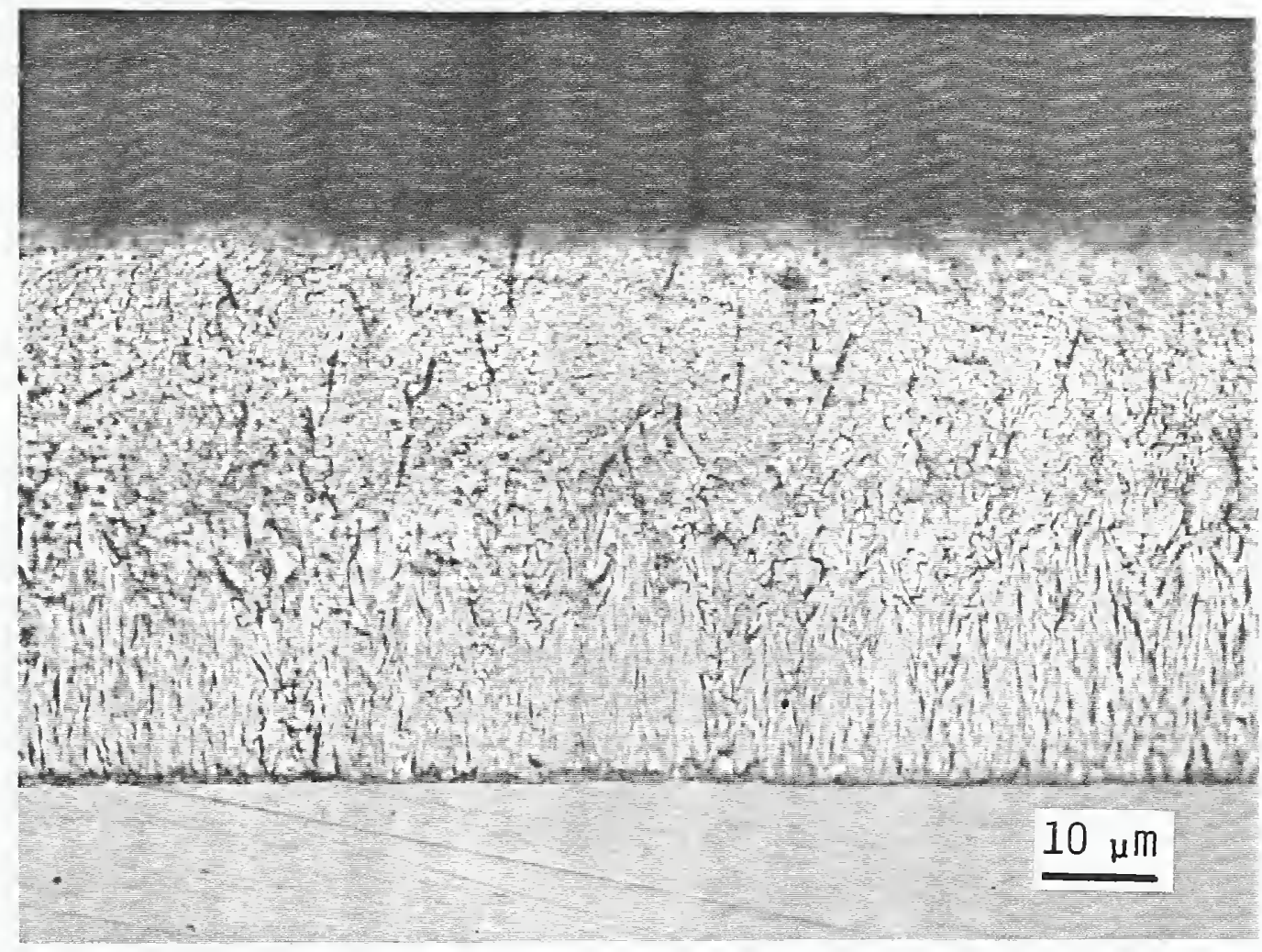

Figure 20. Optical micrograph of an etched section of a DC deposited duplex chromium coating on the nickel. The initial non-cracked layer of this continuous coating was deposited at $70^{\circ} \mathrm{C}, 30 \mathrm{~A} / \mathrm{dm}^{2}$. The deposit was etched in a $1: 1$ hydrochloriclactic acid solution for 10 seconds. 


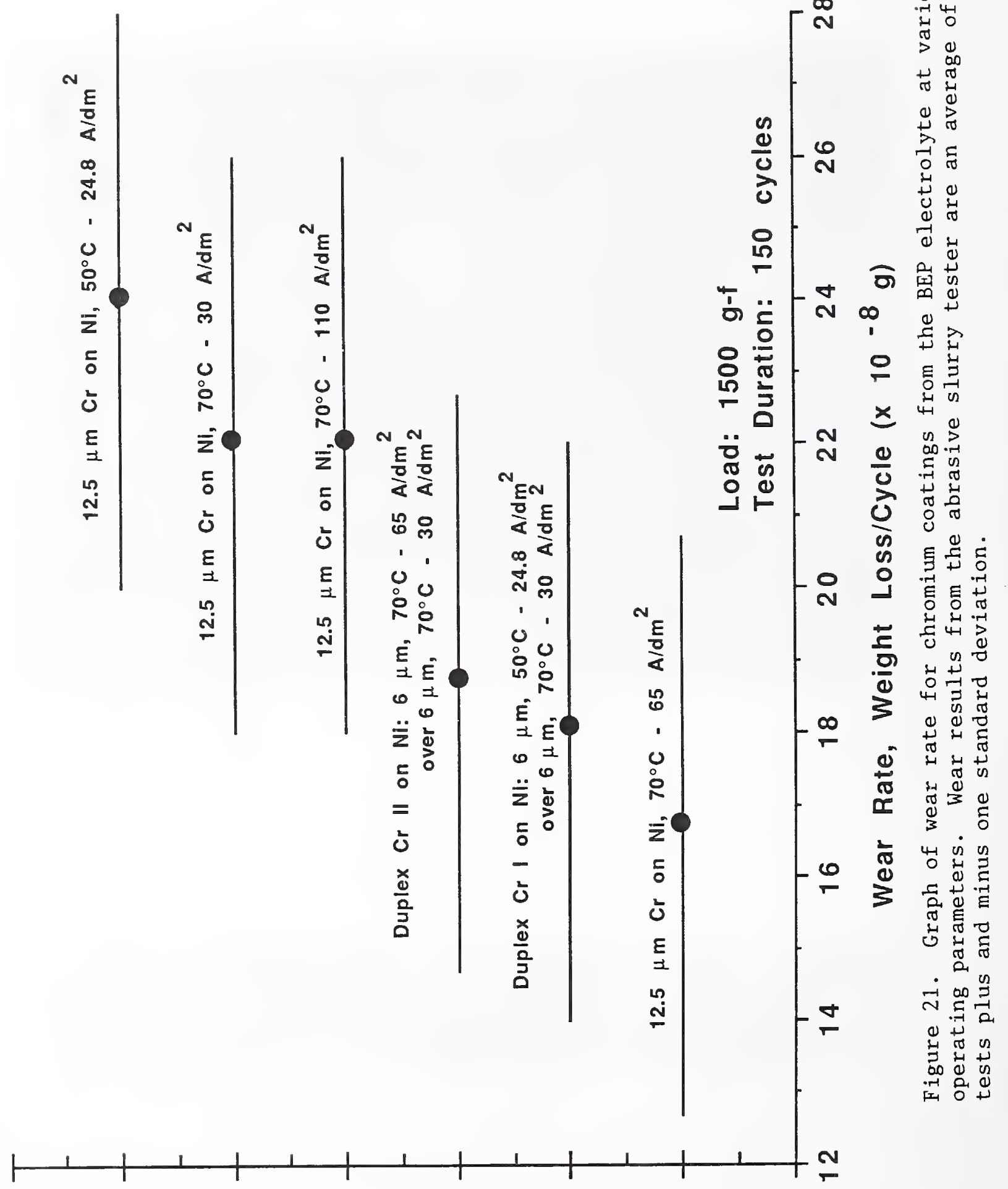




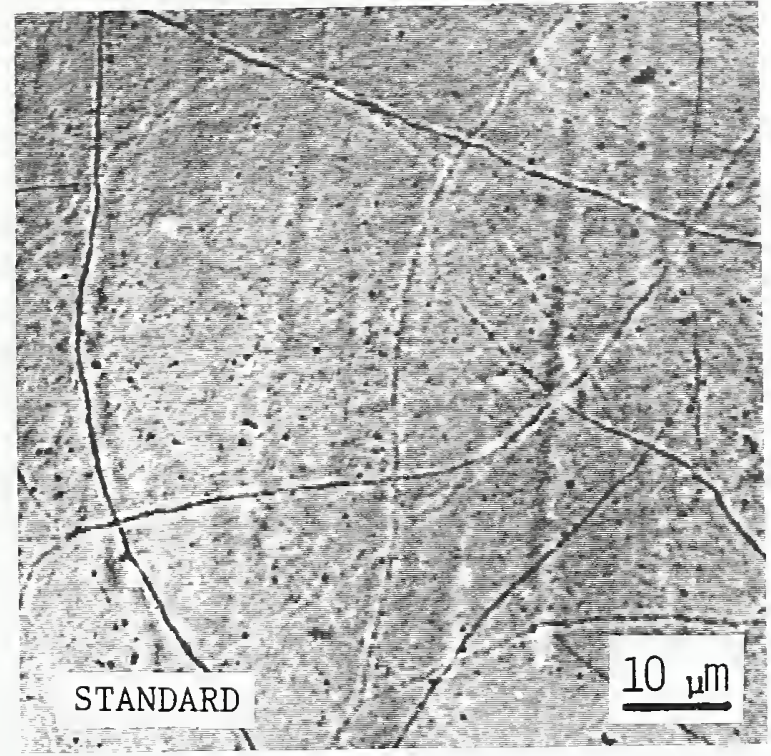

(a)

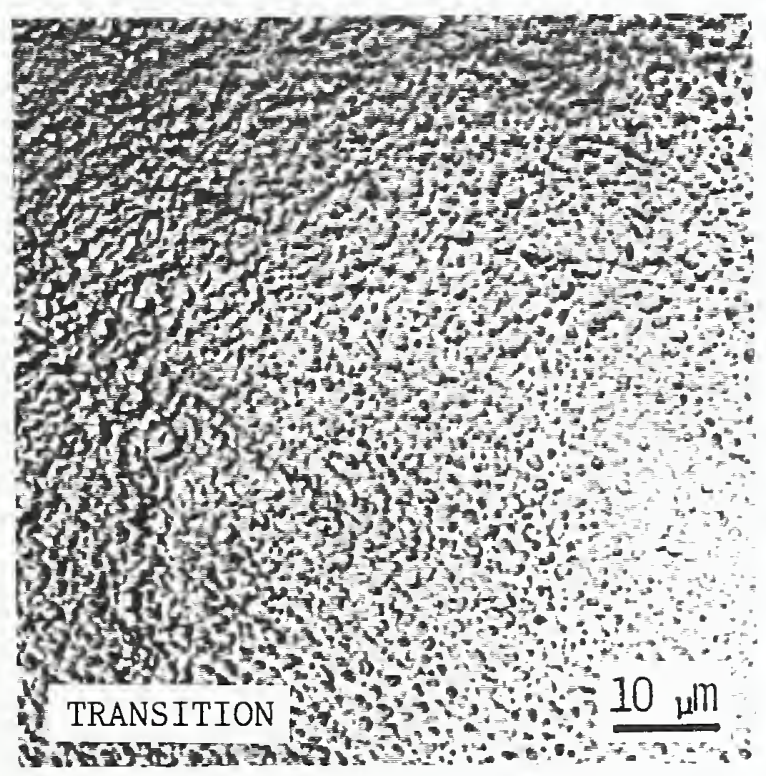

(c)

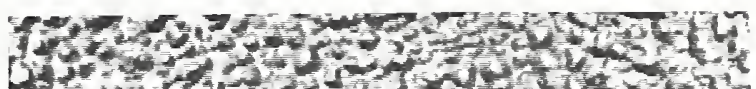

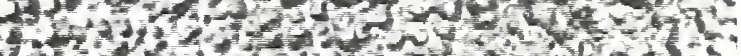

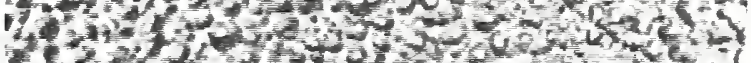

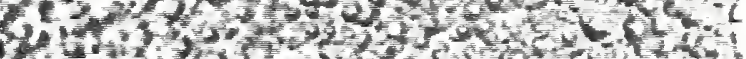

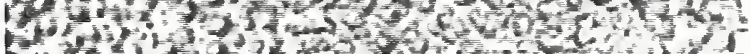

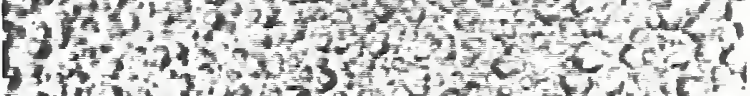

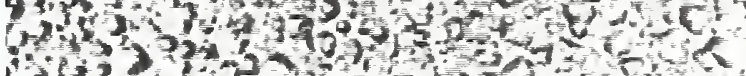

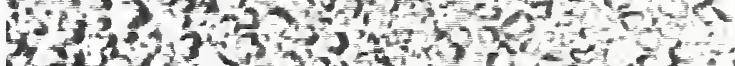

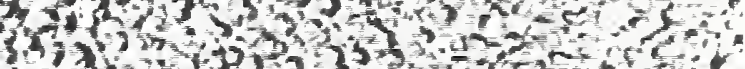

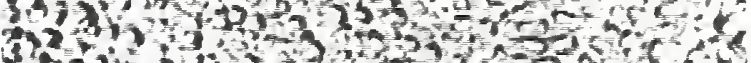

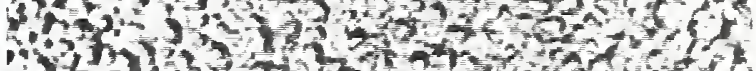

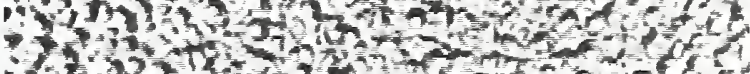

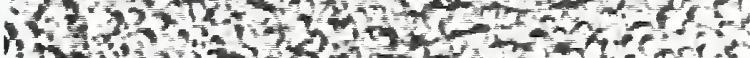

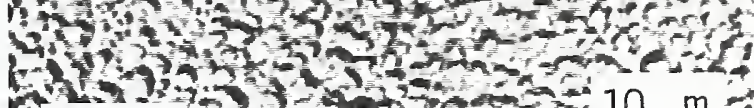

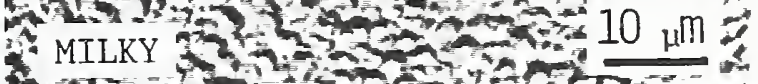

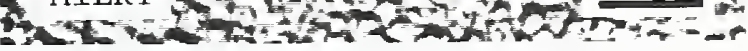

(b)

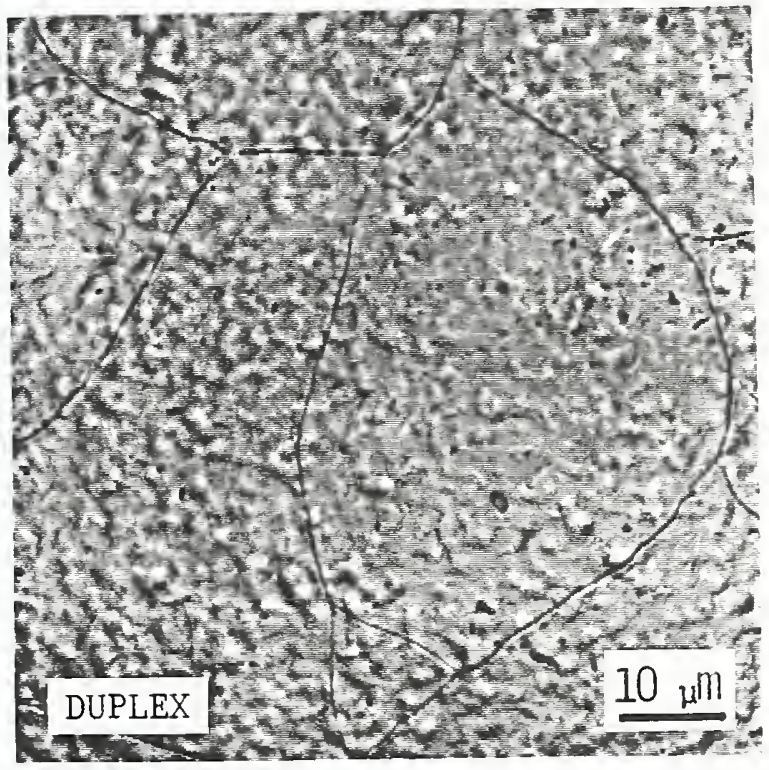

(d)

Figure 22. Optical micrographs of surface texture and microcracking of various chromium coatings. (a) Standard BEP chromium - $50^{\circ} \mathrm{C}, 25 \mathrm{~A} / \mathrm{dm}^{2}$; (b) "Milky" chromium $-70^{\circ} \mathrm{C}, 30 \mathrm{~A} / \mathrm{dm}^{2}$; (c) "Transition" chromium $-70^{\circ} \mathrm{C}, 65 \mathrm{~A} / \mathrm{dm}^{2}$; (d) Duplex chromium $70^{\circ} \mathrm{C}, 30 \mathrm{~A} / \mathrm{dm}^{2}$ and $50^{\circ} \mathrm{C}, 25 \mathrm{~A} / \mathrm{dm}^{2}$. 


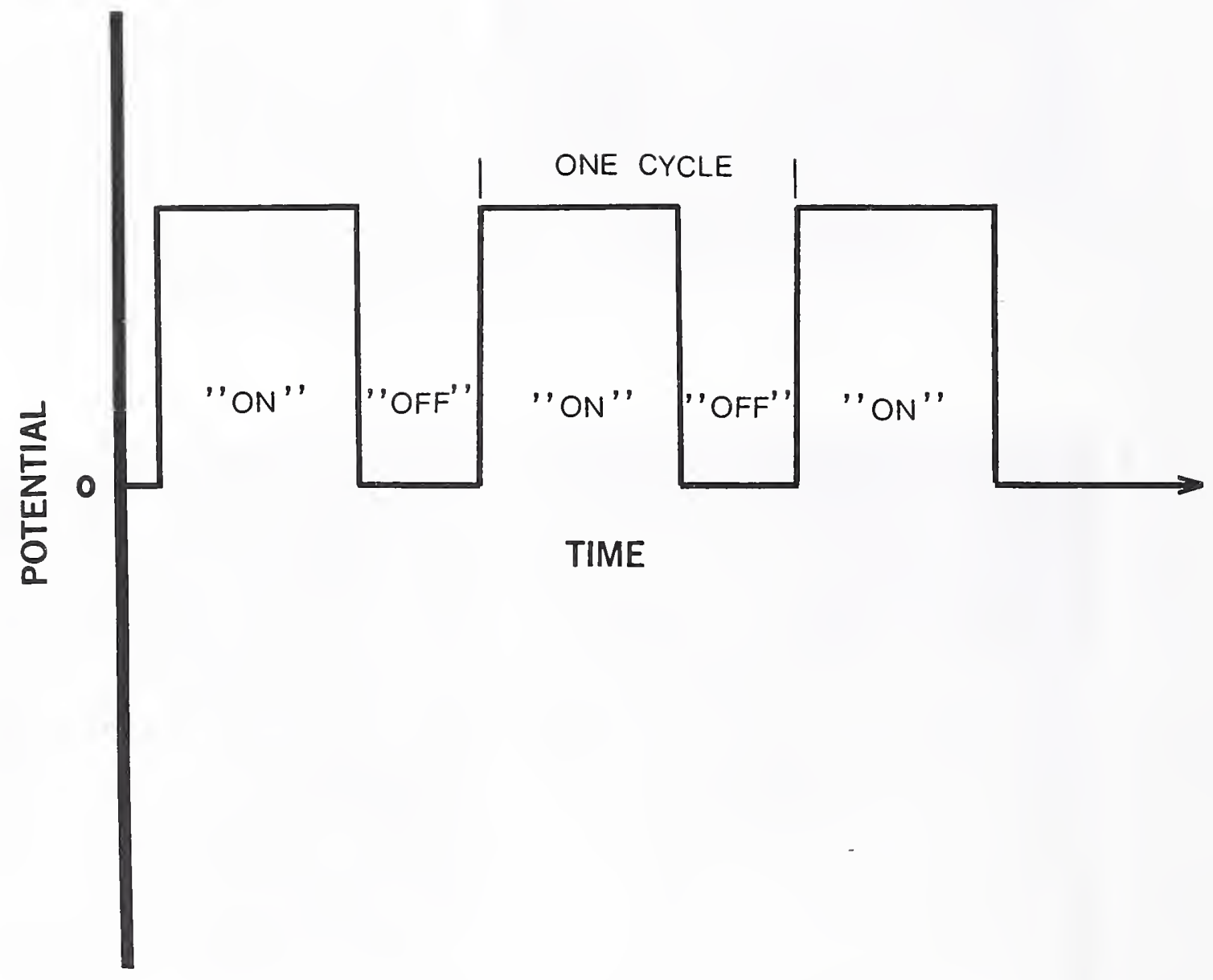

Figure 23. Potential - Time waveform for pulse plating of chromium. 


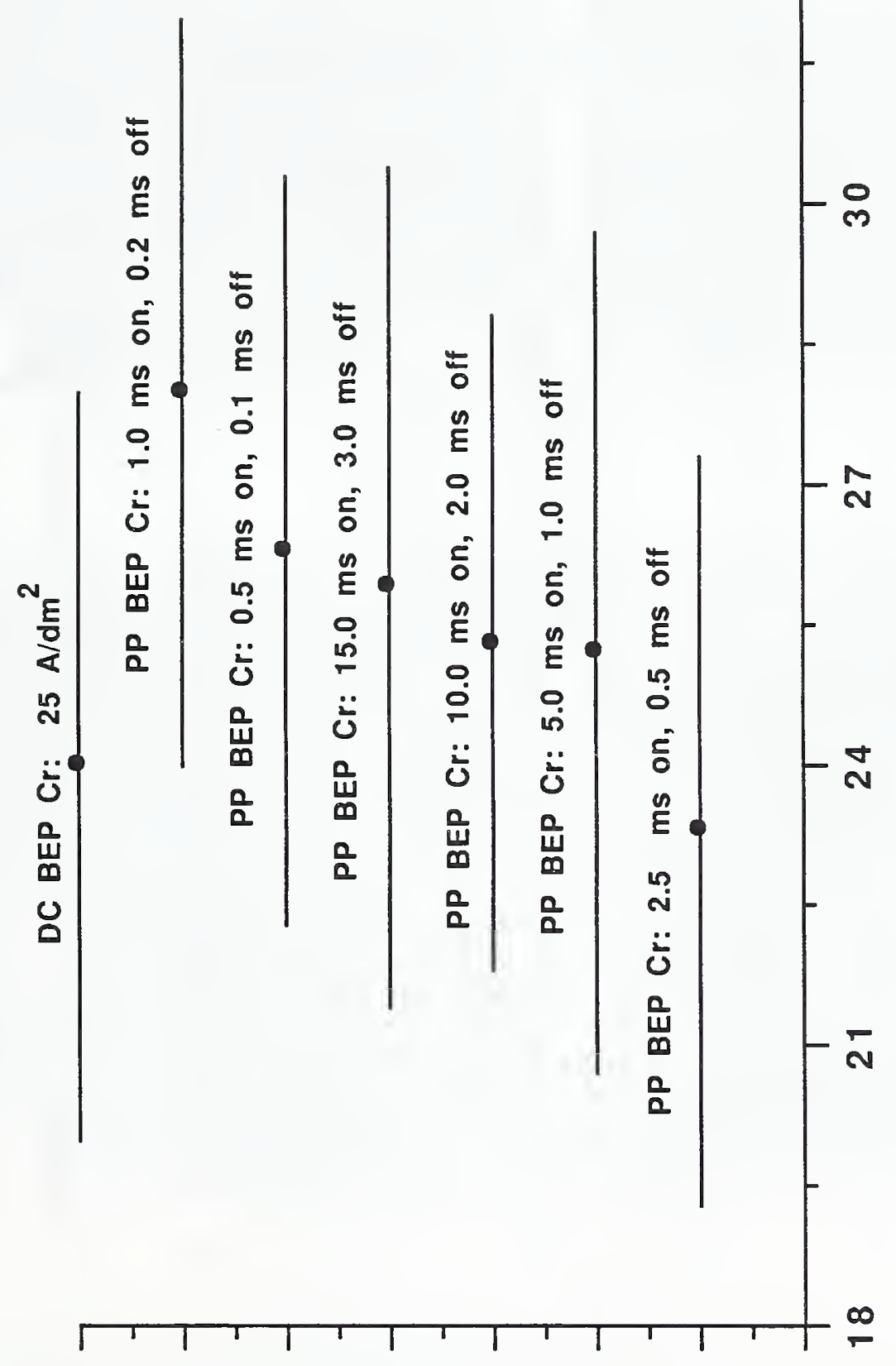

${ }_{0}^{4-1} \frac{4-1}{0} \frac{0}{0}$

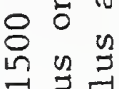
- $0_{0}^{3} \sqrt{2}$ पू मून

$0 \stackrel{\pi}{0}$

$0+\infty$

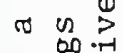

ठ

$\infty \quad \stackrel{0}{*} 0$

- $\stackrel{0}{\varpi} \overbrace{0}^{\infty}$

$\times$ त्च है

×

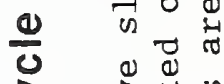

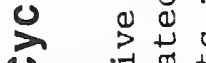

0 . 0 更

(1) क्जि

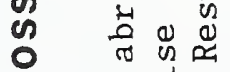

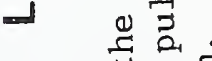

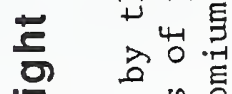

- 1) च 0

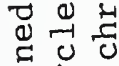

क

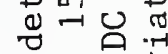

व

\)

3 (1)

누

उ

त 0

㐫岕导

¿

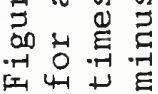




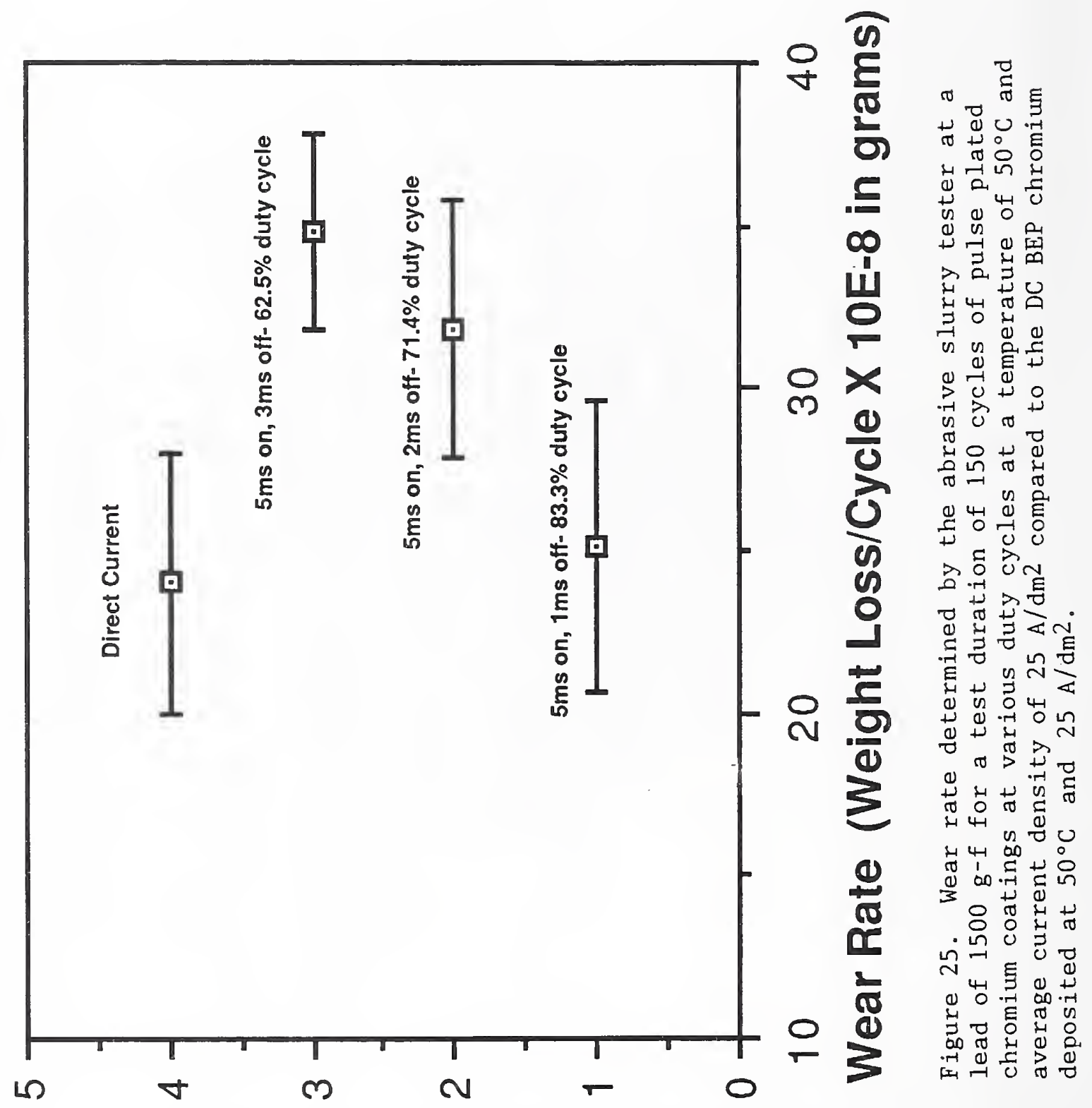



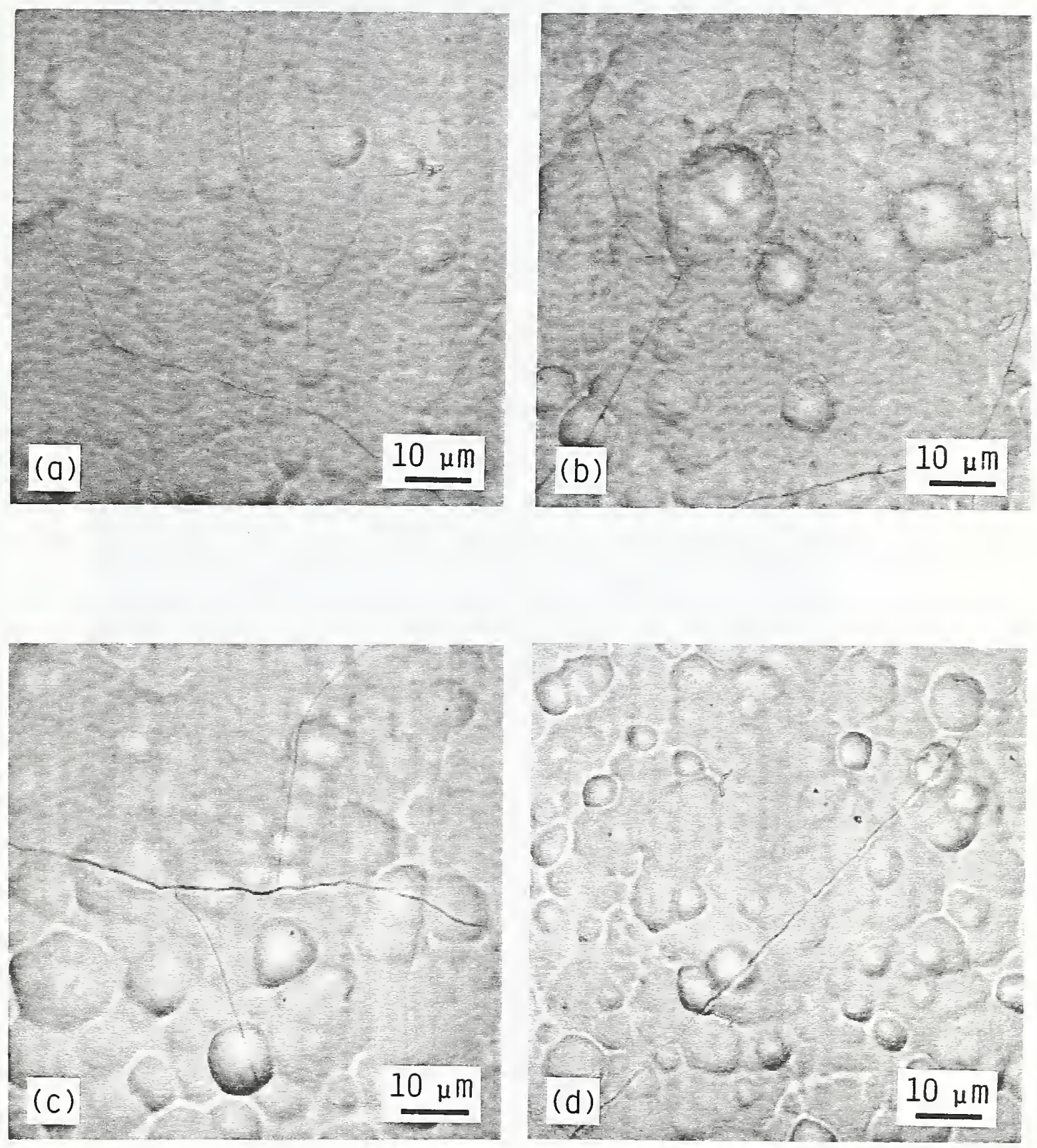

Figure 26. Optical micrographs of the surface texture and crack density of pulse plated chromium coatings for various on/off times at a duty cycle of $83.3 \%$ in the BEP chromium electrolyte at $50^{\circ} \mathrm{C}$ and average current density at $25 \mathrm{~A} / \mathrm{dm}^{2}$. (a) $0.5 \mathrm{~ms}$ on $/ 0.1 \mathrm{~ms}$ off; (b) $1.0 \mathrm{~ms}$ on $/ 0.2 \mathrm{~ms}$ off; (c) $2.5 \mathrm{~ms}$ on $/ 0.5 \mathrm{~ms}$ off; (d) $5.0 \mathrm{~ms}$ on $/ 1.0 \mathrm{~ms}$ off. 

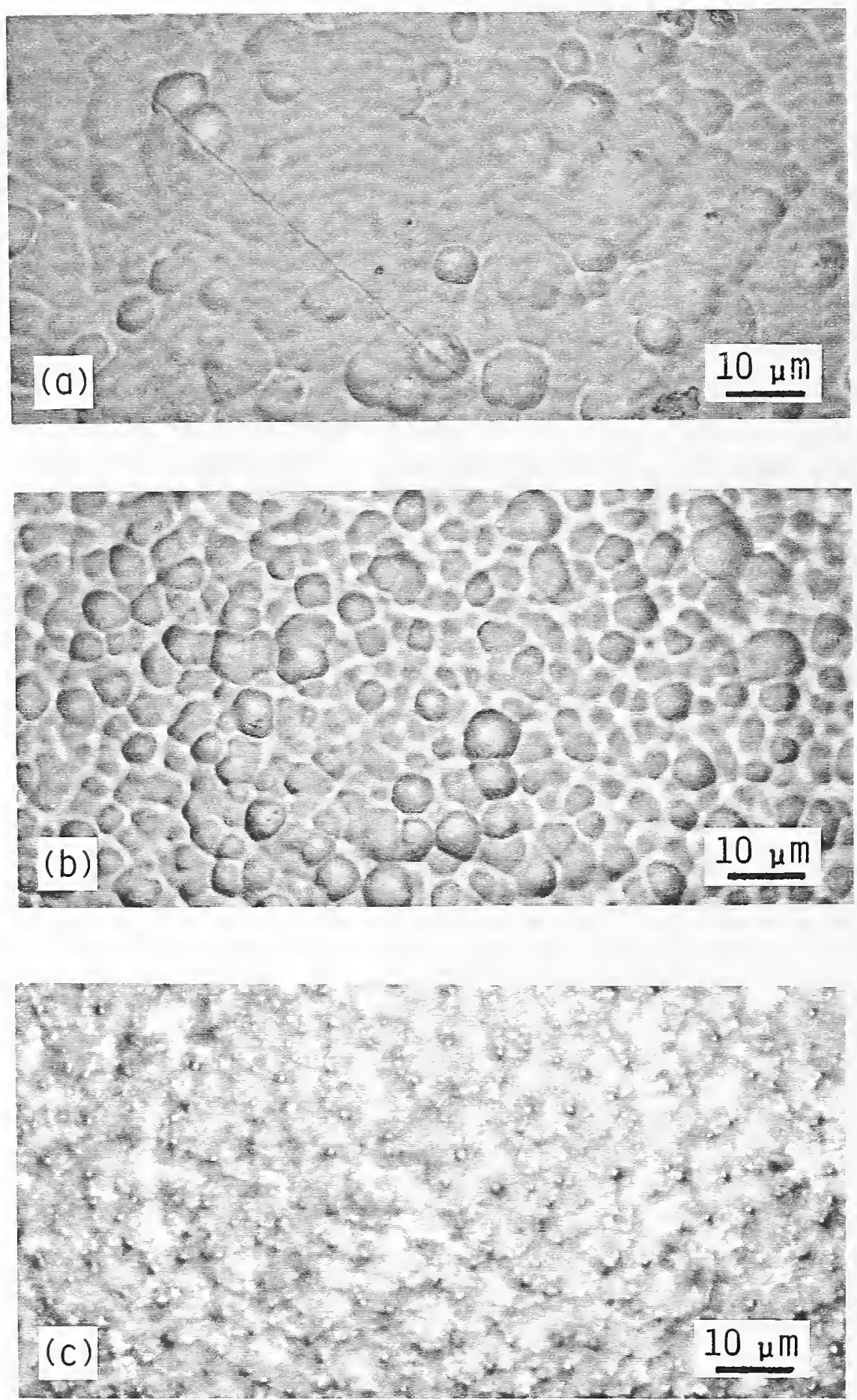

Figure 27. Optical micrographs of the surface texture and crack density of pulse platedchromium coatings for various duty cycles of the same on time of $5 \mathrm{~ms}$ in the $\mathrm{BEP}$ chromium electrolyte at $50^{\circ} \mathrm{C}$ and average current density of $25 \mathrm{~A} / \mathrm{dm}^{2}$. (a) $83.3 \%$; (b) $71.4 \%$; (c) $62.5 \%$. 

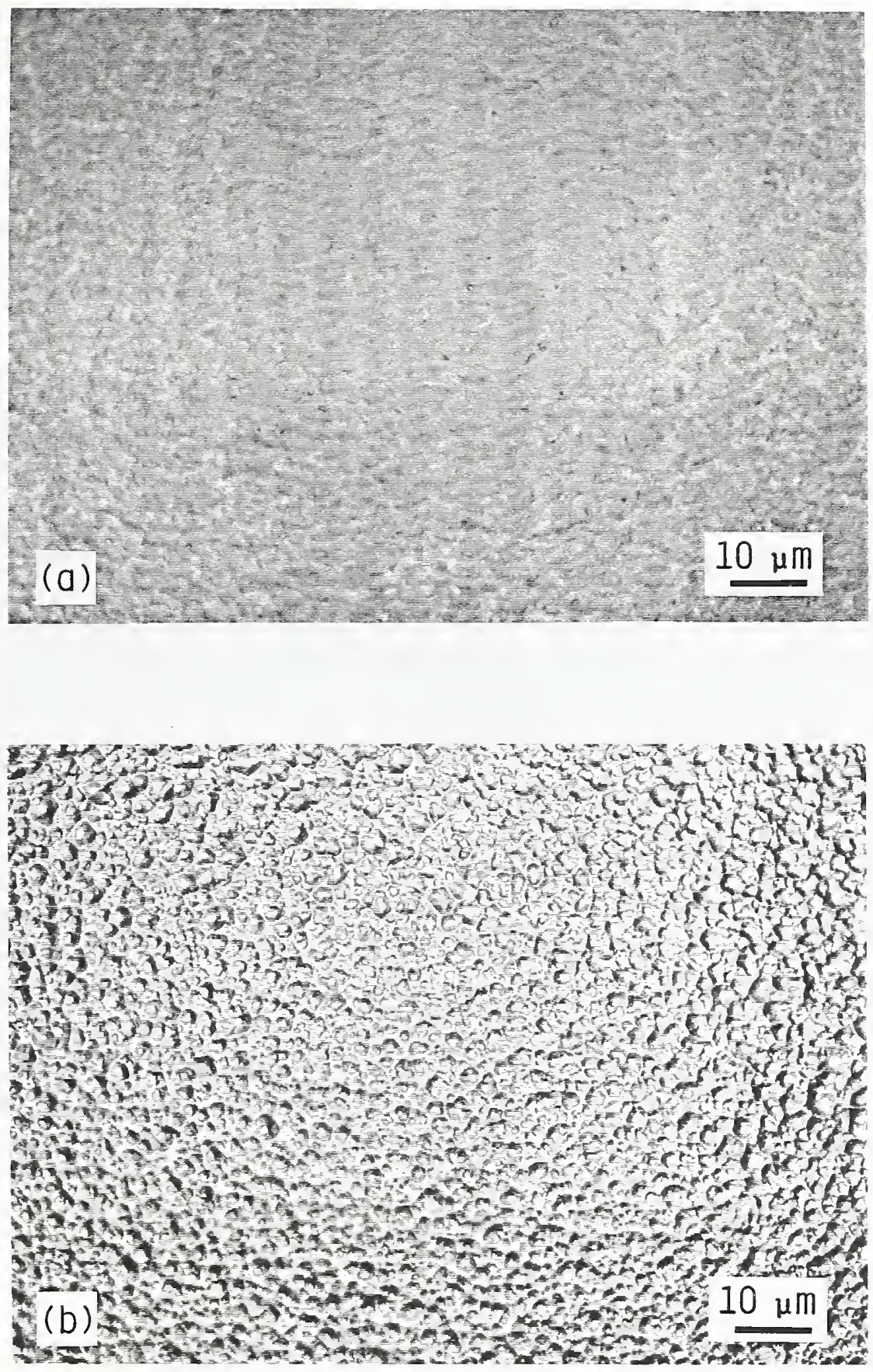

Figure 28. Optical micrographs of the surface texture and crack density of (a) pulse plated semibright chromium coating deposited at $50^{\circ} \mathrm{C}$, peak current density of $25 \mathrm{~A} / \mathrm{dm}^{2}$, and a duty cyle of $62.5 \%$ compared to (b) non-cracked DC coating deposited at $70^{\circ} \mathrm{C}$ and $30 \mathrm{~A} / \mathrm{dm}^{2}$. 


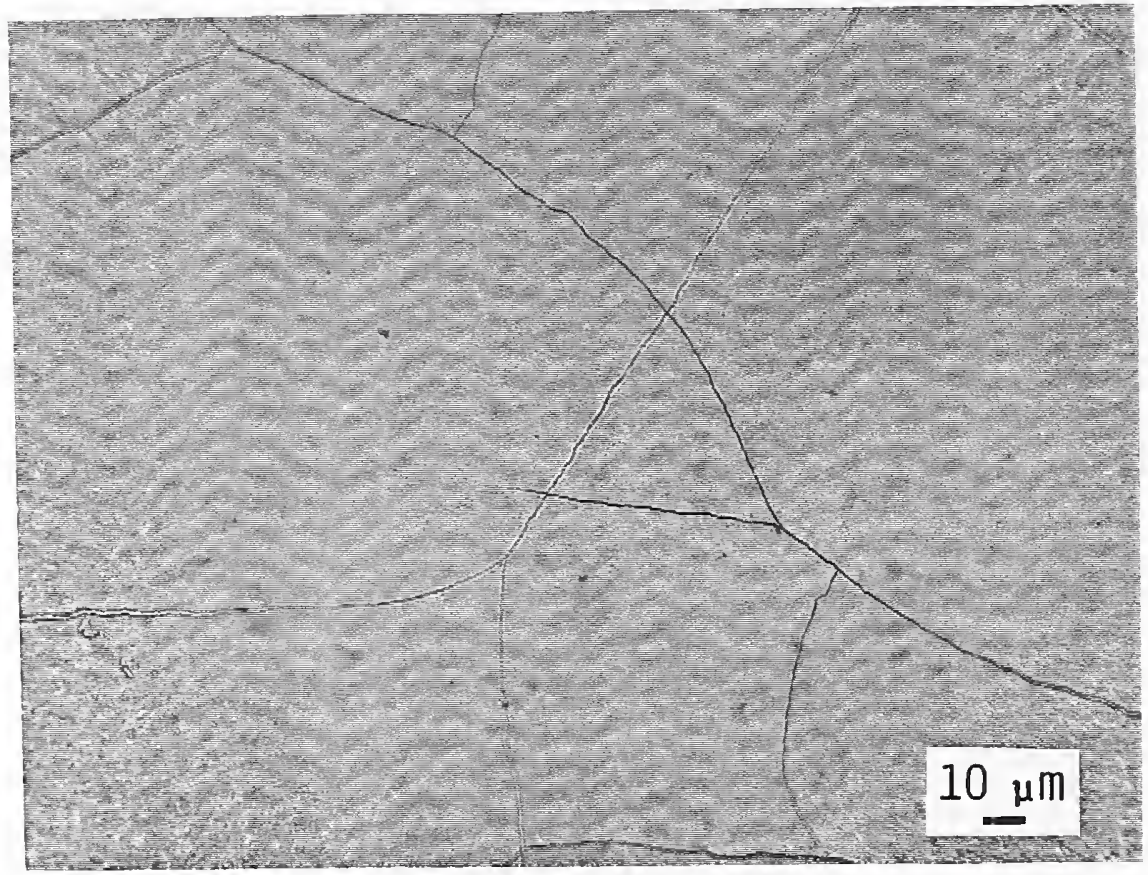

Figure 29. Optical micrograph of the surface texture and crack density of bright pulse plated chromium deposited at $50^{\circ} \mathrm{C}$, peak current density of $25 \mathrm{~A} / \mathrm{dm}^{2}$, and a duty cyle of $71.4 \%$. 


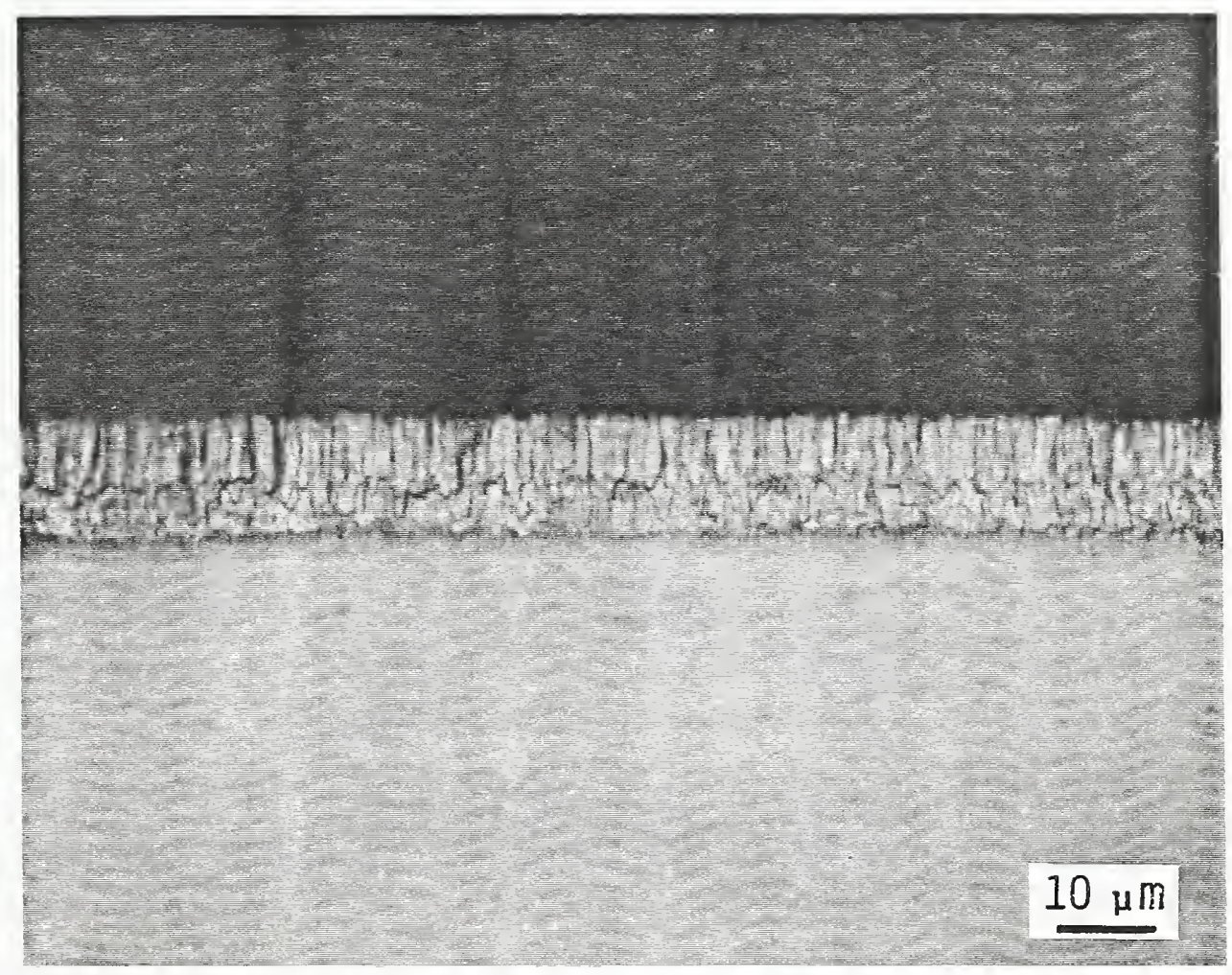

Figure 30. Optical micrograph of a sectioned pulse plated duplex chromium deposit etched in a $1: 1$ hydrochloric-lactic acid solution for $10 \mathrm{sec}$. The coating was deposited at $50^{\circ} \mathrm{C}$ and a peak current density of $25 \mathrm{~A} / \mathrm{dm}^{2}$. The initial layer was deposited while pulsing at $5 \mathrm{~ms}$ on and $3 \mathrm{~ms}$ off $(62.5 \%$ duty cycle) and the final layer at $5 \mathrm{~ms}$ on and $2 \mathrm{~ms}$ off ( $71.4 \%$ duty cycle). 


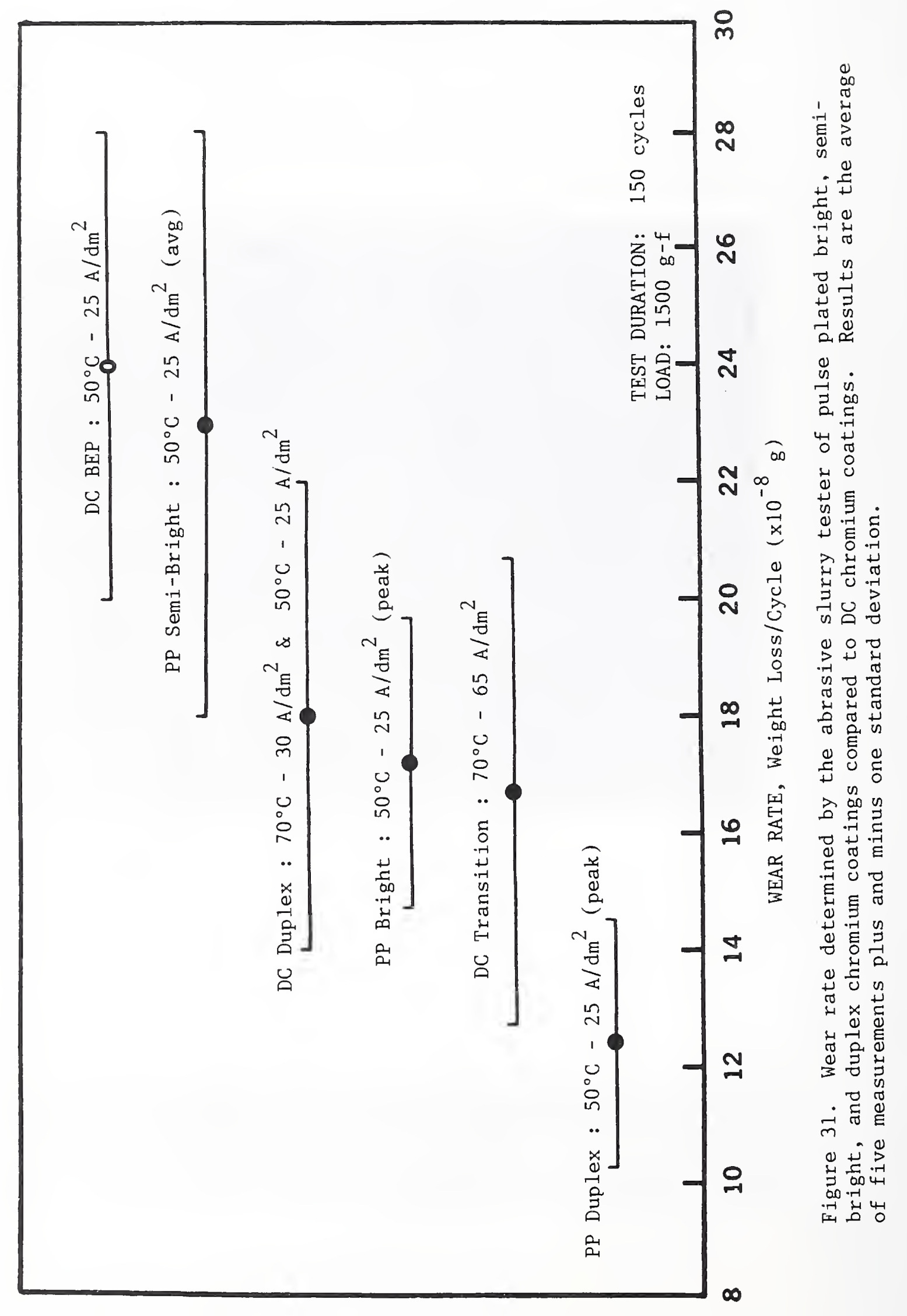




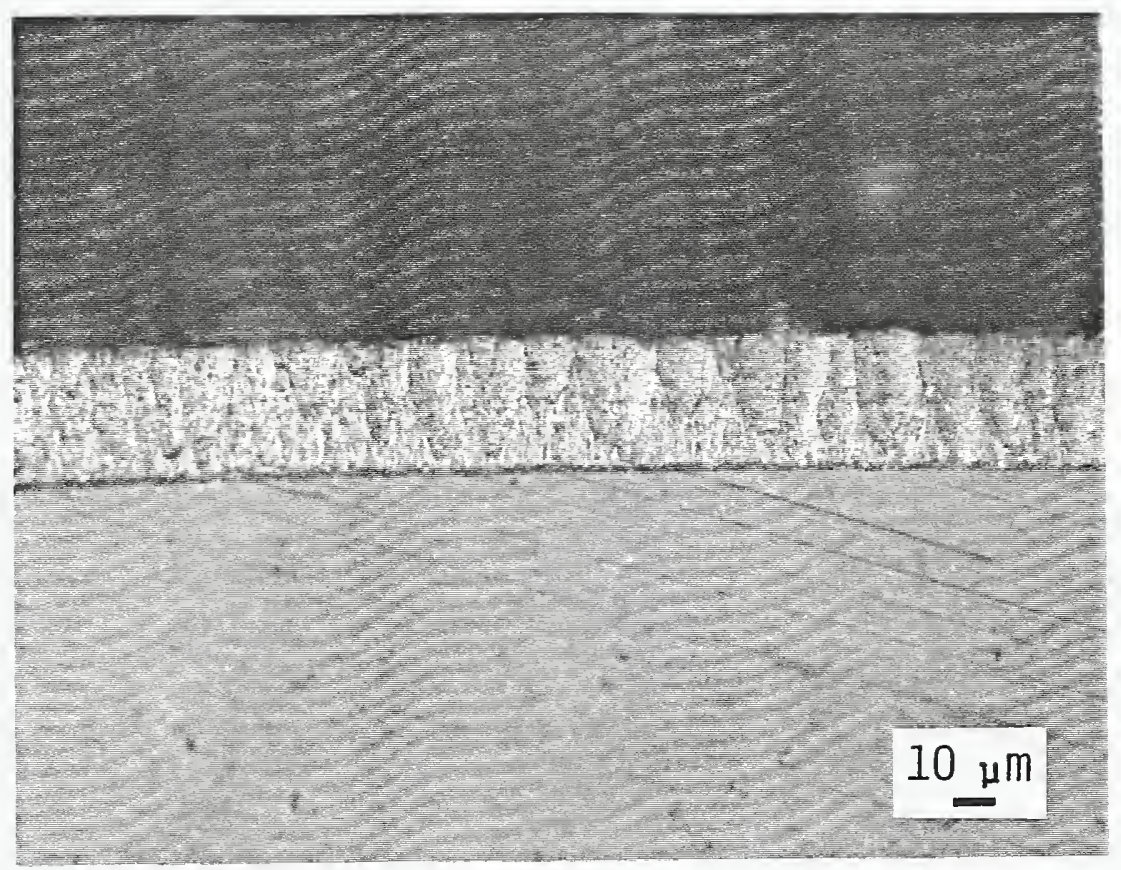

Figure 32. Optical micrograph of a polished and etched section of a pulse plated duplex chromium coating directly on a 52100 steel substrate. Note the superimposed columnar structure on the duplex structure. The columnar structure was not noted when plating on nickel. 

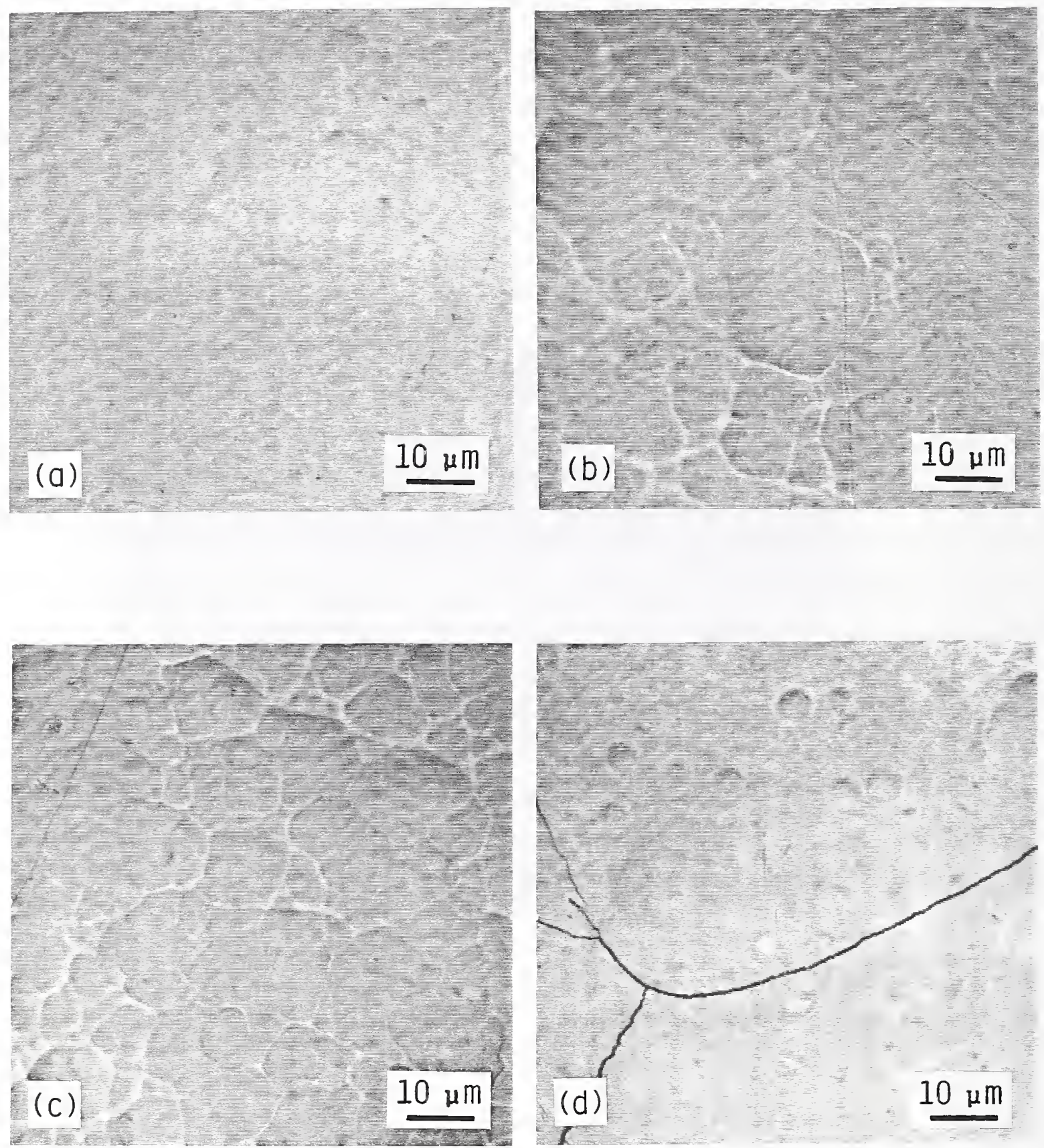

Figure 33. Optical micrographs of the surface texture and crack density of various DC and pulse plated chromium-vanadium deposits from a conventional sulfate catalyzed electrolyte containing $6.6 \mathrm{~g} / 1 \mathrm{~V} 2 \mathrm{O}_{5}$. (a) $\mathrm{DC}-50^{\circ} \mathrm{C}$, $16 \mathrm{~A} / \mathrm{dm}_{2}$. (b) DC $-50^{\circ} \mathrm{C}, 21.5 \mathrm{~A} / \mathrm{dm}^{2}$. (c) $\mathrm{DC}-50^{\circ} \mathrm{C}, 32 \mathrm{~A} / \mathrm{dm}^{2}$. (d) $\mathrm{PP}-50^{\circ} \mathrm{C}$, $25 \mathrm{~A} / \mathrm{dm}^{2}$ (avg) at $10.5 \mathrm{~ms}$ on and $1.0 \mathrm{~ms}$ off. 


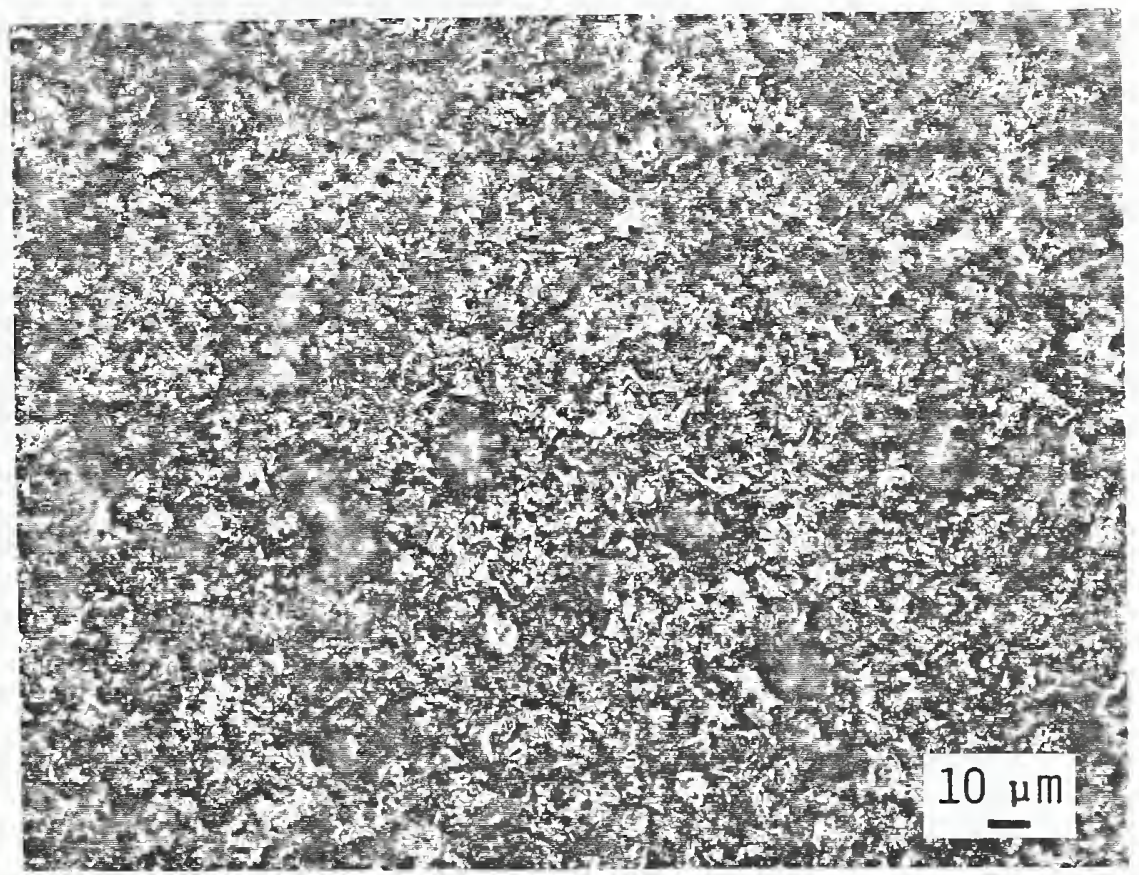

Figure 34. Optical micrograph of the surface of an electroless nickel-phosphorus-silicon carbide coating on a 52100 steel substrate. 


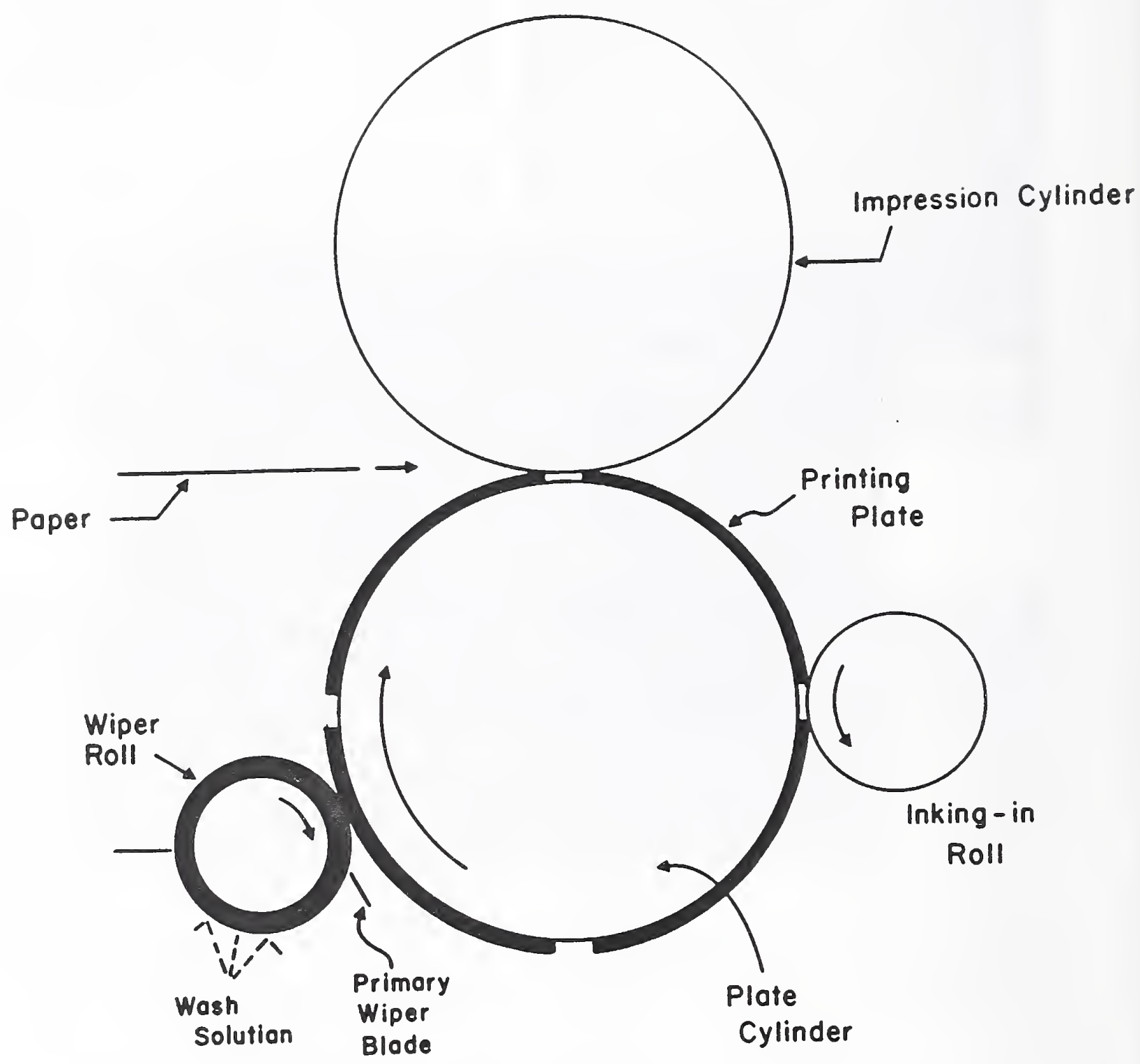

Figure 35. Schematic of printing press showing location of the primary wiper blade used for coatings evaluation in the in situ wear test. 


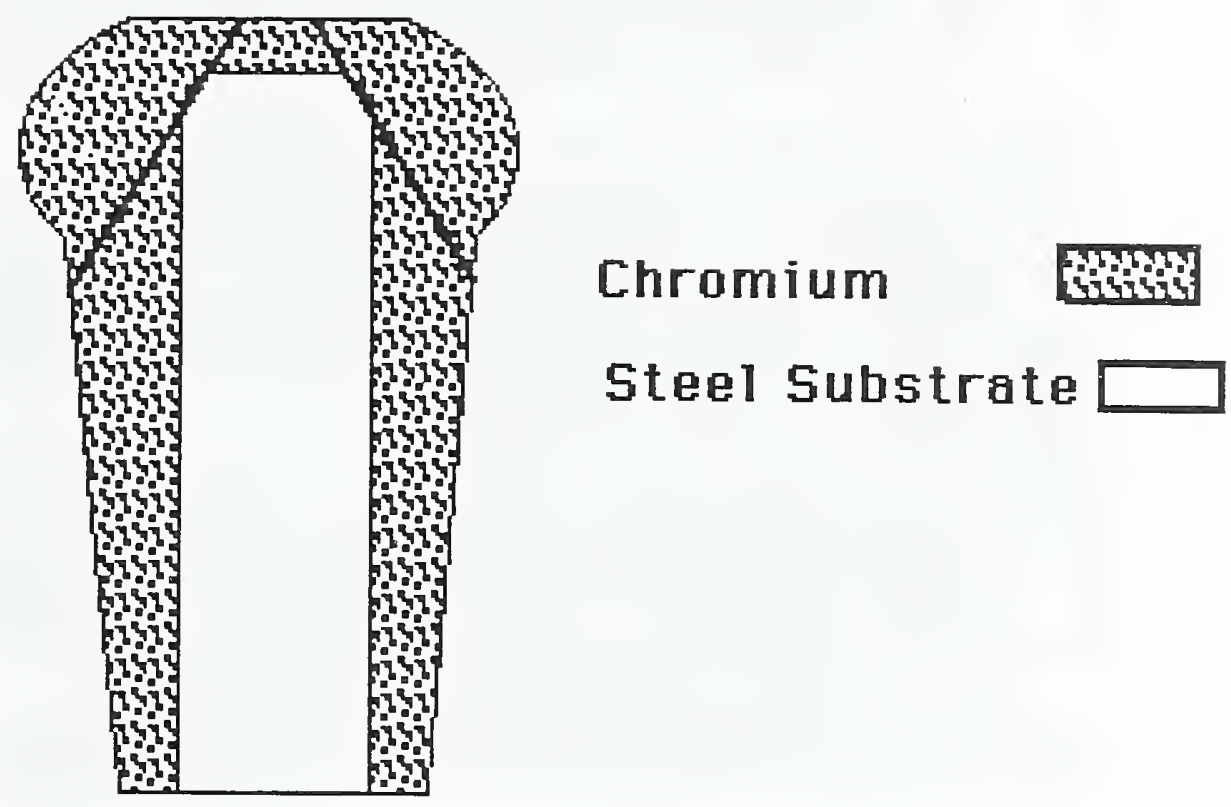

Figure 36. Schematic representation of a sectioned chromium plated wiper blade indicating the build-up (dog bone effect) of chromium on the edge of the blade and the wear scar path (solid angled lines) after in situ testing. 

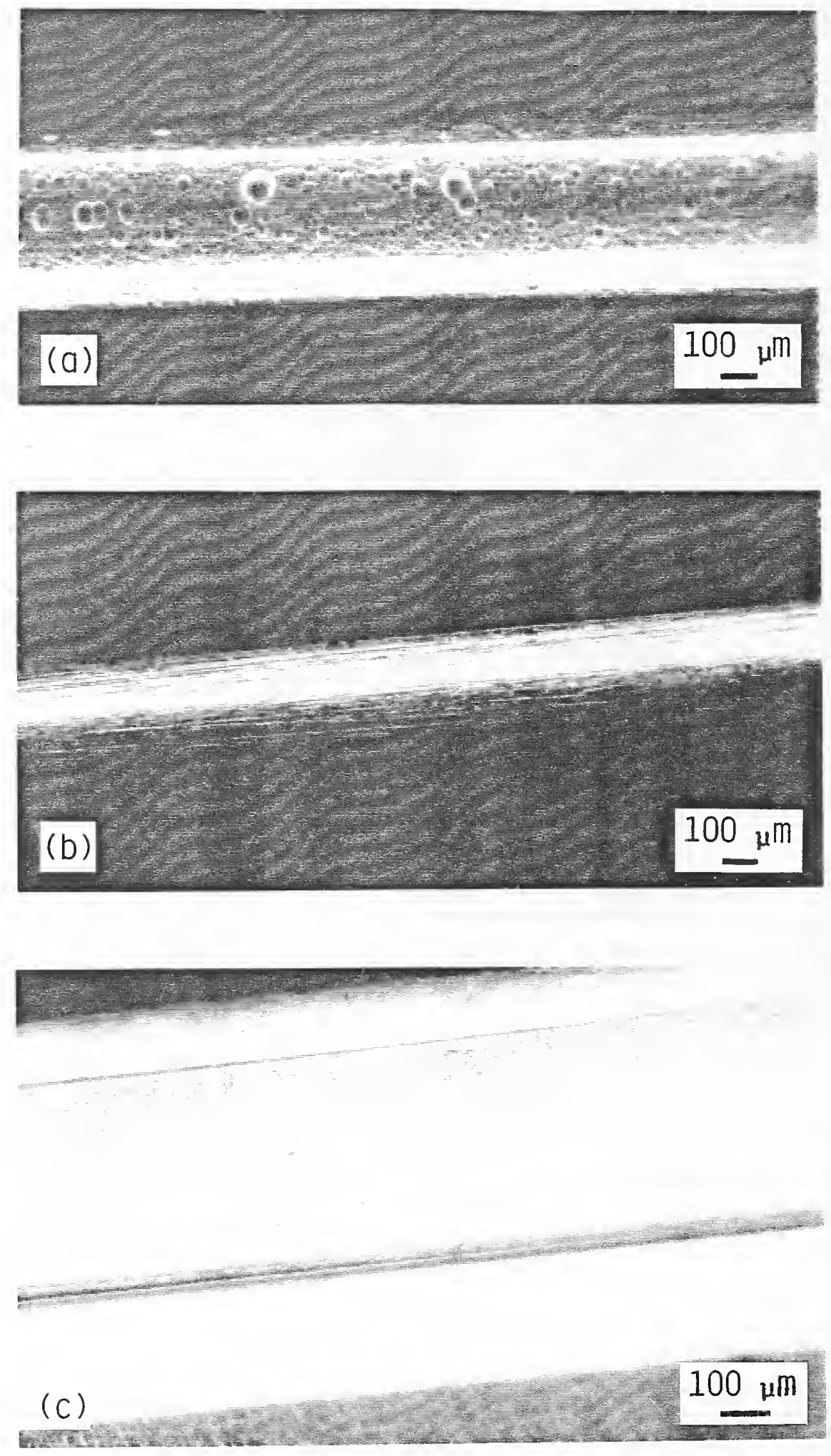

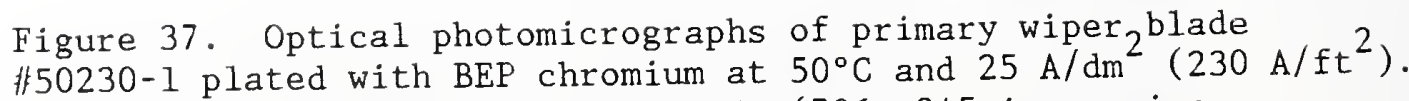
Blade was run to failure on one side (706, 345 impressions, 16 shifts). (a) As plated chromium on blade edge; (b) Worn chromium plated edge; (c) Wear scar area on side of chromium plated edge. 

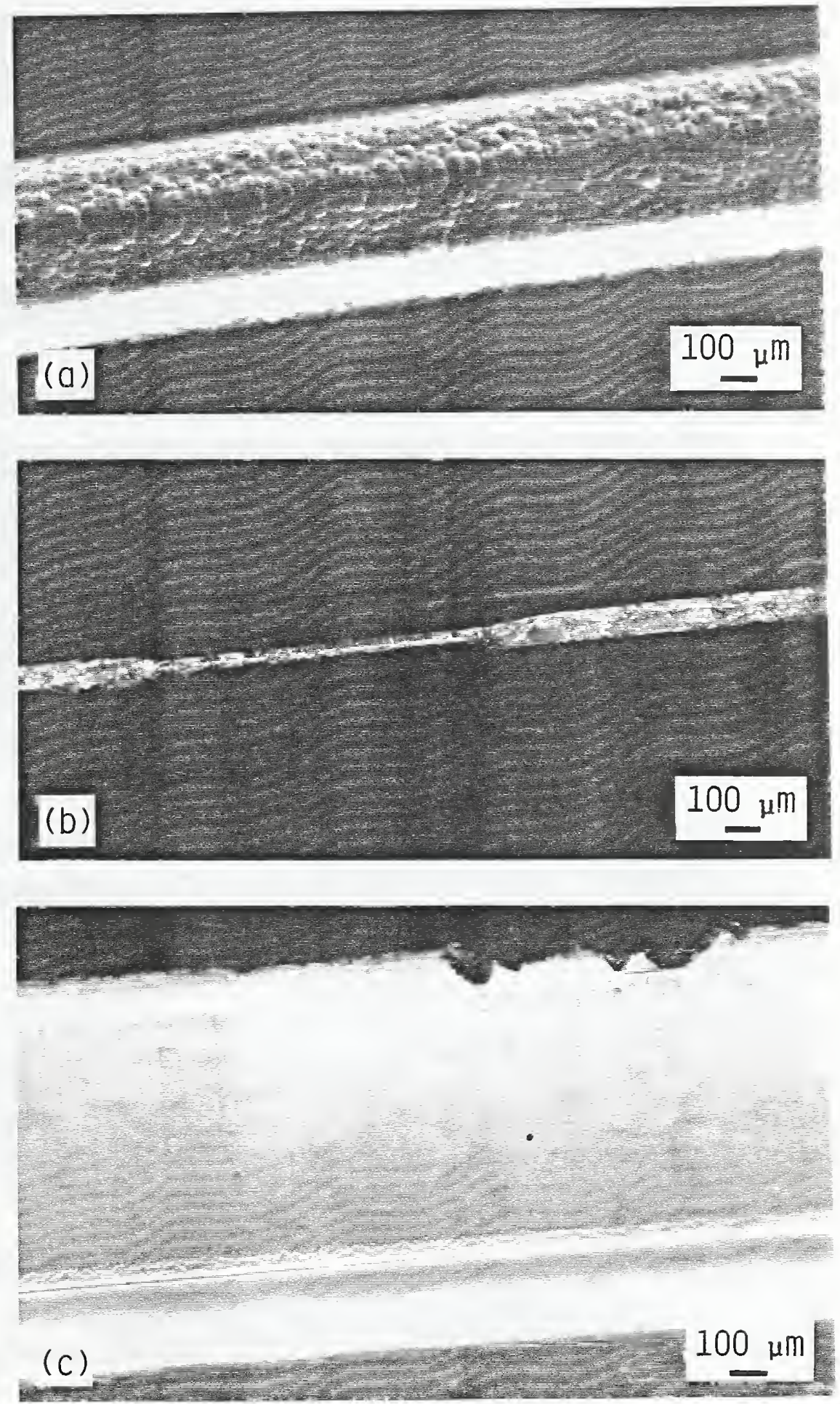

Figure 38. Optical photomicrographs of primary wiper blade 非0230-2 plated with BEP chromium at $50^{\circ} \mathrm{C}$ and $25 \mathrm{~A} / \mathrm{dm}^{2}\left(230 \mathrm{~A} / \mathrm{ft}^{2}\right)$. Both sides of chromium plated edge were tested for a combined $1,113,400$ impressions ( 26 shifts). (a) As plated chromium on blade edge; (b) Worn chromium plated edge; (c) Wear scar area on side of chromium plated edge. 

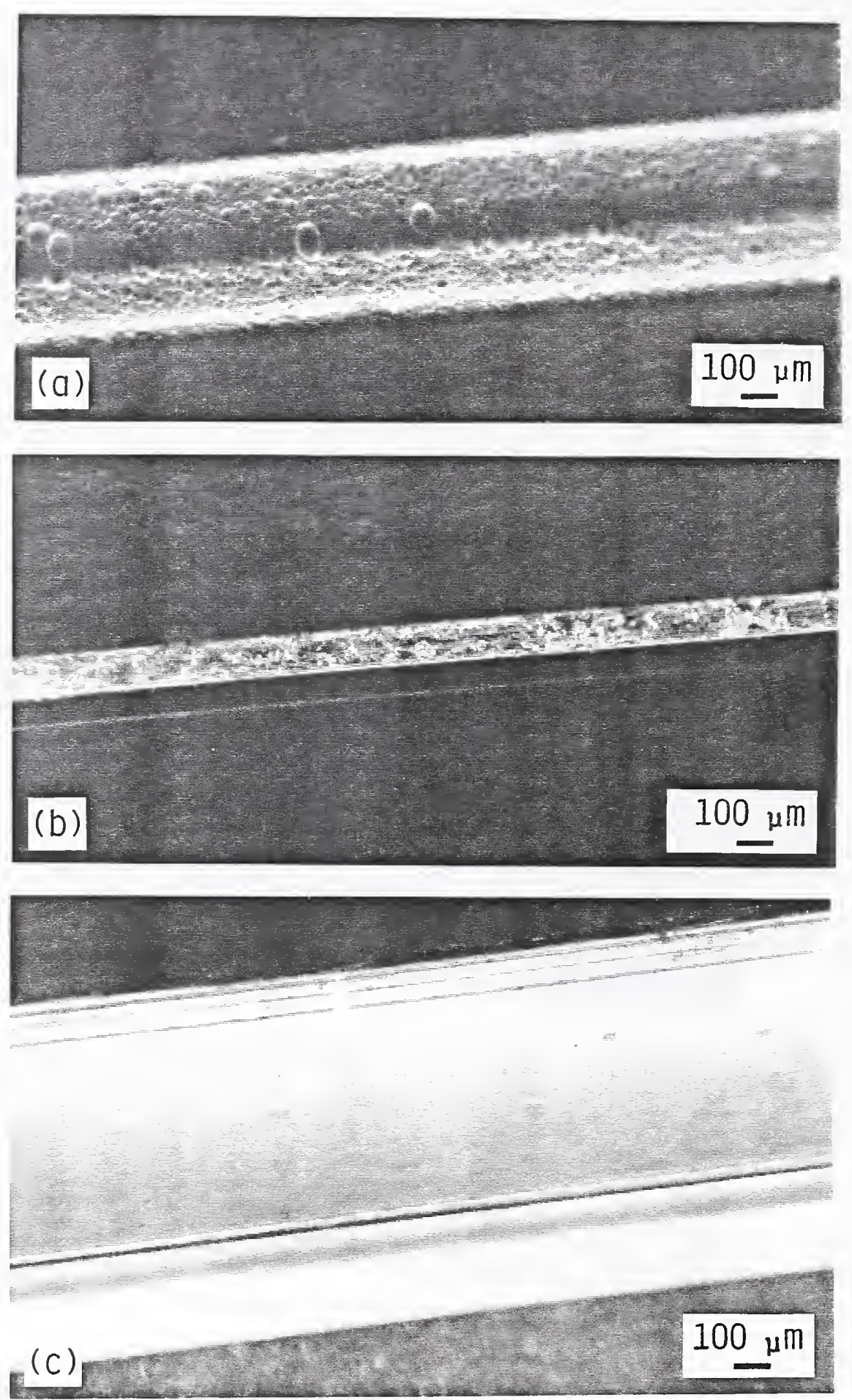

Figure 39. Optical photomicrographs of primary wiper blade $^{2}$ \#50230-3 plated with BEP chromium at $50^{\circ} \mathrm{C}$ and $25 \mathrm{~A} / \mathrm{dm}^{2}\left(230 \mathrm{~A} / \mathrm{ft}^{2}\right)$. Both sides of chromium plated edge were tested for a combined 800,093 impressions (20 shifts). (a) As plated chromium on blade edge; (b) Worn chromium plated edge; (c) Wear scar area on side of chromium plated edge. 

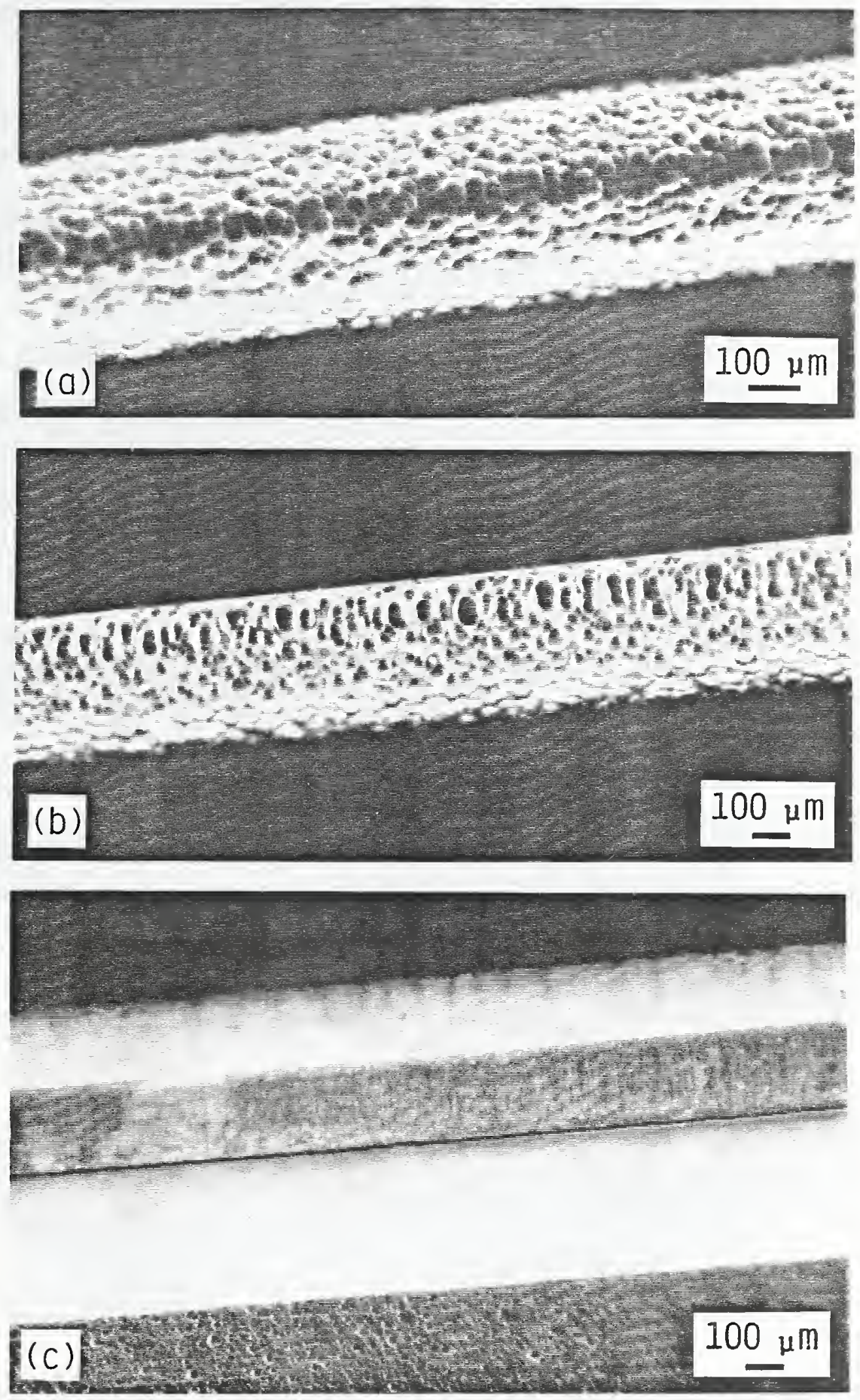

Figure 40. Optical photomicrographs of primary wiper blade $^{2}$ 非50230-4 plated with BEP chromium at $50^{\circ} \mathrm{C}$ and $25 \mathrm{~A} / \mathrm{dm}^{2}\left(230 \mathrm{~A} / \mathrm{ft}^{2}\right)$. Only one side of chromium plated edge was tested. (a) As plated chromium on blade edge; (b) Worn chromium plated edge; (c) Wear scar area on side of chromium plated edge. 

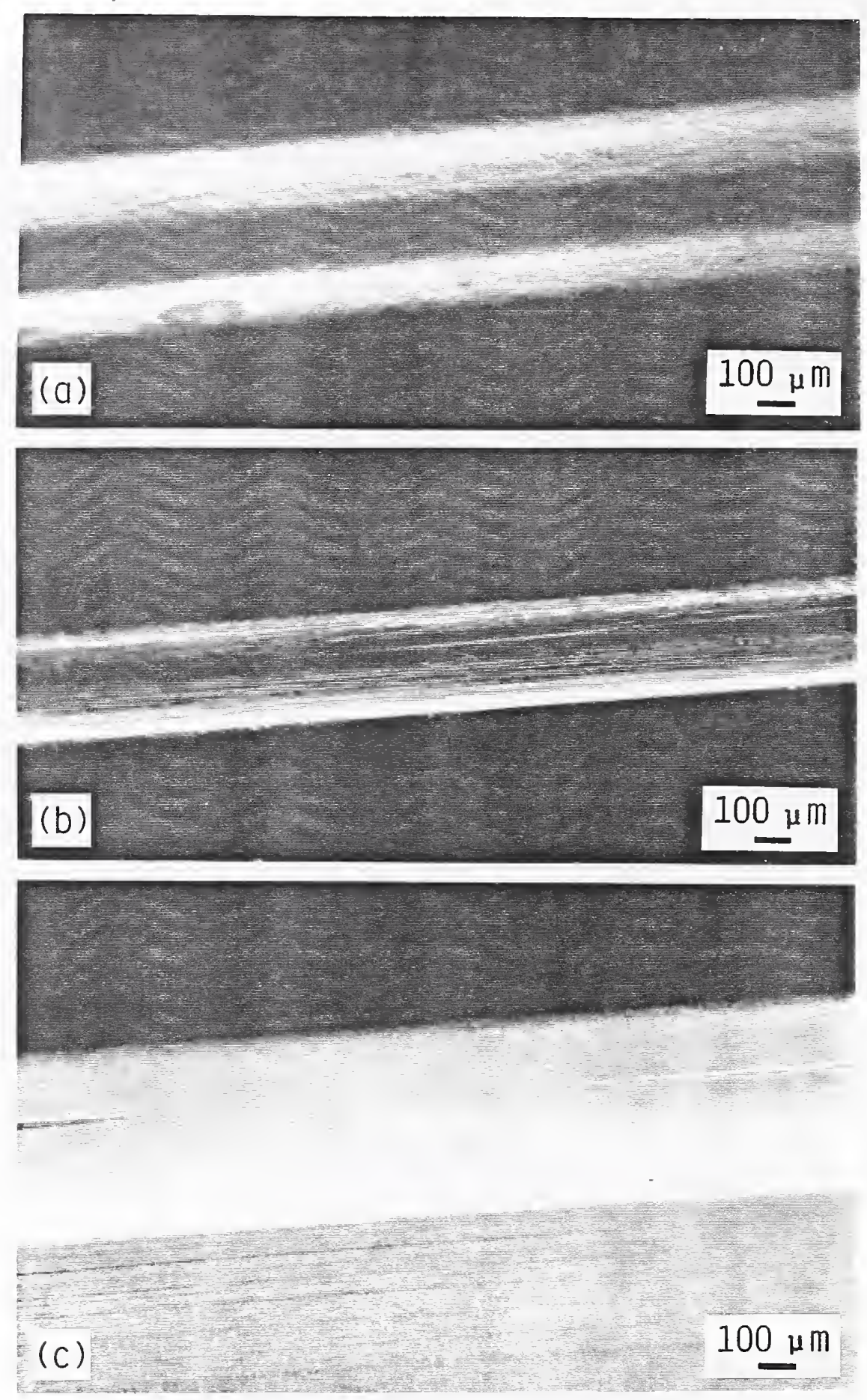
Figure 41. Optical photomicrographs of primary wiper blade
\#70278-2 plated with $\mathrm{BEP}$ chromium at $70^{\circ} \mathrm{C}$ and $30 \mathrm{~A} / \mathrm{dm}^{2}\left(278 \mathrm{~A} / \mathrm{ft}^{2}\right)$. Both sides of chromium plated edge were tested for a combined 840,000 impressions (20 shifts). (a) As plated chromium on blade edge; (b) Worn chromium plated edge; (c) Wear scar on side of chromium plated edge. 

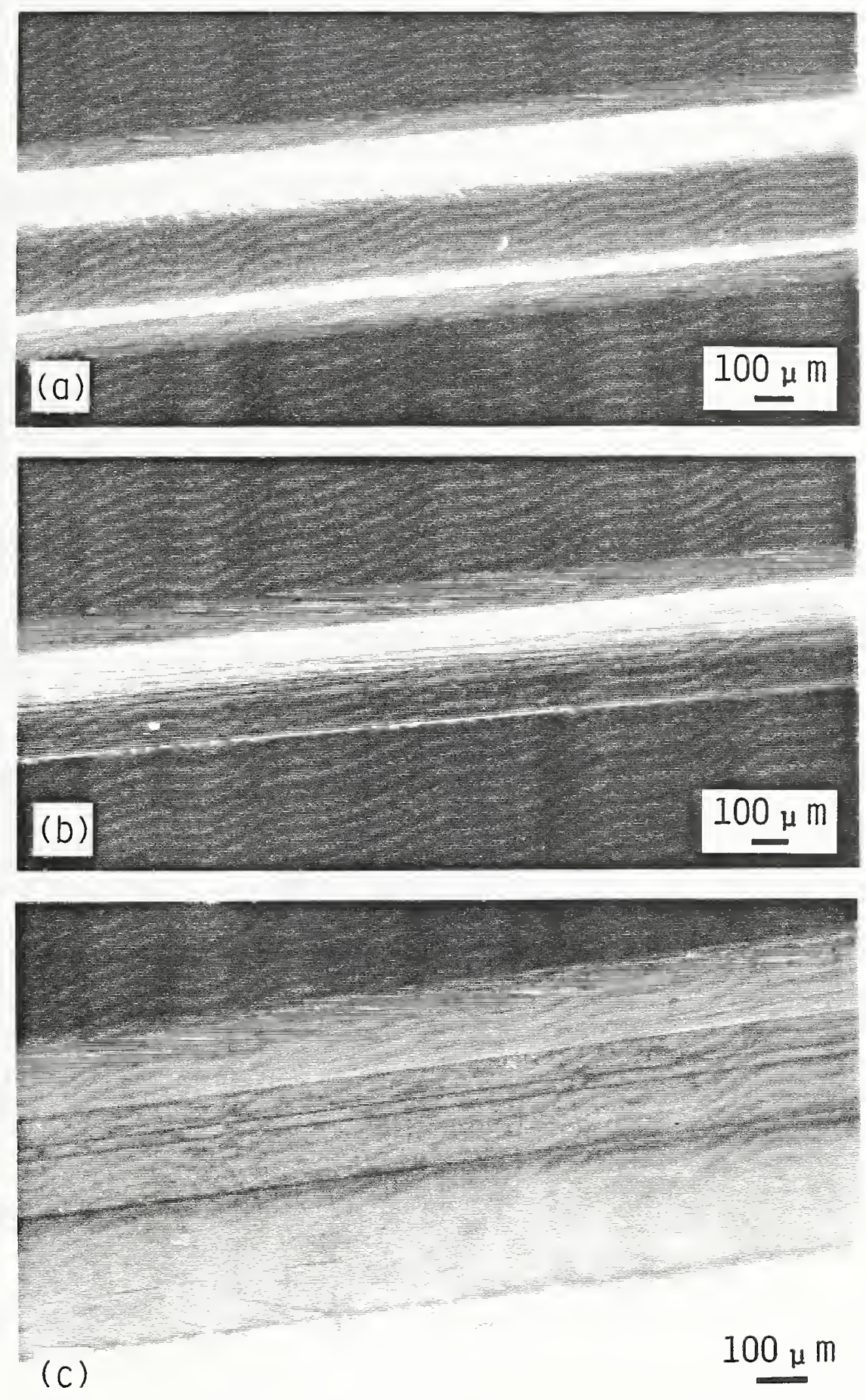
Figure 42. Optical photomicrographs of primary wiper blade
\#70278-3 plated with BEP chromium at $70^{\circ} \mathrm{C}$ and $30 \mathrm{~A} / \mathrm{dm}^{2}\left(278 \mathrm{~A} / \mathrm{ft}^{2}\right)$. Only one side of chromium plated edge was tested. (a) As plated chromium on blade edge; (b) Worn chromium plated edge; (c) Wear scar on side of chromium plated edge. 


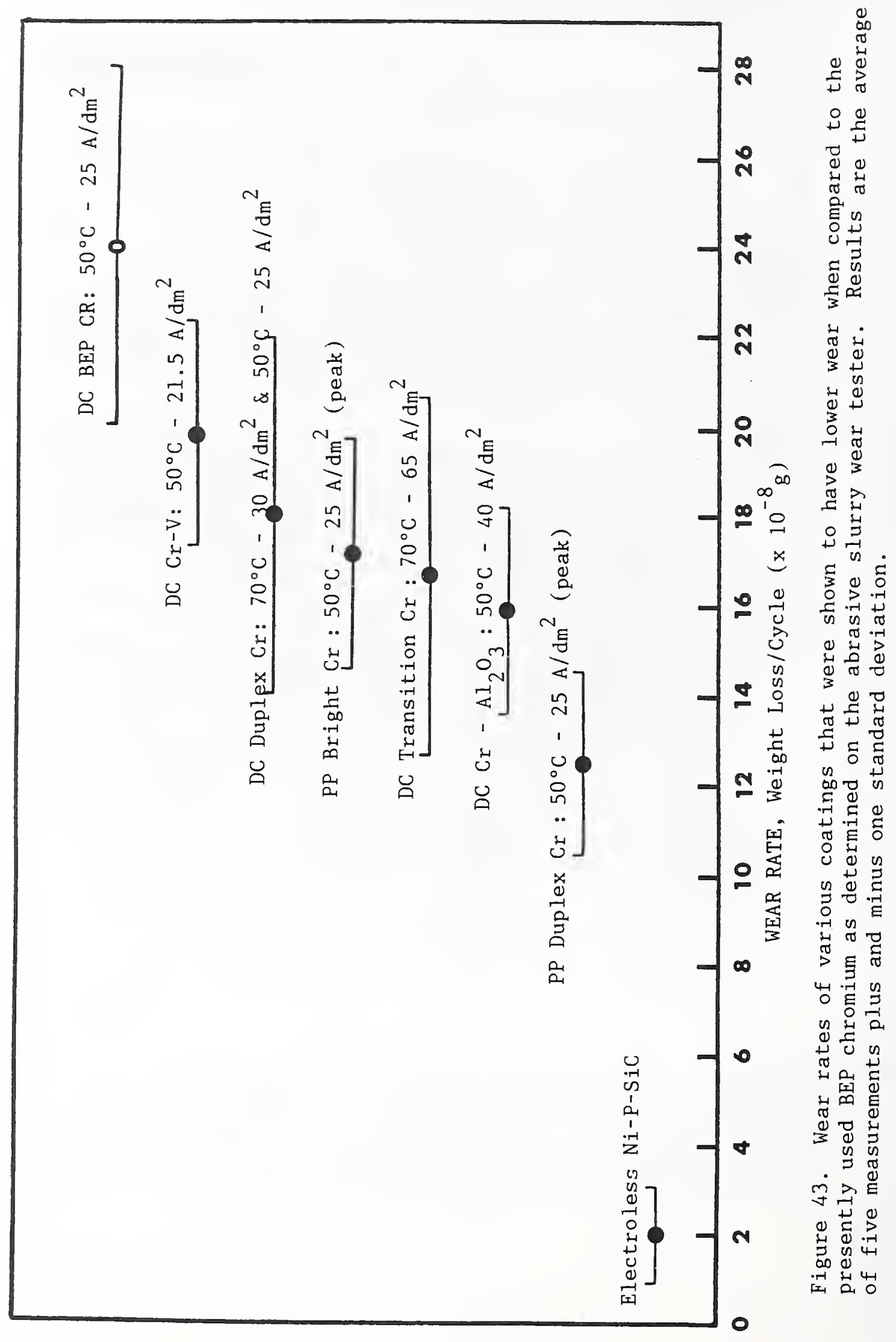




\section{BIBLIOGRAPHIC DATA SHEET}

PUBLCATION OR REPOAT NUMBER

NISTIR 4301

2. PERFORMING ORGAMIZATION REPORT NUMBER

APRIL 1990

\section{ELECTRODEPOSITION OF WEAR RESISTANT COATINGS}

5. AUTHOR(S)

C. E. Johnson, D. S. Lashmore, D. R. Kelley and J. L. Mullen

7. CONTRACT/GRANT NUMBER

8. TYPE OF REPORT AND PERIOD COVERED U.S. DEPARTMENT OF COMMERCE NATIONAL INSTITUTE OF STANDARDS AND TECHNOLOGY GAITHERSBURG, MD 20899

9. SPONSORING ORGANIZATION NAME AND COMPLETE ADDRESS (STREET, CITY, STATE, ZIP)

Bureau of Engraving and Printing 201 - 3 A, 14nth and C Streets, SW Washington, DC 20228

DOCUMENT DESCRIBES A COMPUTER PROGRAM; SF-185, FIPS SOFTWARE SUMMARY, IS ATTACHED.

11. ABSTRACT (A 200-WORD OR LESS FACTUAL SUMMARY OF MOST SIGNIFICANT INFORMATION. IF DOCUMENT INCLUDES A SIGNIFICANT BIBLIOGRAPHY OR LTERATURE SURVEY, MENTION IT HERE.)

Analysis of premature plate failure resulted in a number of recommendations to address a series of problems that were indentified in the plating process of printing plates. An accelerated wear tester was developed and applied to rank electrodeposited coatings for wear. Composite coatings of nickel-phosphorus-silicon carbide exhibited a factor of 10 increase in wear performance over the current chromium technology. Various chromium coatings exhibited a factor of 1.2 to 2 increase in abrasive wear performance. A new pulse plated duplex chromium coating exhibited the factor of two increase over the presently used chromium coating. In situ wear testing of chromium plated wiper blades exhibited a factor of two increase over the presently used chromium coatings. In situ wear testing of chromium plated wiper blades exhibited a 10 to 15 fold increase in the blade life compared to the currently used unplated blades.

12. KEY WORDS (6 TO 12 ENTRIES; ALPHABETICAL ORDER; CAPITALIZE ONLY PROPER NAMES; AND SEPARATE KEY WORDS BY SEMICOLONS)

abrasive; chromium; coatings; electrodeposition; printing; pulse plating; wear

\section{AVAILABILITY}

ए人

\section{UNLIMITED}

FOR OFFICIAL DISTRIBUTION. DO NOT RELEASE TO NATIONAL TECHNICAL INFORMATION SERVICE (NTIS).

ORDER FROM SUPERINTENDENT OF DOCUMENTS, U.S. GOVERNMENT PRINTING OFFICE, WASHINGTON, DC 20402.

ORDER FROM NATIONAL TECMMICAL INFORMATION SERVIGE (MTIS), SPRIMGFIELD, VA 22161.
14. NUMBER OF PRINTED PAGES

104

15. PRICE

A06 


